Portland State University

PDXScholar

Civil and Environmental Engineering

Undergraduate Honors Theses

Spring 2009

\title{
Carbon Sponsoring: A New Idea in Personal Carbon Trading, Direct Carbon Offset Pledges for Travel
}

Alexander Y. Bigazzi

Portland State University

Follow this and additional works at: https://pdxscholar.library.pdx.edu/cengin_honorstheses

Part of the Civil and Environmental Engineering Commons

Let us know how access to this document benefits you.

\section{Recommended Citation}

Bigazzi, Alexander Y., "Carbon Sponsoring: A New Idea in Personal Carbon Trading, Direct Carbon Offset Pledges for Travel" (2009). Civil and Environmental Engineering Undergraduate Honors Theses. 2. https://doi.org/10.15760/honors.370

This Thesis is brought to you for free and open access. It has been accepted for inclusion in Civil and Environmental Engineering Undergraduate Honors Theses by an authorized administrator of PDXScholar. Please contact us if we can make this document more accessible: pdxscholar@pdx.edu. 


\section{THESIS APPROVAL}

The abstract and thesis of Alexander York Bigazzi for undergraduate honors in Civil

Engineering were presented June 10, 2009, and accepted by the thesis advisor and the department.

ADVISOR APPROVAL:

Robert L. Bertini

DEPARTMENT APPROVAL:

Scott Wells, Chair

Department of Civil and Environmental Engineering 


\begin{abstract}
An abstract of the thesis of Alexander York Bigazzi for undergraduate honors in Civil Engineering presented June 10, 2009.
\end{abstract}

Title: Carbon sponsoring: a new idea in personal carbon trading, direct carbon offset pledges for travel.

Public and political consensus expresses the need for broad action to mitigate climate change. To this end, different forms of carbon trading exist to initiate carbon reduction projects. This thesis proposes the idea of carbon sponsoring, a new tool for personal carbon trading. Unlike carbon offsets, the main option for individuals wishing to mitigate their carbon footprint, carbon sponsoring is a purely social instrument involving carbon-reducing pledges. Carbon sponsoring is intended for individuals who seek immediate, direct carbon offsets for their personal emissions. It is not meant as a broad tool correcting the various deficiencies of the carbon trading markets, but a specialized mechanism with a small role in the struggle against climate change.

As a demonstration project, an online implementation for carbon sponsoring of personal travel was crafted with the following objectives:

1. Increase awareness of size of carbon footprint from personal travel and activities

2. Increase awareness of personal carbon reduction strategies

3. Facilitate personal carbon reductions

4. Familiarize users with carbon trading 
A three-week initial study period of the new tool showed good results, with participants reporting increased awareness of person carbon footprints, carbon reduction strategies, and carbon trading. While the overall results were positive, the website created for this study has some deficiencies related to the visual design and ease of navigation. These shortcomings are not central to the idea of carbon sponsoring, and skilled web designers can rectify them as a next step.

Carbon sponsoring sustains some of the problems of carbon offsetting, including insufficient quality control and lack of third-party verification of carbon reductions. Carbon sponsoring also offers new benefits and improvements in the areas of equity, user costs and co-benefits, and carbon reduction time accounting. Carbon sponsoring also accesses personal emissions reductions in a way that indirect, upstream methods cannot. This benefit, especially, secures carbon sponsoring a convincing role in broad mitigation efforts to address climate change. Carbon sponsoring might only lead to a small volume of carbon reductions with respect to the entirety of anthropogenic emissions, but it can provide important assistance in efforts to promote public awareness of carbon footprints, carbon reduction strategies, carbon budgeting, and carbon trading. 


\section{CARBON SPONSORING: A NEW IDEA IN PERSONAL CARBON TRADING, DIRECT CARBON OFFSET PLEDGES FOR TRAVEL}

by

ALEXANDER YORK BIGAZZI

A thesis submitted in partial fulfillment of the requirements for UNDERGRADUATE HONORS

in

CIVIL ENGINEERING

Portland State University

2009 


\section{ACKNOWLEDGMENTS}

The author gratefully acknowledges the assistance and support of the faculty and staff of the Department of Civil and Environmental Engineering at Portland State University, particularly Dr. Robert Bertini and the other transportation faculty members. Many thanks are also due to the 222 people who tested the new tool, especially the 29+ who provided feedback. Final thanks to my family and friends for their support and love, the city of Portland for being so splendid, and computers for being useful (despite my abusive upbraids). 


\section{TABLE OF CONTENTS}

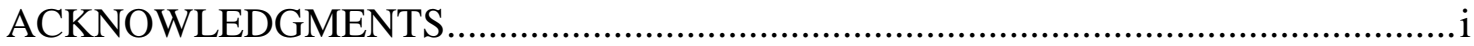

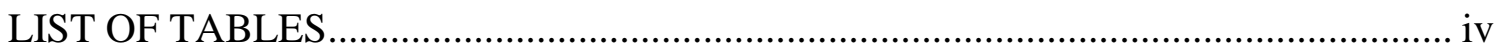

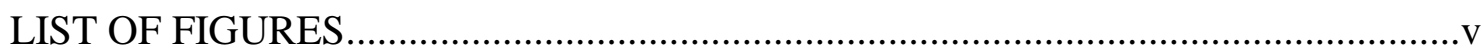

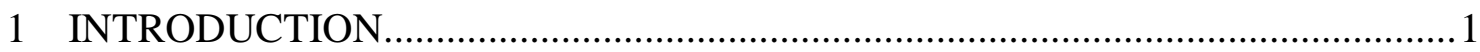

$1.1 \quad$ Climate Change

1.2 Emissions Reduction Strategies...................................................................

1.3 Objectives......................................................................................... 4

2 BACKGROUND: GREENHOUSE GAS MITIGATION ......................................

2.1 Anthropogenic Carbon Emissions................................................................6

2.2 Strategies for Emissions Reductions...............................................................

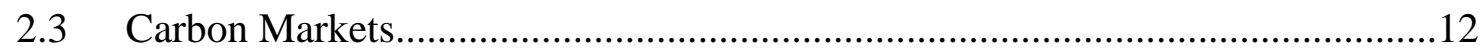

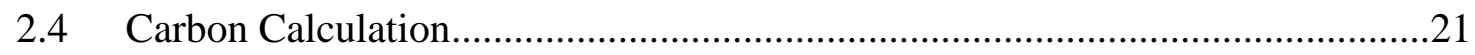

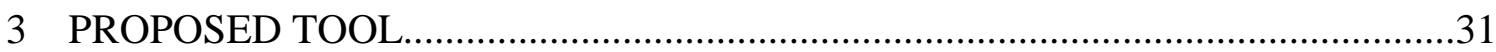

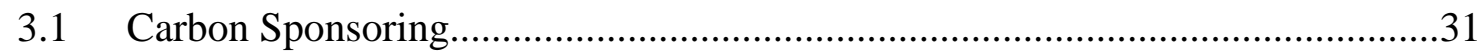

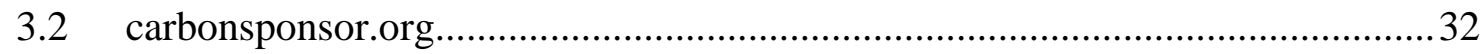

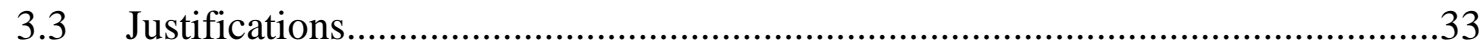

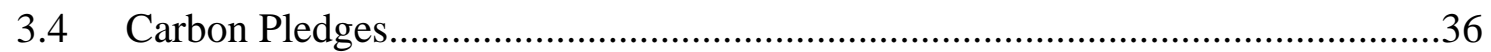

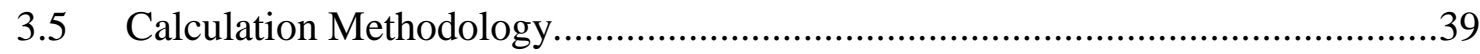

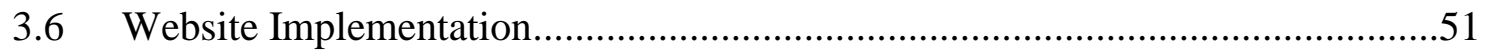

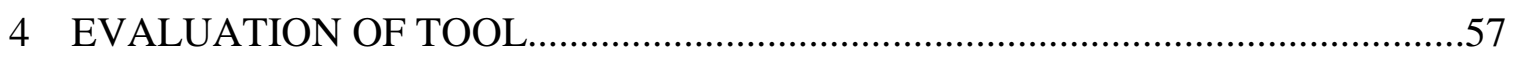

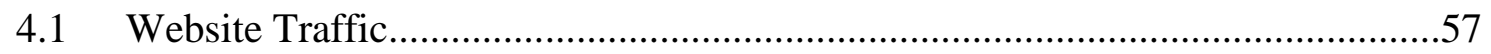

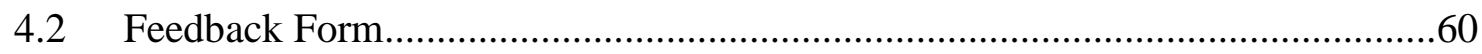

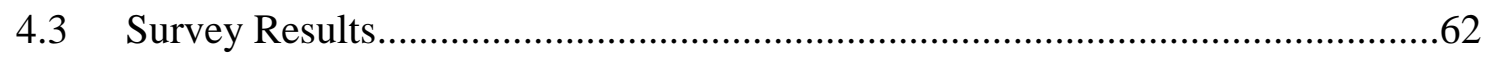

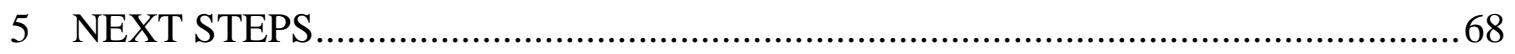




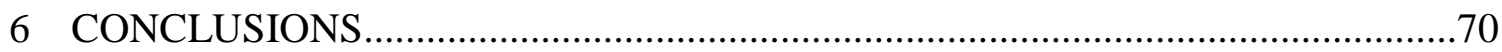

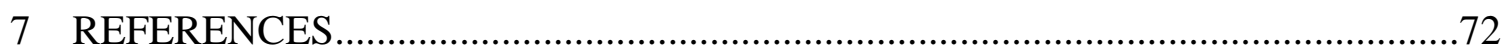

8 APPENDIX 


\section{LIST OF TABLES}

1: Average values for fuel economy and fuel carbon intensity .................................. 41

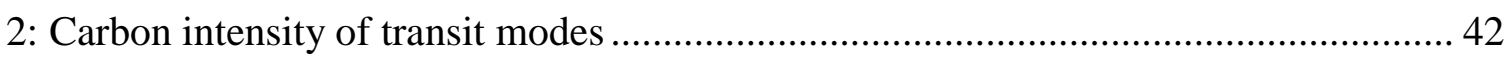

3: Air travel emissions factors by distance and seat class .......................................... 42

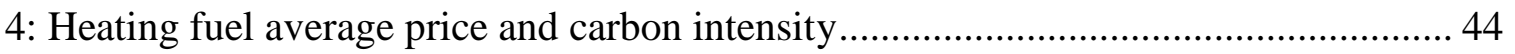

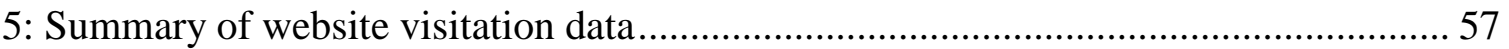




\section{LIST OF FIGURES}

1: Summary of Common Carbon Offset Project Types................................................... 18

2: Greenhouse Gas Sources and Sinks Associated with the Materials Life Cycle .......... 28

3: Carbon intensity of food groups by weight and calorie ............................................... 50

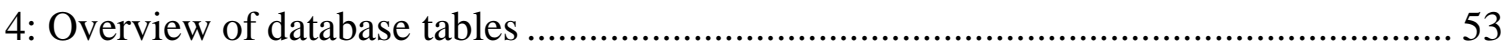

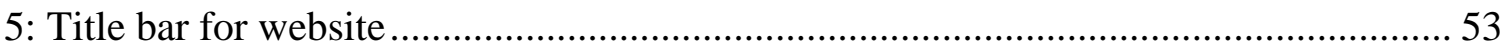

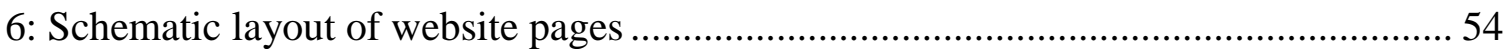

7: Duration of trip visits during study period.................................................................. 58

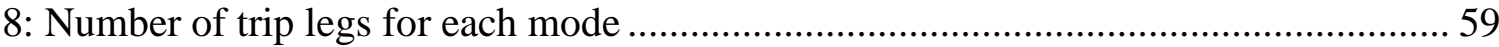

9: Carbon estimate vs. distance for each trip leg created................................................... 59

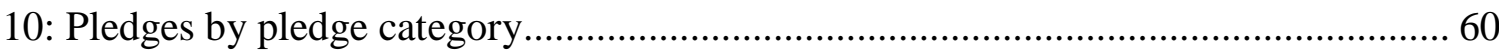

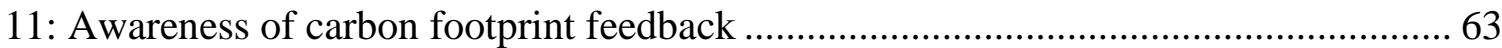

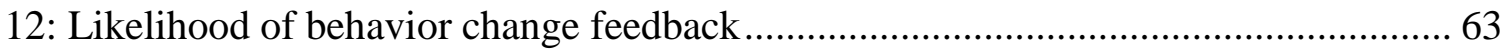

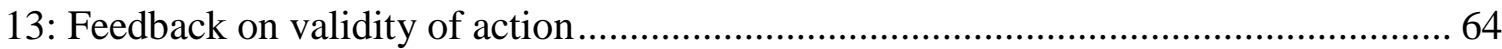

14: Feedback on the likelihood to use again or recommend............................................. 65

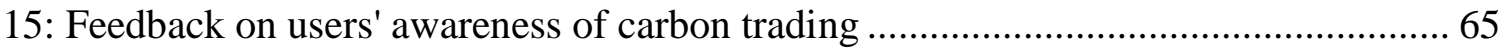

16: Feedback on preference to sponsor or offset carbon footprint ................................... 66

17: Feedback on rating of carbon sponsoring and the website …..................................... 66 


\section{INTRODUCTION}

\subsection{Climate Change}

Consensus exists in the international community that the dangers of climate change demand human attention and action. In the United States, policy and public opinion recently aligned with scientific judgments that the threat is real and significant. Key areas expected to be impacted by climate change include water supplies, food supplies, human health, coastal communities, and natural ecosystems (Intergovernmental Panel on Climate Change [IPCC], 2007a). Despite a recent surge in research, precise long-term impacts are difficult to predict. The multitude of inputs and complexity of processes in atmospheric models lead to persistently high uncertainty.

Public awareness and concern is high (Semenza et al., 2008), with increasing expectations that action must be taken. The call for action roots in the scientific conclusion that recent observed temperature increases are the result of increasing concentrations of anthropogenic greenhouse gases (IPCC, 2007c). Anthropogenic greenhouse gases [GHG] are released due to human activities - primarily the combustion of fossil fuels, releasing carbon dioxide. The U.S. Environmental Protection Agency [EPA] recently proposed to classify six primary greenhouse gases as pollutants under the Clean Air Act, stating that they "endanger the public health and welfare" (EPA, 2009d).

Proposed mitigation strategies typically involve a reduction in emissions or a sequestration of GHG. Sequestered carbon usually resides in trees and soils, though some projects can capture carbon at the point of emission and sequester it underground. With existing approaches, sequestration alone is not sufficient - a reduction in greenhouse gas emissions is also necessary. 


\subsection{Emissions Reduction Strategies}

A battery of strategies to reduce anthropogenic GHG emissions is being developed, studied, and debated by researchers, policymakers, and activists. These strategies range from behavioral and social to purely technological. Some strategies employ regulatory tools, while others rely on market-based incentives. Emissions strategies can target upstream emissions at power plants and refineries or downstream emissions at the point of usage, combustion, or disposal. Each strategy carries a host of benefits and challenges, with varying strength and efficacy for different types of emissions in different scenarios. By some accounts the challenge of reducing anthropogenic GHG emissions is sufficiently daunting that we will need many of these strategies in concert (the proverbial 'kitchen sink' scenario).

Because of the dominance of energy usage (fossil fuels in particular) in GHG emissions inventories (EPA, 2009b), energy consumption is a common target of emissions strategies. The general construct of emissions reductions involves limiting the quantity or the carbon intensity of the energy we use. Carbon intensity (i.e., the amount of carbon dioxide emitted per unit of energy obtained) is usually addressed with technological and systemic approaches, while energy conservation has more behavioral components (reducing demand) in addition to the technological (increasing efficiency).

Regulatory approaches can directly limit the carbon dioxide emitted through carbon caps and low-carbon fuel standards. Market-based strategies motivate new technologies (research and deployment) and manage demand by changing the economics of energy-based activities. Carbon pricing is a market approach that attempts to 
internalize the external costs of climate change into decisions and activities that emit GHG.

Carbon cap-and-trade, carbon taxes, and carbon offsets are all oft-discussed market or hybrid strategies. "Carbon" in a GHG reference frame generally refers to the carbon extant in carbon dioxide $\left(\mathrm{CO}_{2}\right)$. More specifically, the most common unit for GHG measurement is a mass or weight of $\mathrm{CO}_{2} \mathrm{e}$, carbon dioxide equivalents; this unit refers to the climate changing potential of some quantity of carbon dioxide. In this way, “carbon" often loosely refers to greenhouse gases. Carbon dioxide represents $85 \%$ of total U.S. GHG emissions, weighted by global warming potential (EPA, 2009b). Carbon caps regulate maximum allowable carbon emissions for a country, region, market sector, business, household, or person. Carbon credits refer to the emissions allowances granted under a carbon cap system. Under some systems, carbon mitigation projects can generate additional carbon credits. Carbon cap-and-trade programs couple the regulation of a carbon cap with financial instruments that allow trading of unused credits. This commoditization of carbon allowances leads to a carbon market where credits acquire a market value through purchase and sale. Cap-and-trade schemes are not new, and are already active in the United States to mitigate acid rain.

Carbon offsets are a different type of financial instrument, voluntarily purchased to try to compensate for the climate impacts of an emissions source. Carbon offsets can take the form of carbon credits purchased and retired from the carbon markets or independent emissions reductions/sequestration projects. Carbon offsetting is somewhat contentious and discussed further below. 
Carbon calculators, used to estimate carbon footprints for an individual, household, business, or event, are growing in popularity from increased public interest in climate change. Carbon calculators vary greatly in data requirements, breadth of emissions types, depth of indirect emissions included, and accuracy of estimates. Carbon calculators and offsets are often paired to make the claim of "carbon neutrality", when offsets are purchased in equal amount to the carbon footprint estimate.

A major consideration for any strategy is the type of emissions targeted. Direct emissions are easier to quantify because they are GHG released at the point of activity (such as natural gas in a home). Indirect emissions can be more challenging to quantify and track. Indirect emissions include GHG released prior to an activity (upstream, such as factory emissions to produce goods) and GHG released afterward (downstream, such as methane from a landfill). Another important concern is the time scale of emissions targeted. Large projects often have long lead times, and calls for immediate reductions to fight global climate change are mounting.

\subsection{Objectives}

This paper describes a new idea in carbon trading called carbon sponsoring. Carbon sponsoring is a voluntary scheme in which individuals seek pledges of carbonreducing actions to offset the impacts of personal emissions. This scheme targets emissions from personal-level activities, and seeks to access them better than existing strategies. Like other mitigation strategies, carbon sponsoring has its own set of strengths, weaknesses, and appropriate applications.

The broader goal of carbon sponsoring goes beyond the quantity of GHG contained in the pledges (which could be small), and aims to stimulate and facilitate 
sound thinking about personal-level carbon emissions. Carbon sponsoring can be a tool to inform individuals about their current carbon emissions and possible ways to reduce them. By prompting a trial of carbon-reducing activities, carbon pledging can spawn new low-carbon habits. Employing carbon sponsoring can also familiarize individuals with carbon budgeting and so improve the political landscape for aggressive climate change policies that utilize similar tools.

As a concept demonstration, an online tool for carbon sponsoring was created and evaluated over a short trial period. The emissions accommodated for sponsoring with this initial tool are from personal travel only. This construction arose from the multiple factors of project time limits, the large emissions generated by personal travel (discussed below), and the author's knowledge base in quantifying transportation emissions. This thesis describes carbon sponsoring, and this tool in particular, after further discussion of existing mechanisms to set the context and establish the need for this strategy. Concisely, the objectives of this research project are to:

1. Develop and launch an online tool as a demonstration project for carbon sponsoring of personal travel

2. Evaluate the initial success of the tool in meeting these objectives:

1. Increase awareness of size of carbon footprint from personal travel and other activities

2. Increase awareness of personal carbon reduction strategies

3. Facilitate personal participation in carbon reduction

4. Familiarize participants with the concept of carbon trading 


\section{BACKGROUND: GREENHOUSE GAS MITIGATION}

An increasing number of climate change discussions in the U.S. suggest implementation of a regulatory carbon cap-and-trade scheme. The current U.S. approach uses only smaller incentive-based programs for voluntary emissions reductions and to further climate science and technology. The EPA is currently establishing the framework for carbon trading with proposed mandatory GHG reporting standards under the Clean Air Act (EPA, 2009c). Most of the world (184 countries) already operates under a carbon cap-and-trade system established by the Kyoto Protocol (United Nations Framework Convention on Climate Change [UNFCCC], 2009).

Not surprisingly, climate change strategies are heavily debated around the world. Implementing a strategy could have enormous economic and societal effects outside of climate change. Costs and benefits of large-scale strategies could precipitate shifts in economic and community structures, along with fundamental changes of lifestyle. The centrality of energy consumption to both climate change and the industrialized world is a dominating concern.

\subsection{Anthropogenic Carbon Emissions}

The most recent U.S. GHG inventory published by the EPA shows that energy production leads to $86 \%$ of U.S. GHG emissions; the next three largest source categories are agriculture $6 \%$, industrial processes $5 \%$, and waste $2 \%$ (EPA, 2009b). The combustion of fossil fuels, primarily for energy, contributes $80 \%$ of total emissions. While electricity production is the largest emitter of fossil fuel carbon dioxide, transportation is the dominant end-use sector, emitting 33\% of fossil fuel carbon dioxide. Nearly $60 \%$ of transportation emissions come from gasoline consumption in personal 
vehicles, which equals about $16 \%$ of total U.S. GHG emissions from all sources. (EPA, 2009b)

Residential combustion and electricity use contributed $21 \%$ of fossil fuel carbon emissions, or 17\% of total U.S. GHG emissions (EPA, 2009b). The combination of gasoline consumption in personal vehicles and residential energy usage contributed $33 \%$ of total U.S. emissions. This does not include personal emissions attributable to food consumption, non-automotive travel, or goods manufacture and disposal. Although individuals may be constrained in their choices and activities, they are directly responsible for much of the U.S. carbon footprint.

Various levels of government have set GHG emissions targets based on scientific models of "climate stabilizing" concentrations of atmospheric GHG. Emissions targets typically aim at some fraction of emissions during a benchmark year. The Kyoto Protocol establishes the emissions goal of $7 \%$ below 1990 levels by 2012. Although the U.S. signed the Protocol, it was never ratified and so is not enforceable. The federal government currently has no mandatory goals, and the EPA defers to states to set their own targets. Former President Bush stated plans to cut U.S. emissions by $18 \%$ from 2002 levels by 2012, but U.S. emissions have instead increased since that time.

The state of Oregon established the long-term goal of 75\% below 1990 levels by 2050. The City of Portland and Multnomah County went further and set the goal at $80 \%$ below 1990 levels by 2050, with interim targets of $10 \%$ below 1990 by 2010 and $40 \%$ below 1990 by 2030 (City of Portland \& Multnomah County, 2009). These aggressive targets will require huge cuts in per-capita energy consumption. 


\subsection{Strategies for Emissions Reductions}

With growing attention, climate change has recently married other causes such as energy independence, geopolitics, and environmental issues like air pollution. As with any broadening of a coalition, this gives climate change mitigation more momentum but less unity of direction. As large-scale mitigation appears increasingly likely, the debates over the merits of different strategies increase in pitch.

Each suggested mitigation strategy has unique strengths, efficacies, and drawbacks. These distinct qualities must be well understood before implementation, especially considering the likelihood of concurrent multiple strategies. In an attempt to resolve personal vehicles with sustainability, Sperling and Gordon (2009) describe a raft of strategies needed to accommodate two billion cars on earth. The strategies include regulatory, market, and hybrid approaches that target upstream and downstream emissions sources with behavioral and technological changes and innovations. This wide array of tools demands careful inspection of interrelating motivators and effects.

From an economic perspective, Stern (2006) describes three required policy elements to address climate change successfully: carbon pricing (including taxes and trading), support of low-carbon technology, and removing barriers to efficiency while educating/persuading the public about what they can do to reduce their impacts. These strategies encompass economic, technological, and behavioral approaches. Stern also mentions reduction of deforestation specifically because of its global importance in climate change, ecology, and social equity issues.

Like Stern, strategies from the IPCC (2007b) include carbon pricing, technological innovation, and information campaigns, but the IPCC also suggests policy 
frameworks such as voluntary agreements between industry and government, integration of climate change into other, existing policies, and formal standards on climate change mitigation.

The Kyoto Protocol was the first major international commitment to reduce carbon emissions. It established carbon markets and market-based mechanisms for trading carbon credits. Major secondary effects of the Kyoto Protocol include the creation new standards and policies to address emissions quantification and carbon accounting. Concurrently, much research is underway to assess the direct and indirect results of the new carbon mitigation tools, and their efficacy in achieving real emissions reductions.

Due to the dominance of electricity production and transportation fuels in the U.S. emissions inventory, two popular areas to focus mitigation attention are coal-burning power plants and automobile fuel efficiency (Bomberg, Kockelman \& Thompson, 2009). Electricity generation and vehicle efficiency are also common target areas because they are large, consolidated industries that already face emissions regulations for other gases. Although they represent much of the current emissions, they are not necessarily the easiest or most desirable emissions to achieve. The IPCC (2007b) suggests four main criteria to evaluate mitigation strategies:

1. Environmental effectiveness

2. Cost effectiveness

3. Distributional effects such as equity

4. Institutional feasibility In addition to the size of current emissions, selection of mitigation strategies must look at the cost and time scales of reductions in various sectors and the full range of co- 
benefits and secondary effects from different measures. Further complications are the social and institutional changes needed to accommodate carbon reductions, and consideration of whether these changes are otherwise beneficial or detrimental. Cobenefits are an especially important consideration in strategies because they can help build successful coalitions. Co-benefits of GHG emissions reductions can include cost savings (lower utility bills), environmental benefits (less acid rain), and social benefits (public health and quality of life).

As an illustration, mitigation strategies in the transportation sector typically can involve three approaches: reducing the carbon intensity of fuels, reducing the demand for travel, and improving vehicle efficiencies. Reducing the carbon intensity of fuels might have no co-benefits beyond the GHG emissions saved. Improving vehicle efficiency can save drivers money on fuel costs and possibly reduce air pollution, but otherwise has few co-benefits. Vehicle travel demand reduction, however, can provide many co-benefits including large cost and time savings, air pollution reductions, health and safety benefits, and quality of life improvements. This does not mean that demand management is the most effective at reducing GHG emissions, only that it could carry the most co-benefits.

\subsubsection{Behavioral strategies}

Because the scope of carbon sponsoring is limited to personal-level reduction actions, behavioral strategies receive further attention here. In their investigation of behavioral responses to carbon taxes and carbon trading, Bristow and Zanni (2009) found that people are most willing to adopt emissions reduction strategies that are "win-win", saving energy with minimal personal costs in terms of both money and comfort. 
In other research, Semenza et al. (2009) found that when individuals voluntarily changed behaviors in response to climate change concerns, most changes were in the areas of reducing home energy use (43\%) and reducing gasoline consumption (39\%). The most common other behavior was recycling. The researchers also found significantly different likelihoods individuals would engage in these voluntary mitigations based on age, education level, and city of residence. The most commonly cited barriers to behavior change were: not knowing how, impressions of individual futility, and money and time costs.

As polling shows increasing public concern about climate change, Venner, Rue \& Chavez (2009) identify the need for improved tools and techniques to facilitate public involvement in GHG policy decisions. While this public involvement is intended to support better climate policies and inform the public about linkages between actions and GHG emissions, public education is also needed because downstream reductions will be required that are outside of government control (Venner et al., 2009). In the area of education tools, Hepburn (2007) identifies carbon labeling (accurate life cycle GHG footprint labels on products and services) as an important next step in public involvement.

Household or individual carbon budgeting is a general approach to mitigation that involves tracking personal emissions. Detailed awareness of carbon emissions can improve climate-conscious decision-making and help consumers find appropriate mitigation strategies for their lifestyles (Sperling and Gordon, 2009).

An ambitious related suggestion to motivate behavioral mitigation is carbon capand-trade on a personal or household level. This would operate much as on a national 
level, and allow personal carbon trading and banking using online markets. Niemeier et al. (2008) argue that downstream controls are more equitable and have lower total costs to society than upstream approaches. Part of their argument in support of a household carbon cap-and-trade system is that upstream price controls have limited effect on household energy demands. Personal carbon caps have received some consideration in the UK but still face many acceptability issues.

\subsection{Carbon Markets}

Carbon markets arise when pricing mechanisms assign carbon a monetary value and financial instruments allow trading of carbon credits. Voluntary carbon markets stem from public concern about climate change, but the vast majority of carbon trading (98\%) occurs on regulated markets (Hamilton, Sjardin, Marcello \& Xu, 2008). Most carbon trading is the direct result of markets and mechanisms established by the Kyoto Protocol. Carbon trading generally takes place on a large scale, both in the purchase and sale of credits. Individuals can purchase offsets through the voluntary markets, though the regulatory markets are largely inaccessible. Some options exist for individual participation in the creation of offsets through offset aggregators.

The largest market in the world is the European Trading Scheme, a product of the Kyoto Protocol that represented $69 \%$ of global carbon trading in 2007 with a total value of $\$ 50$ billion (Hamilton et al., 2008). While this is large, it will likely represent less than $1 \%$ of total global GHG emissions; carbon markets will have to continue expanding rapidly to encompass the volume of emissions necessary for significant worldwide reductions (Hepburn, 2007). 
The logic behind carbon trading is that from a climate change perspective all atmospheric carbon dioxide has the same effect. Allowing trading finds least-cost reductions worldwide, in any sector. This carbon spatial equality is only true for climate change, however, and mitigation projects can have vastly different costs and co-benefits for local and regional communities. Carbon trading can arrive at the most efficient carbon reductions, but "mainstream economic theory also stresses that an efficient outcome ... is not necessarily fair, equitable, or desirable" (Hepburn, 2007). Fundamental ethical arguments exist against the idea environmental commoditization, and there is some opposition in the environmental community to all forms of carbon trading or markets (Smith, 2007).

Although carbon taxes are more efficient than trading under certain scenarios, carbon trading has several advantages and enjoys more support. In particular, taxes are challenging to implement internationally and are less effective in the developing world. People also harbor a general opposition to taxes, and taxes do not allow the setting of exact carbon limits the way carbon caps do. Lastly is the private sector lobby in favor of lower targets that carbon markets create, along with specialized firms with expertise in carbon reduction (Hepburn, 2007).

\subsubsection{Regulatory carbon markets}

Four of the five regulatory markets arose from the Kyoto Protocol flexibility mechanisms. The fifth market, based in Australia, represents less than $1 \%$ of carbon traded on regulatory markets worldwide. For ratified countries, the Kyoto Protocol sets maximum national carbon emissions in Assigned Amount Units [AAUs] that decrease over time. Annex I countries are industrialized nations and can generate Emissions 
Reductions Units [ERUs] through Joint Implementation projects. Non-Annex I countries can generate Certified Emissions Reductions [CERs] through Clean Development Mechanism projects. CDM projects are typically renewable energy and capture/destruction of methane. AAUs, ERUs, and CERs are all tradable carbon credits, described as flexibility mechanisms under Kyoto Protocol. Nations that exceed their carbon caps must purchase these carbon credits to achieve compliance. The value of these carbon credits vary based on the demand and risk of project failure.

AAUs are sometimes referred to as "hot air" credits because they are based on 1990 emissions levels. These emissions volumes, measured before the economic collapse of the former Soviet Union, now exist in abundance and are less actively traded. The most active unit is the European Union Allowance [EUA], traded in the European Emissions Trading Scheme [ETS], the largest carbon market in the world. The ETS covers most of Europe's GHG emissions, though land and air transport are "notably absent" from the inventory (Hepburn, 2007).

\subsubsection{Voluntary carbon markets}

The voluntary carbon markets are much smaller than the regulatory markets, but growing rapidly. While the regulatory markets had a growth rate of $78 \%$ in $2007(1,642$ to 2,918 million tons of CO2e), the voluntary markets increased $165 \%$ (24.6 to 65.0 million tons of CO2e) (Hamilton et al., 2008). Carbon prices on the voluntary markets (about $\$ 5 /$ ton $\mathrm{CO} 2 \mathrm{e}$ ) are roughly a quarter of the prices on the regulated markets (about $\$ 20 /$ ton CO2e), reflecting the greater uncertainty in carbon savings and the decreased demand. 
A study of the U.S. voluntary carbon markets by the Government Accountability Office [GAO] (2008) highlights a lack of oversight, customer information, and quality assurance. The GAO indicates that while enforced standards would improve the quality of carbon offsets, they would also increase their cost and rigidity. A common trade-off in the carbon markets is cost versus credibility.

A popular source of interest in offset purchases is to cover emissions from air travel. Brouwer, Brander, \& Van Beukering (2008) found 75\% of European air travelers willing to pay for carbon emissions. The average price they were willing to pay was roughly twice the average carbon price on the voluntary markets. Travelers expressed motivation not by a sense of charity but by a sense of responsibility for their carbon footprint.

The only carbon commodity market in the U.S. is Chicago's CCX, which is also the world's only all-voluntary carbon market. It is a voluntary cap-and-trade system similar to the ETS. Most voluntary carbon trading (78\%), however, takes place on the over-the-counter [OTC] markets, where buying and selling of carbon offsets takes place (Hamilton et al., 2008). OTC exchanges vary widely and occur directly between purchasers and sellers. According to Hamilton et al. (2008), roughly $29 \%$ of carbon offsets purchases are not for retiring but for investment, resale, or banking to be used in future regulatory schemes. The volume-weighted average price of carbon on the OTC market in 2007 was $\$ 6.1$ per ton of $\mathrm{CO}_{2} \mathrm{e}$ (Hamilton et al., 2008). The most common carbon offset projects are renewable energy, methane capture and destruction, and biological sequestration in forestry and soil. 
A newer system in North America called the Western Climate Initiative [WCI] is a voluntary, regional program that aims to reduce GHG emissions. A 2008 WCI proposal describes a cap-and-trade system that would first take effect in 2012 with the stated goal of a $15 \%$ reduction below 2005 levels by 2020 .

\subsubsection{Transportation and carbon trading}

Despite its large emissions, the transportation sector does not have a large presence in the carbon markets. This discrepancy presents an opportunity for new funding of transportation projects with carbon reduction features (Millard-Ball, 2008).

Several reasons for transportation's underrepresentation are the difficulties of monitoring, measuring, and assigning ownership of transportation emissions, and the challenges of proving additionality in public works projects (Krambeck, 2009).

Millard-Ball (2008) describes several methods and barriers to transportation participation in carbon trading. Upstream fuel controls such as carbon caps at refineries would be easy to administer, but the current inelasticity of driving demand to fuel prices would likely redirect reductions into other sectors. Creating offsets through transportation projects is an option, but proving additionality and non-leakage can be difficult because of the myriad co-benefits and many dimensions of transportation projects. Offsets are risk-adverse and the uncertainty of behavioral change projects (such as demand management strategies) would greatly reduce the price of the offsets. In general, the two major barriers to transportation projects in the carbon markets are low elasticity of driving demand and privacy, feasibility, and uncertainty issues for downstream behavioral controls. 


\subsubsection{Carbon offsets and criticisms}

Carbon offsets are currently the only tools available in the U.S. for individuals wishing to compensate for their emissions. Key criteria for offsets are that they must be: measurable, verifiable, exclusive, permanent, and additional (Krambeck, 2009). Additionality is often challenging to prove. Most simply, additionality means that the offsets are measured against "business as usual" emissions. A common criterion for additionality is that the offsetting project would not occur without the addition of the offset funds (investment additionality). The GAO (2008) describes eight different additionality tests that can be required of offsets, in any combination.

Clean Air-Cool Planet (2006) publishes a consumers' guide to retail carbon offsets that demands offset quality, transparency in operations, third-party verification, education, and co-benefits from offset providers, and ranks online sites according to these evaluative criteria. The consumers' guide, like the GAO, reports a lack of quality and consistency in the offset market.

Carbon offset projects occur in limited fields. In 2007, renewable energy accounted for $31 \%$ of offset projects, energy efficiency constituted $18 \%$, methane destruction $16 \%$, and forestry/land based sequestration 18\% (Hamilton et al., 2008). Although those numbers change year to year, few sizable projects ever venture outside this range. Personal-level actions are rarely included because of the impracticability of validation and high administrative costs. Figure 1 from GAO (2008) illustrates the field of offset projects.

Soil or forest sequestration projects are low-tech, low capital, and relatively easy to show additionality. Wise and Cacho (2005) found that carbon trading improves the 
economics of tree growing as a land use by $22 \%$. While this is an effective option now, McCarl and Sands (2007) found that over time and at higher carbon prices, biofuels and other strategies dominate. Tree plantations are a common form of biological carbon sequestration where planting trees is credited with the carbon contained over the life of the tree (up to 100 years). Smith (2007) argues that trees are an active part of the carbon cycle and cannot offset additions of inactive carbon from fossil fuels. Smith further criticizes the high uncertainty in the effectiveness of biological sequestration, partly caused by the long time scales of accounting.

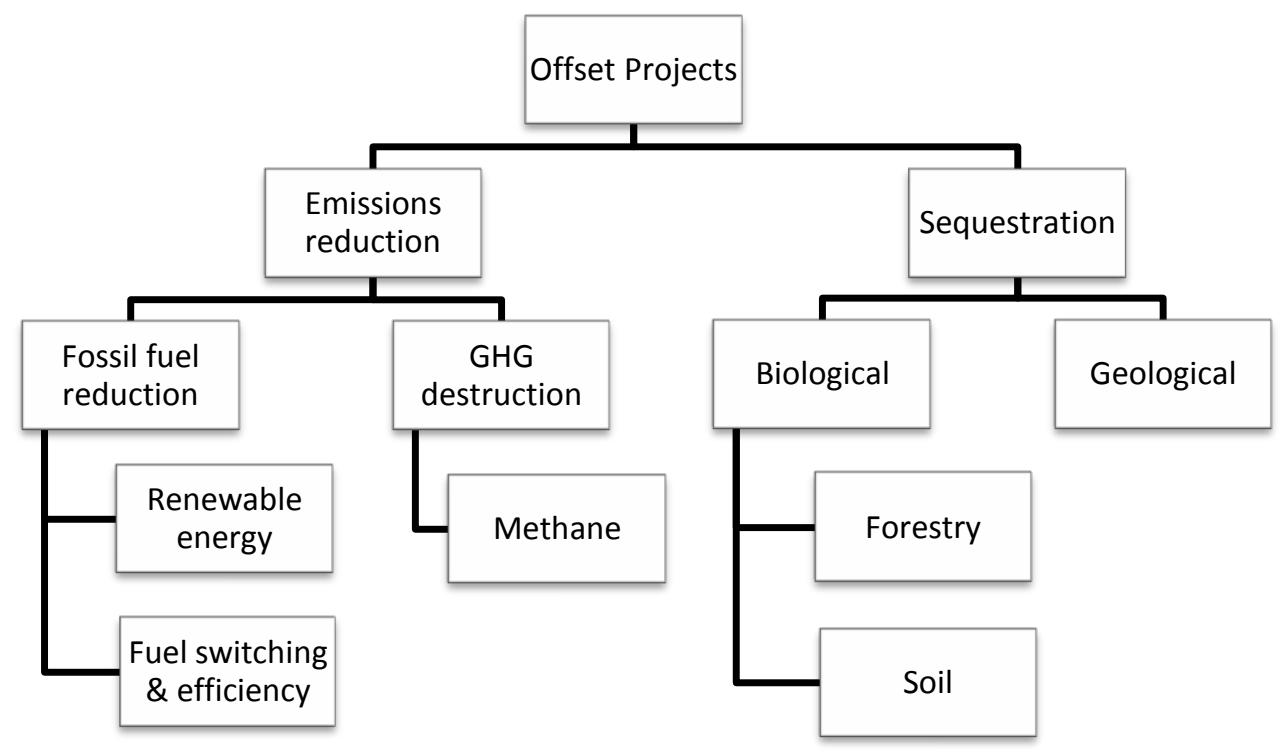

Figure 1: Summary of Common Carbon Offset Project Types (GAO, 2008)

The most common criticism of offsets in general is a lack of quality control and verification (Rousse, 2008). Offset projects also often fail to show true additionality (Passey, MacGill \& Outhred, 2008). Projects can fail to be completed or not reach the predicted savings, such as not achieving modeled building efficiency. These project failures are rarely accounted for. Projects do not often confirm emissions after completion, and the use of outside certification is rare and inconsistent. Another offset 
criticism is high administrative costs or lack of transparency when administrative costs are not reported.

Offset projects often count carbon savings over the life of an object such as an efficient light bulb (6 years), a wind turbine (12 years), or a tree (100 years). The first problem with this approach is a lack of future-value accounting, where future carbon savings should be discounted because of their uncertainty (as is done with money). The second problem is that while carbon is not spatially distinct on the earth, it is temporally distinct. With clear carbon targets timed to reduce emission now, present emissions cannot equate with reductions many years from now.

An important concern for all carbon trading instruments is equity. Carbon trading aims to achieve the cheapest reductions first, often found in developing countries. The resulting exporting of emissions (and related energy) from poor countries to wealthy ones presents an equity problem. International carbon trading can create monetary incentives for the developed world to interfere in with land rights and energy use in the third world (Smith, 2007). For nations not currently capped under the Kyoto Protocol, Rose, Bulte, \& Folmer (1999) argue that Joint Implementation projects will expend their easiest carbon reductions (for sale in the developed world). This can harm developing countries in the future when they incur regulation and have only high-cost reductions available.

The final criticism of carbon offsets to mention is greenwashing, a neologism describing the disingenuous marketing of business practices or products as environmentally friendly. The primary step in mitigating carbon impacts is reducing emissions, with purchasing offsets as a last resort. Carbon offsets (especially cheap, low quality offsets) can allow companies and events to make claims of being "carbon neutral" 
without actually reducing their carbon footprint at all. On the individual level, offsets should not be a tool to ease consciences or avoid thinking about climate change without making any real changes (Clean Air-Cool Planet, 2006). In a related way, Smith (2007) claims that all market-based schemes are essentially games that distract from the real systemic and policy changes that must happen to control climate change.

\subsubsection{Personal-level trading}

As previously stated, personal involvement in carbon trading is currently limited. Interested individuals can purchase carbon offsets online, but the quality of the offsets is often unclear. As an alternative to offsets, Rousse (2008) suggests letting citizens buy carbon in a capped carbon market and retire the credits (let them expire). This method is straightforward and avoids some of the issues of offsets such as additionality, time lag, and quality control.

Bristow \& Zanni (2009) studied behavior responses to personal carbon trading as compared to carbon taxes. They found that while personal carbon trading is currently more complex, costly, and unfamiliar, it could achieve greater reductions with more certainty. This argument mirrors that made by Hepburn (2007) for cap-and-trade schemes on a national level.

An important component of implementing personal-level trading is public education. Familiarizing the public with carbon trading schemes will help with acceptance and compliance, should a mandatory system be implemented (Rousse, 2008). In addition, education on carbon budgeting at the household level can itself lead to emissions reductions through better understanding of individual contributions. 
The rapid growth in the voluntary carbon markets reflects the public interest to act on climate change. A proliferation of business greenwashing also shows this in a way, because marketing targets consumer interests. While interest is high, there is also a perception of inability to change personal emissions, especially in the area of transportation. Bristow and Zanni (2009) found that air travel is the personal emissions area least likely to change from carbon pricing. At the same time, air travel is one of the largest sources for individuals purchasing carbon offsets.

Individuals who wish to generate rather than purchase offsets cannot easily access carbon markets. Most retailers demand carbon in large volumes, so individuals must sell to aggregators who will then consolidate diverse offsets. As an example Climate Trust (n. d.), a large non-profit offset provider in the Pacific Northwest, will not accept carbon offset projects smaller than 50,000 metric tons of $\mathrm{CO}_{2} \mathrm{e}$ (about 492,000 gallons of diesel fuel combusted). Additionally, the burdens of proving the validity of offsets through criteria of additionality and quality can be prohibitively time consuming and expensive for individuals working on small reductions.

\subsection{Carbon Calculation}

A primary step for individuals interested in their carbon impacts is carbon calculation. Accompanying the growth of climate change interest and voluntary carbon markets, the number of online carbon calculators has increased in recent years. Carbon calculation often pairs with retail offset sales using the target of "carbon neutral." As the price of carbon on carbon markets escalates, demand for accurate emissions estimates increases as well. Precision and accuracy in emissions estimates has especially benefitted from mounting carbon-reporting standards worldwide. 
The scope and accuracy of carbon calculators must match the demands of the emissions measured. For reduction strategies that target personal emissions, personallevel carbon calculators are needed. Similarly, when seeking small behavioral changes calculators must be able to estimate marginal emissions changes. While online carbon calculators can estimate individual footprints, almost all are on an annual scale. Broad annual estimates can raise awareness of individuals' impacts, but fail to capture shortterm effects and behavior changes.

Various studies have investigated the quality and utility of online carbon calculators. Padgett, Steinemann, Clarke, \& Vandenbergh (2008) studied U.S. calculators and found varying estimates, especially with electricity usage. Another deficiency was lack of transparency in methodology, which impedes independent validation. Calculators also varied significantly in suggesting mitigation strategies, ranging from no suggestions at all to specific suggestions tailored to the individual's footprint.

Kenny \& Gray (2009) compared calculators for application in Ireland and found inconsistencies in the inclusion of full indirect, lifecycle emissions. Jones \& Niemeier (2009) also found a lack of consistency in the depth of online calculators, along with the breadth of emissions included. Like Padgett et al. (2008), they reported insufficient transparency in methods and inconsistently clear feedback on reduction strategies. Quantitatively, Jones \& Niemeier found significant variance in carbon estimations using the same set of inputs.

Calculators can be a useful tool to promote public awareness and lead to policy and behavior changes, but they need to improve accuracy while balancing data demands, and offer personalized feedback in the form of suggested actions and even cost/benefit 
analyses. Transportation and home energy (followed by food and waste) are the most common areas included in personal-level carbon estimates. Tukker \& Jansen (2006) identify housing, transport, and food as responsible for $70 \%$ of environmental impacts in the E.U., though representing only $55 \%$ of household expenditures. Of particular importance are car and air travel, meat and dairy consumption, building structures, home heat, cooking, hot water usage, and electric appliances. Of course, these only represent the major sources of personal-level emissions, not necessarily where emissions are most readily reduced by individual actions.

Carbon calculator suggestions for reductions vary in cost, time frame, efficacy, and co-benefits. In transportation, travel reduction is the most effective method, though not mentioned as often as smaller measures like tire inflation, slower driving, and "ecodriving." Air conditioning usage has a rocky reputation, sometimes suggested to eliminate and sometimes to use instead of lowering windows. Home energy suggestions are more consistent, with the popular items being thermostat adjustments in winter and summer, turning off lights when not in use, replacing incandescent bulbs with compact fluorescents, and unplugging electronics. In the area of food impacts, the three common suggestions are to reduce red meat and dairy consumptions and to eat local foods.

\subsubsection{Electric energy mix}

Electric energy consumption makes up $72 \%$ of residential carbon emissions (EPA, 2009b) and is an important element in carbon estimates. The carbon intensity of electricity (lbs $\mathrm{CO}_{2} \mathrm{e}$ emitted per kWh of electricity) varies by location because of the mix of power generation used. The EPA tracks these values nationwide and produces the eGRID database with detailed emissions data (EPA, 2009a). Un-weighted average carbon 
intensity for U.S. states in 2007 was $1.69 \mathrm{lbs} \mathrm{CO}_{2} \mathrm{e} / \mathrm{kWh}$ (with a usage-weighted average of $1.36 \mathrm{lbs} \mathrm{CO}_{2} \mathrm{e} / \mathrm{kWh}$ ). Carbon intensities ranged from a low of $0.24 \mathrm{lbs} \mathrm{CO}_{2} \mathrm{e} / \mathrm{kWh}$ for Vermont to a high of $2.78 \mathrm{lbs} \mathrm{CO}_{2} \mathrm{e} / \mathrm{kWh}$ for Montana. Due to hydroelectric generation, Oregon was below average with $1.00 \mathrm{lbs} \mathrm{CO}_{2} \mathrm{e} / \mathrm{kWh}$.

\subsubsection{GHG units}

Emissions of diverse greenhouse gases are generally quantified in the common unit of carbon dioxide equivalents $\left(\mathrm{CO}_{2} \mathrm{e}\right)$ for simplicity and due to the dominance of carbon dioxide as a GHG. This unit refers to the global warming potential, or relative radiative forcing, of each gas with respect to carbon dioxide on an equal mass basis. After $\mathrm{CO}_{2}$, the next most important gases are methane $\left(\mathrm{CH}_{4}\right)$ and nitrous oxide $\left(\mathrm{N}_{2} \mathrm{O}\right)$ with global warming potentials of 21 and 310, respectively. Other greenhouse gases such as CFCs and HFCs can have global warming potentials in the thousands (IPCC, 2007c).

To make emissions estimates more tangible, other units are sometimes used that relate to activities. For example, a carbon footprint can present emissions as gallons of gas consumed, light bulbs replaced, barrels of oil, etc. In their study of diet and the environment, Eshel \& Martin (2006) equate different diets to miles driven in different types of automobiles.

\subsubsection{Transportation footprints}

As with all carbon estimates, transportation footprints must be calculated with a balance of data and accuracy requirements. Estimates usually involve a combination of the carbon intensity of the transportation fuel (lifecycle carbon emitted per unit of fuel), 
the efficiency of the vehicle (distance per unit of fuel), and the distance traveled. A common rule of thumb for the current U.S. fleet is $1 \mathrm{lb} \mathrm{CO}_{2} \mathrm{e}$ per mile driven.

An important consideration in transportation emissions is who bears the carbon ownership for indirect emissions. For example, should emissions from building the transportation infrastructure be assigned to users according to distance travelled? If not, should all of society bear the carbon responsibility for the creation of the infrastructure, and users only "own" the carbon emitted to propel their vehicle? This second approach is the most common.

Similarly, should users of public transportation bear the responsibility of the carbon emitted during their trip, divided equally among riders? In this way riders on a nearly empty bus will have extremely high emissions per mile of travel, though the bus would still be running if they were not on it. A relevant question here is the sensitivity of the mode to demand. A personal vehicle trip is completely dependent on the driver's decision to travel. Transit, however, often has excess seating capacity that can accommodate more riders without a noticeable increase in emissions. In the short term, each rider's marginal impact is zero. However, transit is not completely inelastic to demand, so at some point entire trips are eliminated or created as ridership changes. One approach is to assign part of transit's carbon emissions to society, much the same way we conceptually distribute infrastructure emissions. In practice, total transit system emissions are distributed equally per passenger-mile, which neglects the occupancy of individual trips but does consider system ridership.

The EPA tracks carbon intensity of transportation fuels. These measurements include the direct carbon content of the fuel, but not the full lifecycle emissions. The 
proportion of carbon emissions at the point of use varies widely, down to zero for electric vehicles. As with all life cycle assessments, carbon estimates should include all effects, including detailed land use changes. Biofuels are often accounted as carbon neutral, despite the significant land use changes (deforestation) that can result from production (Johnson, 2009).

Air travel calculations are challenging because of high variability and unknown factors. Filippone (2008) asserts that most air travel estimates are unclear on methods and factors considered. Not surprisingly, distance is a primary consideration in air carbon estimates. Actual trip distances often vary from great circle distances between airports because of inefficiencies in the flight path and holding patterns. Flight passenger occupancy is also important for the distribution of emissions among passengers. Some calculators include the cargo shipped, which can make up 2-20\% of the payload weight in commercial flights (TRX, 2008). Another optional consideration is a passenger's seat class. Premium seat classes occupy additional cabin real estate, which reduces possible flight occupancy. Business class seats occupy twice the space of economy seats on average (TRX, 2008).

TRX takes the most detailed approach, utilizing air travel databases with specific aircraft assignments and seat arrangements. Less detailed air travel estimates use similar approaches to transit systems, where emissions from total aviation fuel use are distributed evenly among total air seat-miles to get an annual average carbon emitted per passengermile. This aggregate approach neglects the marginal impacts of choices and changes individuals can make to reduce their footprint (such as choosing economy seat classes or 
airlines with a more fuel-efficient jet fleet). As with other performance measures, what carbon we measure is where we look for improvements.

Although distance is the biggest factor in true emissions, the question of radiative forcing heavily influences emissions estimates. Scientific uncertainty remains about the global warming effects of aircraft emissions. Releasing catalyst GHG and water vapor in the stratosphere has distinct effects from ground level emissions, but current models do not agree on what the exact effects are. In 1992, the IPCC recommended a radiative forcing index (RFI) of 2.7, indicating global warming potential 2.7 times that of the $\mathrm{CO}_{2}$ emissions alone (TRX, 2008). The UK Department for Environment, Food and Rural Affairs [DEFRA] calculator uses a multiplier of 1.9 based on recent research (2008). RFI estimates are likely to change as scientific study continues. Obviously a doubling or tripling of emissions impacts will greatly affect carbon estimates; accordingly, many air travel calculators allow users to optionally include a radiative forcing index.

\subsubsection{Home energy footprints}

Home energy carbon estimates, usually annual, use fuel consumption from utility bills and the carbon intensity of different fuels. Electricity is the only common fuel with significantly varying carbon intensity, requiring location data for high accuracy. In the U.S., appliances (such as refrigerators, dryers, and TVs), air conditioning, space heating, and water heating dominate home electricity usage.

Druckman \& Jackson (2008) studied home energy consumption in the UK and found consumption closely tied to income and other household characteristics such as urban/rural and dwelling type (apartment, detached house, etc.). When utility bills are not available, some calculators use dwelling type as a primary input to estimate consumption. 


\subsubsection{Product life cycle assessments}

Outside of transportation fuels, home heating, and gas-powered tools, most personal emissions are indirect, occurring during food and goods production, transport, and disposal. Figure 2 illustrates the various life cycle components of solid goods (EPA, 2006). These indirect emissions can lead to complex carbon accounting processes and regulations that grow in intricacy as interest increases (British Standards Institution, 2008).

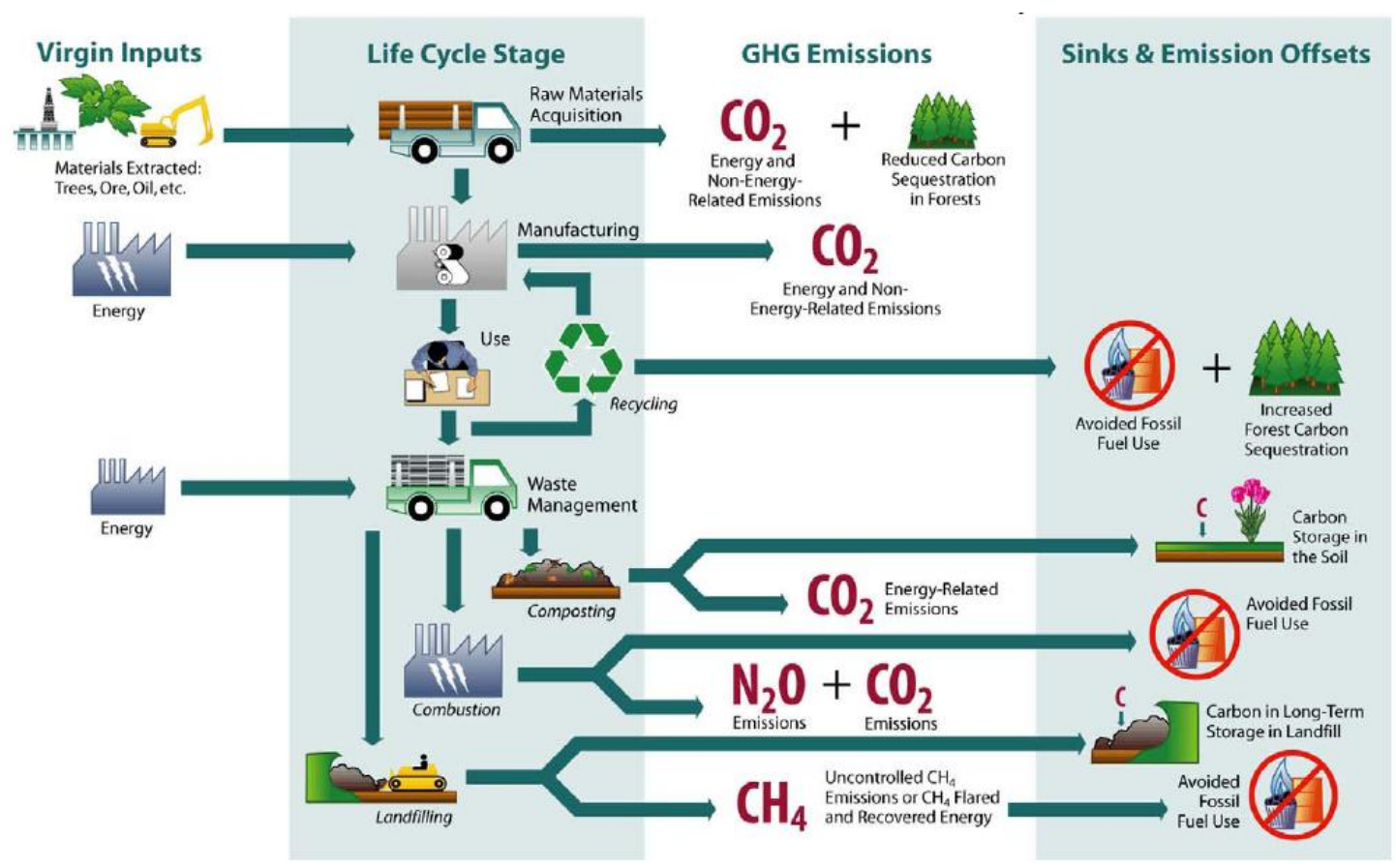

Figure 2: Greenhouse Gas Sources and Sinks Associated with the Materials Life Cycle (Source: EPA, 2006)

In the U.S. the top three category components of municipal solid waste by weight are cardboard (13\%), yard trimmings (12\%), and food discards (11\%) (EPA, 2005).

Although life cycle carbon estimates for individual materials are increasingly well researched, the footprint for individual products is more difficult. Necessary data includes the weights of different materials involved and manufacturing processes. 
For example, a detailed analysis of DVD rentals by Sivaraman, Pacca, Mueller, \& Lin (2007) used data from 14 different life cycle stages to arrive at carbon estimates of $2.53 \mathrm{lbs} \mathrm{CO}_{2} \mathrm{e} / \mathrm{DVD}$ for e-commerce and $4.23 \mathrm{lbs} \mathrm{CO}_{2} \mathrm{e} / \mathrm{DVD}$ for a traditional video store. These estimates were very sensitive to several of the input assumptions. While this approach is possible for a detailed analysis of one item, it is currently impractical for the range of goods individuals use in daily life.

\subsubsection{Food footprints}

Food life cycle assessments (LCA) are similar to those for product life cycles, though downstream emissions are typically excluded (human waste emissions not attributed to the food input). A robust meta-study by Weber \& Matthews (2008) found that most food-related carbon emissions occur during production (83\%). Garnett (2009) argues that LCAs are insufficient for food because they fail to capture the more complex land-use interactions that occur worldwide, particularly with livestock food consumption, deforestation, and feeder crops.

In the past, food environmental impacts were simple input-output energy balances (Pimentel \& Pimentel, 1996). Climate change analysis demands more complex assessments because of the disproportionate presence of GHGs from animal waste. For eggs, sheep, and poultry, non- $\mathrm{CO}_{2}$ GHGs are relatively low $(<1 \%)$, but pork, dairy, and beef emissions of methane and nitrous oxide make up 15\%, 29\%, and $56 \%$ of their total GHG footprints, respectively (Eshel, 2006). Phetteplace, Johnson, \& Seidl (2001) found an even greater share of non- $\mathrm{CO}_{2} \mathrm{GHG}$ emissions for milk at $87 \%$.

In general, the presence of cows in the life cycle of a food greatly increases the carbon footprint. Weber \& Matthews (2008) found red meat is on average three times 
more carbon intense than fish and poultry. For this reason, the food literature on climate change focuses on cows and feedstock such as soy. Calorie shifting to less carbon intensive foods is a primary strategy to reduce food carbon. Large-scale efforts in this area are closely tied to public health and land use issues. An often-discussed aspect is land competition between food production and biofuels.

After reducing dairy and red meat consumption, the next most common suggestion to reduce food impacts is buying locally grown food. Weber \& Matthews (2008) found that only $4 \%$ of the total carbon footprint of food, on average, is due to transportation from producer to retailer. In fact, the total transportation supply chain is about four times the distance traveled from farm to store. There are many co-benefits for locally grown food, but climate change is not chief among them. To compare local production with red meat consumption, if the average American switched just 10 to $20 \%$ of their diet away from red meat and dairy they would have the equivalent GHG savings of growing all of their food in their own back yard (Weber \& Matthews, 2008). 


\section{PROPOSED TOOL}

In light of the limitations of available options for individuals wishing to take action on climate change, this paper proposes a new tool called carbon sponsoring. While the proposed tool is not a panacea for heavy emissions, it does offer new opportunities for public education and voluntary personal participation in carbon trading.

\subsection{Carbon Sponsoring}

The idea of carbon sponsoring relates to emerging strategies about personal carbon budgeting and household carbon caps and taxes. After reducing their own emissions, motivated individuals can solicit pledges for emissions reductions to cover the emissions they see as unavoidable. Pledge solicitations can occur through any relevant social network: friends, coworkers, family. The persons selected for solicitation will likely depend on the type of emissions being sponsored. Individuals can also make crosssector pledges for their own emissions, for example pledging to reduce their food impacts to compensate for unavoidable transportation emissions.

The primary audience for this tool is likely to be those either not involved in the carbon markets or those currently purchasing offsets. Although it is a fundamentally different system, based on social currency instead of monetary currency, it must address the deficiencies in the offsetting system. One possible use of carbon sponsoring is by organizations desiring to establish expectations of climate mitigation by its members to cover group activities.

Carbon sponsoring can also appeal to individuals wishing to participate in the supply side of the offset system. The types of carbon reductions in carbon sponsoring are 
different from those on the carbon markets because they are small-scale and downstream, unlike the upstream and sequestration projects common in established carbon trading.

The desire to maintain the strengths and eschew the weaknesses of carbon offsets and calculators leads to the following set of principles for carbon sponsoring tools:

1. Personal-level emissions - suggestion and quantification of activities should emphasize individual accessibility with minimum or no net cost on short time horizons

2. Emphasize co-benefits - although they can complicate additionality proofs, monetary, social, and environmental co-benefits should be sought whenever possible in emissions reductions strategies

3. Simplicity - consistency is of principal importance; carbon estimates for carbon sponsoring are not for inventories or regulations; balance should be sought to achieve high accuracy while keeping data requirements practical and participant burden low

4. Transparent methodology - for education and trust; allow users to customize any numbers they feel are more accurately estimated by other methods

5. Provide feedback and education - one of the primary intents of citizen participation is to inform and familiarize the public about carbon footprints and reduction strategies

\section{2 carbonsponsor.org}

As a demonstration of carbon sponsoring, this paper proposes a system for carbon sponsoring of personal travel. This is an apt area because of the amount of personal emissions in transportation and because air travel is a common activity where people 
purchase carbon offsets. The full demonstration project created an online tool, launched a short pilot release, and evaluated the participation and feedback.

The online tool facilitates carbon sponsoring for personal travel; facilitating the social networking aspects of carbon sponsoring was not within the initial scope. The website performs carbon calculations and presents pledge options for travelers and sponsors. Other functions were to record trip and pledge information, and allow editing and tracking of trips and pledges. The online format of the demonstration project is a low-cost, easy medium familiar to most Americans.

The fundamental operations necessary in the online tool allow users to:

1. Enter trip information and calculate a carbon footprint

2. Solicit pledges by emailing trip information to acquaintances

3. Make pledges for your own trip or others' trips using a provided set of common recommended actions (or using an independent methodology)

4. Edit trips and pledges, and provide completion information for pledges

5. Provide feedback and suggestions

\subsection{Justifications}

\subsubsection{Voluntary}

The voluntary carbon market growth of the last several years reflects steadily increasing interest in individual action on climate change. Voluntary tools allow immediate actions before implementation of broad policy tools on climate change. Early public participation can also signal policy makers about constituent interests. Finally, voluntary tools have low administrative costs and work well with non-monetary, social currencies. 


\subsubsection{Alternative to offsets}

Carbon offsets suffer from a range of deficiencies discussed above, such as lack of validation, time lag, lack of transparency, inequity, and high administrative costs. While carbon sponsoring does not correct all of these shortcomings, it does have several advantages for individuals wishing to participate.

1. Equity issues are reduced because the emissions and reductions are linked through a social network. The emitters and reducers are more likely to be in similar locations and demographics than with offsets.

2. Soliciting pledges applies a social pressure for the emitter first to make all possible reductions on their end, unlike offsets, which only provide small cost incentives. Criticisms of offsets allowing individuals to assuage guilt while avoiding change are reduced because of the individual action involved.

3. The high administrative costs for offset retail sales and projects are essentially eliminated.

4. Additionality is still difficult to prove on the personal level, but the use of social currency transfers the burden of proof to the "honor system". Instead of uncertainty and additionality driving up administrative costs and offset prices, they require greater attention from participants. This individual attention to quality and validity raises awareness about the effects of activities.

5. Like offsets, carbon pledges lack standards and oversight, but tying the emitter to the reducer provides a form of interpersonal quality control lacking in offset programs. 


\subsubsection{Personal-level emissions reductions}

Most carbon projects are upstream and do not utilize personal emissions reduction strategies. Upstream schemes are easier to administer but cannot access all mitigation options. 17\% of U.S. GHG emissions are attributable to home energy (EPA, 2009b), either through fossil fuel combustion or electricity use. While individuals cannot readily decrease the carbon intensity of the electricity they use, they can reduce their electricity consumption. Other than compact fluorescent light [CFL] projects, almost no offset projects address personal consumption. Carbon sponsoring directly targets individual energy use and other emissions sources. Most personal-level emissions reductions have the benefits of short lead times and low capital costs. When carbon sponsors encounter systemic barriers, this will increase awareness of necessary societal changes.

\subsubsection{Public education}

Accompanying increasing public interest, education can expand awareness of the size of carbon footprints and effective reduction strategies. Carbon sponsoring serves this purpose, and advances understanding of carbon budgeting, caps, and taxes, which will improve the landscape for policy changes. A unique advantage to cross-sector marginal carbon quantification is the ability for individuals to appreciate the relative effects of changes in diverse activities (for example, taking the bus versus not eating a hamburger).

\subsubsection{Persistent challenges}

While carbon sponsoring offers improvements, it still suffers some of the problems of other carbon trading schemes. 
1. Quality assurance issues persist, with a shift of responsibility from third-party validation to interpersonal trust. Because pledges are voluntary, there is no material penalty for failure to complete them. Like offset projects, it is surely possible that expected reductions will not be achieved. To account for this shortcoming, uncertainty could be included in pledged carbon calculations.

2. While conventional carbon projects are limited to upstream strategies, carbon sponsoring is limited to downstream strategies. In its present conception, carbon sponsoring can only address a subset of total emissions, though its indirect benefits through public information can be far reaching.

3. Greenwashing is still a concern, as with any trading scheme. Critics who claim that every entity should be entirely responsible for its own emissions still have a strong case against carbon sponsoring.

4. Carbon sponsoring is a trading scheme only, not a new calculation tool. The high uncertainty in detailed carbon estimates remains.

\subsection{Carbon Pledges}

To avoid time lag issues and carbon accounting challenges, a three-month time window is set for carbon pledges. In addition to the option of directly inputting a total carbon pledge amount, the tool includes suggested pledge options with carbon calculations. Selection of pledge options was a detailed process that involved consideration of data needs, co-benefits and costs, calculation methodology, and time frames. The field of options was defined from existing personal mitigation strategies for which some methodology was discernable. The unlikelihood of individuals using their own methods for carbon pledges placed special import on the selection of pledge options. 
An important consideration was to limit the possibilities for negative secondary

effects such as carbon migration or ecologic harm besides to the atmosphere. The dominance of transport, home energy, and food in personal carbon inventories and carbon mitigation actions led to focus in these areas.

The four main criteria for carbon pledges, as presented in the tool, are:

1. Immediate - all carbon pledges must be completed within 3 months

2. Additional - pledges must be for actions beyond what you already do or would do to reduce your carbon footprint

3. Non-migrating (permanence) - carbon saved through the pledge must not be shifted to another time, place, or person

4. Good faith - pledges must be made with real intentions of completion and full, honest reporting of the results

Further criteria are that pledges must be quantifiable and follow the principles of simplicity and providing economic and environmental net co-benefits.

\subsubsection{Transport}

The complexity of transport options and decisions led to a pledge framework that compares the carbon from complete trips under two different travel scenarios. Suggested options for lowering total trip carbon are:

1. Reduce travel (for example trip chaining, eliminating flight layovers, or telecommuting)

2. Reduce carbon intensity through mode shift, carpooling, air travel options, or fuel switching 
Vehicle efficiency strategies (such as proper tire pressure, not idling, removing roof racks, etc.) are not included because of uncertainty in estimates and quantification and data challenges.

\subsubsection{Home energy}

The heavy energy demands of home heating and cooling brings thermostat adjustments immediately to the fore as a pledge option. Home HVAC system efficiency upgrades can also reduce energy use, but are capital intensive and require years of use to pay off, both from monetary and carbon emissions perspectives. This reasoning eliminated any appliance upgrades from pledge consideration, as well as light bulb replacement with CFLs. Dishwasher operation can be replaced by hand washing, but the carbon benefits are not well known. Reducing hot water use through switching from baths to showers or taking shorter showers is likely to reduce footprints, but difficult to measure.

Line drying clothes instead of using a dryer is a sound option, well quantified and unlikely to have secondary detriments. Washing clothes in cold water instead of hot can also save energy with migration unlikely. Although unplugging electronics when not in use reduces electricity consumption, savings for individual products is difficult to estimate, as would be the total savings for the pledge. Televisions, especially newer large-screen versions, draw much power, but watching less television is likely to lead to carbon migration as other activities replace TV watching, possibly with greater carbon effects. 
The four home energy pledges selected to include are lowering the thermostat for heat, raising the thermostat for cooling, line drying clothes instead of using the dryer, and washing clothes in cold water instead of hot.

\subsubsection{Food}

The dominance of red meat and dairy in food carbon footprints, along with their easy replacement by other foods, makes them clear candidates for carbon pledges. Eating "local" food has limited carbon benefits, as described above, and would be difficult to quantify accurately. Only red meat and dairy consumption reductions are included for pledges.

\subsubsection{Goods}

Reducing the consumption of goods and the material used in goods consumed can have clear carbon benefits. Quantifying those benefits, however, requires a large amount

of data to have any certainty. Recycling also has carbon benefits, though the data required to quantify the benefits is unlikely to be available. Another problem with pledging goods reductions is the high possibility of carbon migration when other activities or goods are substituted. For this project, no consumer product or recycling pledges were included, although they are worthwhile environmental activities and should be encouraged.

\subsection{Calculation Methodology}

The proposed methodology approaches carbon estimates for personal travel and pledges with a balance of data requirements and accuracy expectations. Whenever possible, established methodologies are used, such as those adopted by the EPA or DEFRA. These methodologies mostly use annual average values, so marginal estimates 
of individual activities require different tactics. To this end, either annual methods are adapted to small-scale estimates or published studies on marginal emissions are used.

The main calculation challenge is a lack of published micro-footprint literature and tools. Aggregate emissions are important for inventories and currently better estimated than marginal emissions. The marginal approach is fundamentally different, attempting to quantify emissions changes rather than total emissions. In keeping with the core principles, all methodology and factors are described on the website, and individuals can override calculated carbon or emissions factors if they prefer other methods.

\subsubsection{Travel footprint}

Carbon estimates for a trip are generated leg by leg, with each leg operating on a single mode. Input data for each leg generates an emissions rate, then combined with the leg distance for total carbon. Walking and bicycling modes are assigned emissions rates of zero. An "other" mode allows user input of fuel carbon intensity and vehicle efficiency, travel carbon intensity and distance, or a total carbon estimate directly.

\subsubsection{Direct emissions modes}

Emissions estimates for direct emissions modes (car, motorcycle, and taxi) require fuel carbon intensity (lbs $\mathrm{CO}_{2} \mathrm{e} /$ gallon of fuel), vehicles efficiency (gallons of fuel/vehicle-mile of travel), and distance traveled. The "car" mode includes all 4-wheeled personal vehicles (SUVs, vans, pickups, etc.). Road travel distances are easily found using online mapping programs, though these are not embedded in the tool. Fuel carbon intensity and vehicle efficiency default to U.S. national average values, obtained from the Energy Information Administration [EIA] (2008) and the EPA (2008b). For fuels other than gasoline, average values of carbon intensity are supplied as shown in Table 1. 
Average values are also included for vehicle efficiency by different vehicle classes, shown in Table 1. For taxi travel, only the distance driven with the passenger is included. The emissions associated with empty miles for taxis are excluded because of uncertainty and a lack of data on the part of riders.

Table 1: Average values for fuel economy and fuel carbon intensity (EPA, 2008b; EIA, 2008)

\begin{tabular}{|lc|lc|}
\hline $\begin{array}{c}\text { Vehicle } \\
\text { Class }\end{array}$ & $\begin{array}{c}\text { Average Fleet Fuel } \\
\text { Economy (miles/gallon) }\end{array}$ & \multicolumn{1}{c|}{ Fuel } & $\begin{array}{c}\text { Carbon Intensity } \\
\text { (lbs CO2e/gallon) }\end{array}$ \\
\hline Cars & 23.4 & Gasoline & 19.4 \\
SUVs & 16.9 & Diesel & 22.4 \\
Vans & 18.5 & $100 \%$ Biodiesel & 20.9 \\
Pickups & 16.7 & $100 \%$ Ethanol & 12.3 \\
& & Liquefied Petroleum Gas [LPG] & 12.8 \\
& & Liquefied Natural Gas [LNG] & 9.8 \\
\hline
\end{tabular}

\subsubsection{Surface public transit}

Average carbon intensity per passenger-mile for various transit modes was taken from the EPA (2008a) and the World Resources Institute [WRI] (n.d.), as shown in Table 2. These emissions factors require trip distance and number of passengers to compute total carbon. As with other calculations, participants can directly input the carbon intensity of their local transit agency if they have that data. This approach uses the standard method of aggregating emissions and ridership to average emissions intensity for each mode, rather than considering the specific occupancy or fuel on each bus or train (which is unlikely to be available to riders). In reality, an individual switching a trip from car to bus will have a larger total reduction than computed here because car emissions are almost entirely dependent on demand, while bus emissions are less sensitive. 
Table 2: Carbon intensity of transit modes (EPA, 2008a; WRI, n.d.)

\begin{tabular}{|ll|}
\hline Mode & lbs CO2e/pax-mi \\
\hline Bus & 0.236 \\
Light Rail/Subway/Tram & 0.361 \\
Heavy Rail & 0.409 \\
\hline
\end{tabular}

\subsubsection{Air travel}

Computation of air travel emissions is more complicated and uses a method described by DEFRA (2008b) and adapted by WRI (n.d.). Each flight leg is computed separately. The calculation begins with a flight distance, available from an airline ticket, airline booking site, or from TRX (www.carbon.trx.com), which is linked through the tool. The distance is adjusted for inefficiencies in the flight path using the formula:

$$
D_{\text {adj }}=D_{\text {nom }} * \max \left(1.09-\frac{D_{\text {nom }}}{1,000}, 1.01\right)
$$

where $D_{a d j}$ is the adjusted distance and $D_{\text {nom }}$ is the nominal flight distance.

Average carbon intensity per passenger-mile is then taken from the DEFRA data tables based on a combination of flight distance and seat class, as shown in Table 3. If participants choose to include radiative forcing index for aviation emissions (described above), a multiplier is applied of 1.9 .

Table 3: Air travel emissions factors by distance and seat class (DEFRA, 2008b)

\begin{tabular}{|c|l|c|}
\hline Distance (mi) & Seat Class & $\begin{array}{c}\text { Carbon Intensity } \\
\text { (lbs CO2e/pax-mi) }\end{array}$ \\
\hline$<280$ & All & 0.622 \\
280 to 2300 & Economy & 0.332 \\
& First/Business & 0.498 \\
& Unknown & 0.349 \\
& Economy & 0.286 \\
& First/Business & 0.830 \\
\hline
\end{tabular}


More detailed estimates based on actual flight databases are available through the TRX website, which is linked through the tool. Users may calculate the carbon from the flight and input the total carbon estimate directly.

\subsubsection{Pledged carbon calculations}

Carbon calculation for pledges is based on available methodologies using the principles and criteria described above. One pledge option simply called "other" allows sponsors to use any valid method to calculate the carbon savings from a pledge activity and enter the value directly (along with a description of the pledge activity).

\subsubsection{Transport pledge calculations}

Carbon calculations for transport pledges follow the same methods described above for the travel footprint. The website allows input of the existing trip data, which generates an existing carbon estimate, and then input of proposed trip data, which generates a proposed carbon estimate and the carbon savings per trip of this kind. This method of calculation provides side-by-side comparison of carbon estimates from different travel scenarios. Transport pledges are suggested to be regular trips (such as commutes or regular shopping or activities) to avoid carbon migration and additionality problems. After estimating the carbon savings per trip, users enter the number of trips pledged within the next three months. The exact text of the pledge suggestion on the website reads: 
To qualify as carbon sponsoring, these actions must be additional. If you already bicycle to work every day, that's great - but you can't count those as carbon-reducing trips!

There are several ways to reduce your carbon from these trips. For example, you can:

1. Avoid making the trip (i.e., telecommute) - this can often bring your carbon emissions to zero! However, you must also consider secondary effects. If you regularly commute in a carpool, then the carbon from your saved trip will simply be redistributed among the remaining members of the carpool. Also, if you regularly chain another trip to your commute (i.e., stopping for groceries on the way or picking up your kid from school), your carbon savings will be reduced if you still make that trip, but this time from home.

2. Chain the trip - combine it with another trip you are already making

3. Switch to a less carbon-intensive mode like walking, bicycling, or the bus

\subsubsection{Home energy pledge calculations}

\section{Lower thermostat during winter}

Calculation of the carbon savings from lowering the thermostat during winter starts with the input of local state, month, heating fuel, and typical bill for the month. The carbon intensity of the heating fuel comes from the EPA (2009b) as shown in Table 4.

For electric heat, the carbon intensity for the given state comes from the eGRID data tables (EPA, 2009a). Volume of fuel consumed for heating is based on the user-input typical utility bill for the month. When users input utility bills in monetary units instead of volume units, volume usage is estimated using average prices, shown in Table 4, from the EPA (n.d.).

Table 4: Heating fuel average price and carbon intensity (EPA, 2009b; EPA, n.d.)

\begin{tabular}{|llcc|}
\hline Heating Fuel & Volume Unit & $\begin{array}{c}\text { Carbon Intensity } \\
\text { (lbs CO2e/volume unit) }\end{array}$ & $\begin{array}{c}\text { Average Price } \\
\text { (\$/volume unit) }\end{array}$ \\
\hline Natural Gas & 1,000 cubic feet & 120.593 & 14.14 \\
Electricity & kWh & ref (EPA, 2009a) & 0.106 \\
Fuel Oil & gallon & 22.384 & 2.78 \\
Propane & gallon & 12.669 & 2.19 \\
\hline
\end{tabular}


For non-electric heating, all fuel usage is assumed to go to space heating, with no other sources of heat. For electric heat, the portion of electricity used for heating is based on the concept of degree-days. A degree-day method is also used to estimate the monthly savings per degree of thermostat adjustment. This approach is adapted from the EIA (2000), which uses the method on an annual scale to predict winter thermostat adjustment savings.

Heating degree-days [HDD] is the number of degrees the average daily temperature is below a reference temperature. Monthly HDD is summed for all days in the month, and statewide HDD is calculated from a population-weighted average of small climate regions within each state. Estimation of the portion of monthly electricity used for heating begins with a national average of $10 \%$ of annual electricity use for space heating (EIA, 2001). Each state then adjusts based on HDD where PAEH is the percent of annual electricity used for heating:

$$
P A E H=\frac{1}{\frac{9 \times H D D U S}{H D D} \text { state }}+1
$$

This adjustment assumes other electricity uses are constant through the year and across the country, and that heating usage is directly proportional to the local HDD. The range of PAEH in the lower 48 states from this calculation is $1.7 \%$ for Florida to $19 \%$ for North Dakota. The entire set of calculated PAEH by state is shown in the Appendix.

The state annual percentage of electricity for heat is then distributed to months by the portion of annual HDD in the month to find the PMEH (percent of monthly electric used for heating):

$$
\mathrm{PMEH}=\frac{1}{1+\frac{(1-\mathrm{PAEH})}{12 \times \mathrm{PAEH}} \times \frac{\mathrm{HDD} \text { year }}{\mathrm{HDD} \text { month }}}
$$


This calculation assumes that non-heating electric use is constant throughout the year. Full results for each month in each state are shown in the Appendix. The appropriate PMEH can then be multiplied by typical monthly electric consumption to estimate the amount of electricity used for space heating in the month.

To estimate the fuel savings from lowering the thermostat a reference temperature is selected at $70^{\circ} \mathrm{F}$. The first assumption is that a 1-degree change in the thermostat setting is equivalent to a 1-degree change in the outside temperature in the opposite direction. Then the change in HDD per degree change in reference temperature is assumed to equate to a change in the thermostat setting. Historical temperature data for the U.S., including HDD and cooling degree days [CDD] were obtained from the National Oceanic and Atmospheric Administration [NOAA] (2009). CDD is the parallel of HDD, measuring the distance of the average daily temperature above a reference cooling temperature.

A 1-degree decrease in reference temperature would reduce the monthly HDD by the number of days with an average temperature below the reference temperature. Because temperate data were aggregated by month, it was necessary to assume a normal distribution for daily average temperature and a value for the standard deviation of daily average temperatures in the month $\left(8^{\circ} \mathrm{F}\right)$. Assuming heating energy is directly proportional to the number of HDD, the energy savings is then calculated as the change in HDD as a percentage of total HDD.

Reasonable bounds were set at $0.5 \%$ to $10 \%$ energy savings per ${ }^{\circ} \mathrm{F}$. These only come in to effect for mild months and climates when the average daily temperature is close to the reference temperature so small changes have a large effect. The complete list 
of estimated energy savings per degree of thermostat adjustment is shown in the Appendix.

The monthly carbon savings estimate per degree-day of adjustment is then the combination of volume of fuel consumed (calculated for electricity), fuel carbon intensity, and estimated monthly percent savings per degree-day. The final step is for the sponsor to input the number of degrees and number of days for the pledge, resulting in a total carbon pledge estimate.

Many assumptions go in to this method concerning home energy usage and temperature effects. The uncertainty for these estimates is high, but little research exists on marginal, short-term savings from thermostat adjustments; all other methodologies with reasonable data requirements are on the annual scale. The uncertainty, though, is not an obstacle to using the estimates because, as stated previously, the action of carbon sponsoring is more important than the precision of the carbon estimates. Improved methods that refine estimates can readily be substituted as available.

\section{Raise thermostat during summer}

The method for air conditioning $[\mathrm{A} / \mathrm{C}]$ thermostat adjustment is similar to that for electric heat described above. After user input of month, state, and typical electric bill (in dollars or $\mathrm{kWh}$ ), the monthly electricity consumption for cooling is calculated from the PMEC (percent of monthly electricity used for cooling). PMEC calculation mirrors PMEH calculation, with the exception that $16 \%$ of annual electric usage goes to air conditioning (EIA, 2001). Thus, Equation (1) becomes, with CDD replacing HDD and using $16 \%$,

$$
P A E C=\frac{1}{\frac{.84 \times C D D_{U S}}{.16 \times C D D_{\text {state }}}+1}
$$


where PAEC is the percent of annual electricity used for cooling. The calculated range for PAEC in the lower 48 states was $2.8 \%$ for Washington to $34 \%$ for Florida.

PMEC is calculated the same as PMEH in Equation (2), with the substitution of CDD for HDD and PAEC for PAEH. Calculated values for PAEC and PMEC are shown in the Appendix. Electric bills input as dollars are converted to kWh using Table 4, and carbon intensity of electricity is mined from eGRID (EPA, 2009a).

Estimating the percent savings in cooling energy for thermostat adjustments follows the same method as for heating energy. The reference temperature was set at $75^{\circ} \mathrm{F}$. The percent savings per thermostat degree change was estimated as the change in CDD per degree change in reference temperature, as a portion of the total monthly CDD. Again, reasonable bounds were set at $0.5 \%$ to $10 \%$ per ${ }^{\circ} \mathrm{F}$. Estimated savings per degree of adjustment are shown in the Appendix.

The monthly carbon savings estimate per degree-day of adjustment is then the combination of estimated cooling electricity consumption, carbon intensity of the electricity, and estimated percent savings per degree-day. The final step is for the sponsor to input the number of degrees and number of days for the pledge, resulting in a total carbon pledge estimate. This methodology maintains the high uncertainty of the heating energy method, with similar assumptions regarding electricity consumption and temperature effects.

\section{Line dry clothes instead of using dryer}

This pledge action follows a straightforward calculation. The EPA (n.d.) provides a carbon savings estimate, but it is on the annual scale. DEFRA (2008b), however, provides an estimate for dryers in the UK of $2.5 \mathrm{kWh} / \mathrm{load}$. The only other input required 
is the sponsor's state to find the carbon intensity of electricity from eGRID (EPA, 2009a). The pledge is then made by combining the electricity per load, the carbon intensity of electricity, and the number of pledged dryer loads in the 3-month time window.

\section{Wash clothes in cold water instead of hot}

This pledge is estimated from aggregate appliance values. EPA (n.d.) estimates electricity savings of $1.04 \mathrm{kWh} / \mathrm{load}$ when washing in cold water instead of hot, based numbers from a product database. DEFRA (2008b) estimates the savings of using cold water at $1.35 \mathrm{kWh} / \mathrm{load}$, based on samples in the UK of a variety of washing machine qualities. This tool uses a simple average of these two estimates, $1.2 \mathrm{kWh} / \mathrm{load}$. The next input is the sponsor's state to find the carbon intensity of electricity from eGRID (EPA, 2009a). The pledge is then made by combining the electricity savings per load, the carbon intensity of electricity, and the number of pledged washing machine loads in cold water within the 3-month time window.

\subsubsection{Food pledge calculations}

\section{Red meat reduction}

As described above, the major carbon intensities in food are cow-related (red meat and dairy). For red meat reductions the carbon savings estimate is bases on calorie substitution with different food groups and their relative carbon intensities from Weber \& Matthews (2008). The default assumption is a substitution with chicken, fish, eggs, fruits, or vegetables, which have close red meat relative carbon intensities around 2.7 on a calorie basis (red meat is about 2.7 times more carbon intense, per calorie). Other suggested substitutions are cereals/grains and dairy, with red meat relative carbon 
intensities of 8.3 and 2.0, respectively. The absolute carbon intensities of these food groups are shown in Figure 3.

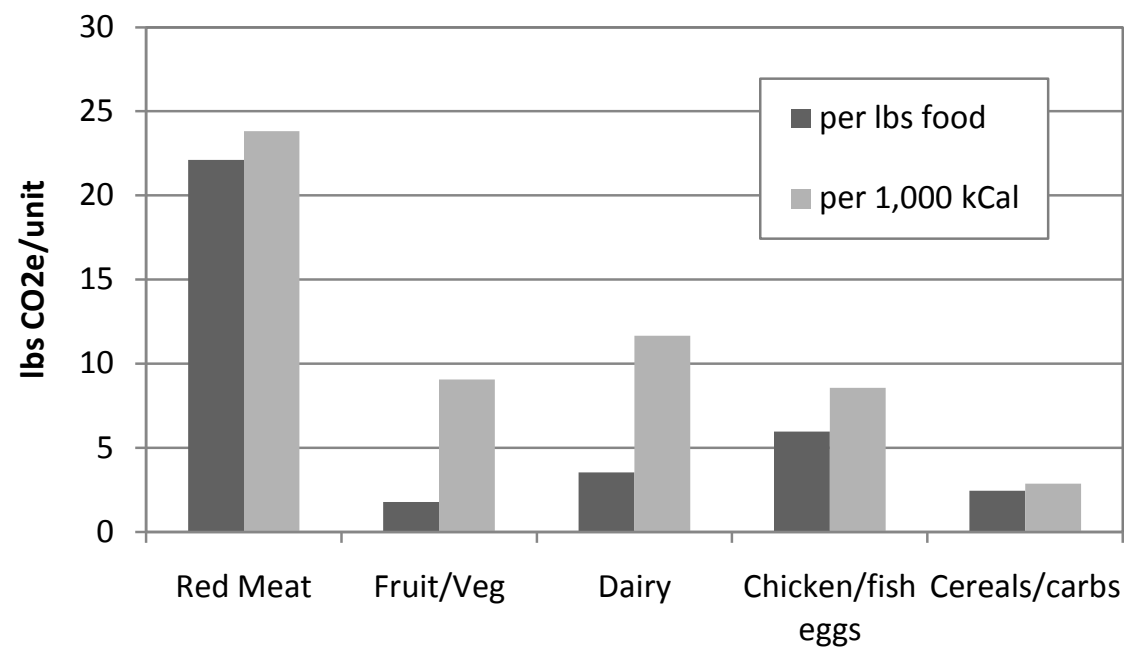

Figure 3: Carbon intensity of food groups by weight and calorie (Weber \& Matthews, 2008)

The red meat relative carbon intensity is then combined with the carbon intensity of red meat, $22.1 \mathrm{lbs} \mathrm{CO}_{2} \mathrm{e} / \mathrm{lbs}$ meat (Weber \& Matthews, 2008), and the inputted red meat serving size, which defaults to $4 \mathrm{oz}(0.25 \mathrm{lbs})$. The final step is to pledge the number of meals to move away from red meat and calculate the total carbon savings.

\section{Substitute soymilk for cow milk}

Milk substitution is more challenging to estimate. Looking at energy inputs only, on a calorie basis soybeans are about 20 times more efficient than milk (Pimentel \& Pimentel, 1996). However, this neglects the factory processes of making soymilk, which can be energy-intensive, and the non-energy GHG emissions of dairy, which are also large. A different approach uses protein as a reference for measure. On a protein basis, both kinds of milk are about $3.5 \%$ protein and soybeans are about $35 \%$ protein (Dalgaard et al., 2008). LCA of soybeans estimates $0.642 \mathrm{lbs}$ CO2e/lbs beans (Dalgaard et al., 2008), so soybeans have a per-protein carbon intensity of $1.83 \mathrm{lbs} \mathrm{CO} 2 \mathrm{e} / \mathrm{lbs}$ protein. 
Further energy enters the equation during the creation of soymilk from soybeans. Hakansson, Gavrilita, \& Bengoa (2005) found that for tofu production, electricity inputs at the manufacture stage constituted $47.6 \%$ of the total energy impact. Soymilk is an intermediate product of tofu production. As an upper-bound approximation, this method assumes the processing carbon for soymilk is $47.6 \%$ of the total carbon intensity, and the remainder is from soybean production. Depending on the method of production, approximately $78 \%$ of the protein in soybeans emerges in soymilk (Lusas, Erickson, \& Nip, 1989). Combining the carbon intensity of soybeans, the loss of protein during manufacture, and the manufacturing share of carbon output, the total estimate for carbon intensity of soymilk on a protein basis is $4.49 \mathrm{lbs} \mathrm{CO} 2 \mathrm{e} / \mathrm{lbs}$ soymilk.

Estimated total GHG emissions for cow milk are $1.09 \mathrm{lbs} \mathrm{CO2e/lbs} \mathrm{milk}$ (Phetteplace et al., 2001). For 3.5\% protein in milk, the carbon intensity of milk on a protein basis is $31.1 \mathrm{lbs} \mathrm{CO} 2 \mathrm{e} / \mathrm{lbs}$ protein. Thus, the relative carbon intensity for cow milk is 6.94 times that of soymilk. Using $1.09 \mathrm{lbs}$ CO2e/lbs cow milk, the LCA carbon emissions from a gallon of cow milk and a gallon of soymilk are then 9.4 lbs CO2e and $1.4 \mathrm{lbs} \mathrm{CO} 2 \mathrm{e}$, respectively. The estimated carbon savings is $8.0 \mathrm{lbs} \mathrm{CO} 2 \mathrm{e}$ per gallon of cow milk switched to soymilk. The only step in the pledge process is to confirm this savings estimate and pledge the number of gallons to switch in a 3-month time window.

\subsection{Website Implementation}

The online implementation of the proposed carbon sponsoring tool is housed at www.CarbonSponsor.org. The requirements of participant interaction and data storage and retrieval led to a dynamic website design. The intent of the website is to serve as a demonstration of carbon sponsoring and a first implementation of an actual tool. 
Limitations in time, money, and programming/web development skills put modest constraints on the site design. Emphasis was placed on introducing participants to the idea of carbon sponsoring and allowing exploration of possible uses. As a demonstration project, a main goal is to garner interest and support for more ambitious implementations. The domain name "CarbonSponsor.org" was selected and purchased as a clear identifier of the new concept. The ".org" extension reinforces the non-profit and nonmonetary nature of the tool. There was some confusion about the domain name, and a valid next step would be purchase and redirection from the domain misspelling "CarbonSponser.org" and the alternative domains "CarbonSponsoring.org" and "CarbonSponsor.com".

The scripting for the website uses PHP, a popular open source server language. Website programming uses the open source Apache server environment. Data storage and retrieval requires a database backend for user, trip, pledge, and feedback information. Another open source tool, MySQL, provides the database functionality.

Database table construction coincides with website areas that collect information. The database holds 11 tables in all, illustrated in Figure 4. Six of the tables are static, used for carbon calculations of home energy and transport emissions; the other five tables store user inputs and calculated emissions (users, trips, legs, pledges, and feedback). Details of the database structure, including all fields (with data formats and descriptions), are in the Appendix. 


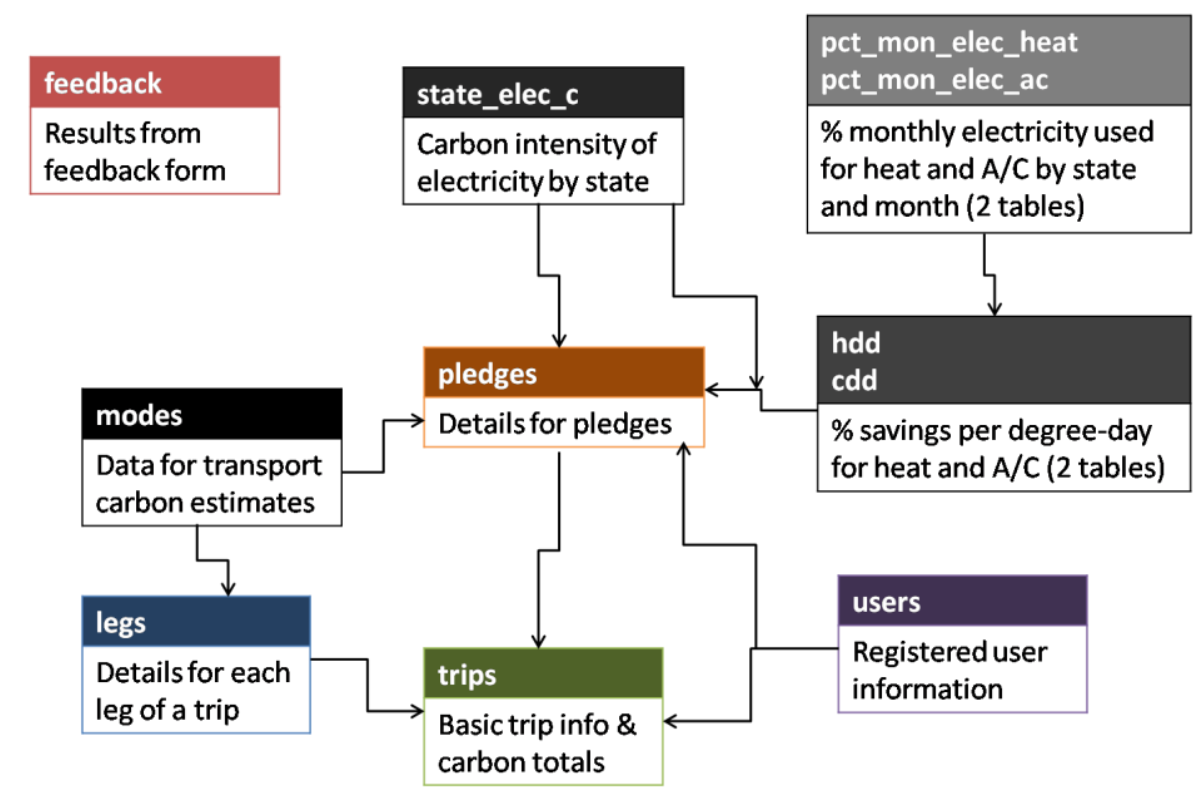

Figure 4: Overview of database tables; grey tables are static and colored tables are dynamic

A simple logo created for the site provides identity for web browser bookmarks, fliers, and other promotional materials. The logo, shown in Figure 5, juxtaposes a bicycle and an airplane, representing two extreme modes on the transportation carbon intensity spectrum. This logo appears in the title bar of all pages on the website, along with the site name, login information, and a navigation bar to the site's six main areas: Home, Create/Edit a Trip, Solicit pledges, Sponsor a Trip, About, and Feedback. Figure 5 shows a screenshot of the title bar.

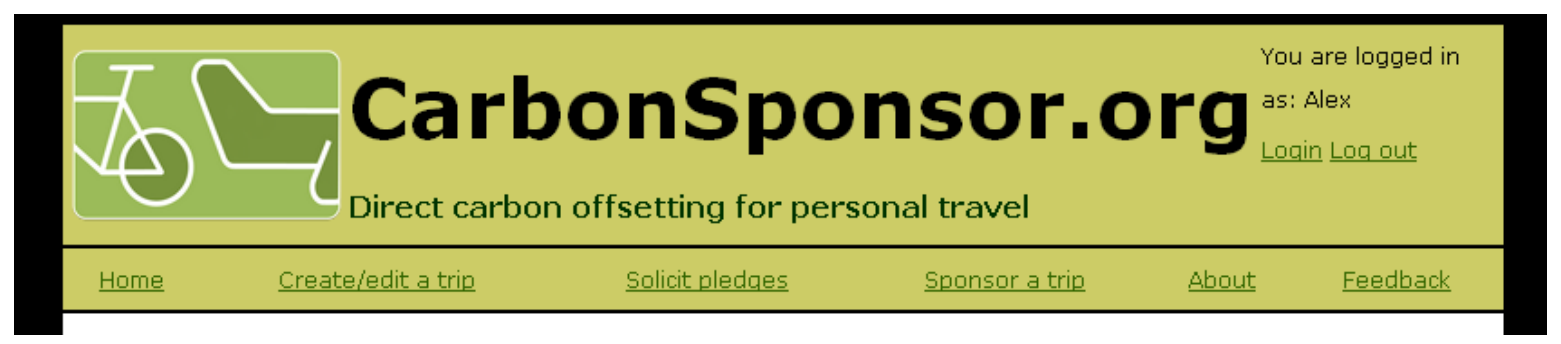

Figure 5: Title bar for website

Much of the site requires logging on with a personal username (obtained after a simple registration requiring only a username and password, with optional input of zip 
code and email address). Requiring a login has negative effects because of the burden on participants and resistance to sharing personal information. Balancing this, people are increasingly accustomed to having personal accounts on internet sites, and logging on protects individuals' pledges and trips from online mischief. The final consideration was the likelihood of increased accountability for sponsors by linking pledges to a certain user account.

Figure 6 shows the basic layout of the website, with main connections through solid arrows and secondary links through dashed arrows. User login is required to perform any actions under "Trips" or "Sponsor a Trip" sections. "About" and "Feedback" are accessible without logging in.

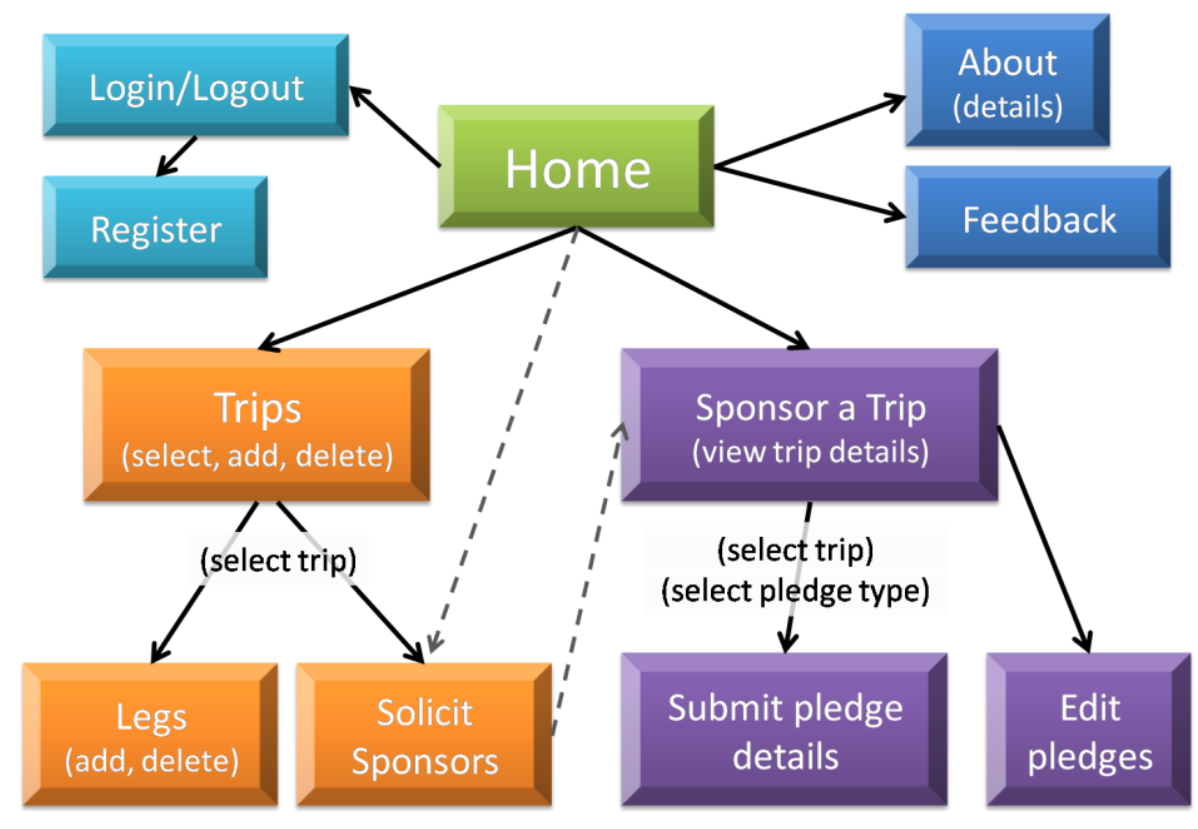

Figure 6: Schematic layout of website pages

Detailed description of the methodology and other aspects are provided in the "About" page. The home page presents the basic instructions for carbon sponsoring and a solicitation for feedback with the following text: 


\section{What is carbon sponsoring?}

Carbon sponsoring is a new way to offset the climate changing impact of your personal travel. Purchasing carbon offsets has become common, but it has many problems. Carbon sponsoring works on a volunteer basis with no exchange of money. Travelers minimize the carbon impact of their travel, then solicit sponsors from friends and acquaintances who are willing to pledge to undertake new carbon-saving activities on their behalf.

\section{How does it work?}

1. First minimize the carbon output of your travel by choosing low carbon intensity modes, minimizing distances, or eliminating trips altogether. Enter the details of your trip for an estimate of the climate footprint: Trip

2. Then pledge some actions in your life that will result in immediate, real reductions in your total carbon output to offset the extra carbon from your trip. Pledge

3. Finally, solicit friends to do the same. Try to persuade friends, family, and acquaintances to take immediate carbon reduction actions in their lives by making carbon pledges. Your goal is to find total carbon savings equal to the carbon generated from your trip. Solicit

Details on carbon sponsoring and the calculation methodologies can be found here: Details You can try out some carbon pledges on this Sample Trip (Trip ID 23)

\section{We need your feedback!}

This is a new tool and we need your help to improve it. After exploring the site and learning about carbon sponsoring and pledge options, please take a few minutes to complete the short (16 question) feedback form here: Feedback!

An introductory email to students, colleagues, and acquaintances initiated the full launch of the website. The solicitation asked recipients to try out the site, leave feedback, and forward the request on to others. Paper fliers with a solicitation to try the website and leave feedback were also distributed around the Portland State University campus and at various events and locations in the city of Portland.

This approach to recruiting participants arose from time and money constraints. This technique clearly would not achieve a representative sample of a broad population. Many potential participants would be young, living in Portland, study engineering, and/or acquainted with the researcher. As found by Semenza et al. (2008), some of these 
characteristics significantly increase the likelihood that individuals will be concerned and act on climate change. These likely biases should be born in mind when inspecting participant feedback.

The full launch of the website transpired with minimal errors and bugs. The website scripts required a few corrections regarding variable scope and numeric truncation, but no major changes occurred to the website during the study period. The website opened for use and feedback on May 11, 2009, and the study period lasted 21 days, to the end of the month. 


\section{EVALUATION OF TOOL}

Evaluation of carbon sponsoring and the demonstration website is based on the project objectives and principles. Of primary interest is the efficacy of the tool in educating users about carbon trading, carbon footprints, and carbon reduction actions. Participants input feedback through a page on the website, linked from several other key pages. The website and promotional materials encourage participant feedback.

\subsection{Website Traffic}

The test period covered the last 21 days of May 2009 (three full weeks). Table 5 summarizes the visitation statistics. With 222 unique visitors, the number of participants was in line with expectations. 58\% of all visits were in the first two days of release, in response to the initial mass emailing.

Table 5: Summary of website visitation data

\begin{tabular}{|l|l|}
\hline 21 & days of data \\
297 & total visits (without bots) \\
222 & unique visitors (without bots) \\
172 & visits in first 2 days of full release \\
1.33 & visits per unique visitor \\
14.1 & visits per day \\
9.02 & average minutes per visit \\
$97 \%$ & visits from US \\
\hline 50 & registered users \\
57 & active trips at end of study period \\
65 & trip legs at end of study period \\
29 & pledges at end of study period \\
29 & feedback forms submitted \\
\hline
\end{tabular}

Most visits were short duration, as is common on the internet (see Figure 7). Only $29.3 \%$ of visits (87) lasted more than 5 minutes, which can be assumed the minimum time necessary to learn the tool. Average visit duration was 9 minutes, but a few very 
long visits can over-influence the average. Most visitors only came once, with an average of 1.33 visits per unique visitor.

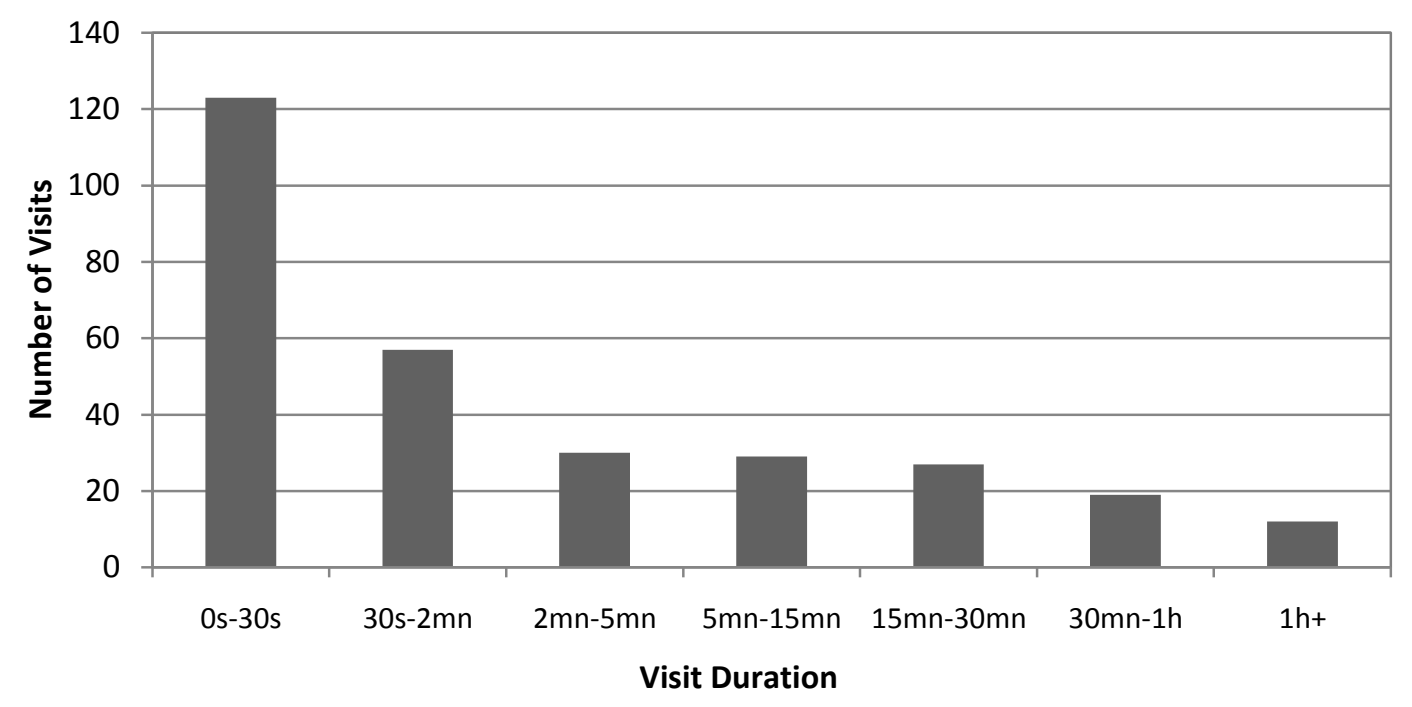

Figure 7: Duration of trip visits during study period

Fifty people total registered at the website, only $22.5 \%$ of visitors. This reflects the resistance to a login requirement, and could be reconsidered in future implementations. Registered users created 88 total trips, with 57 still active at the end of the study period (1.14 per user). These 57 trips were composed of 65 individual trip legs. At just 1.14 legs/trip, there are likely many test trips because most real trips consist of at least two legs. As further evidence, many trip titles contained the word "test." This result is expected, as participants were encouraged to create trial trips if they had no planned trips with which to try out the tool.

Figure 8 shows the distribution of modes for each trip leg created, reflecting the dominance of the car and air modes for trips. No users created trip legs under the motorcycle, taxi, or 'other' modes. Figure 9 compares the carbon estimate and distance for each trip leg created. As expected these two values have a strong positive relationship, where the spread reflects the effect of individual trip characteristics. 


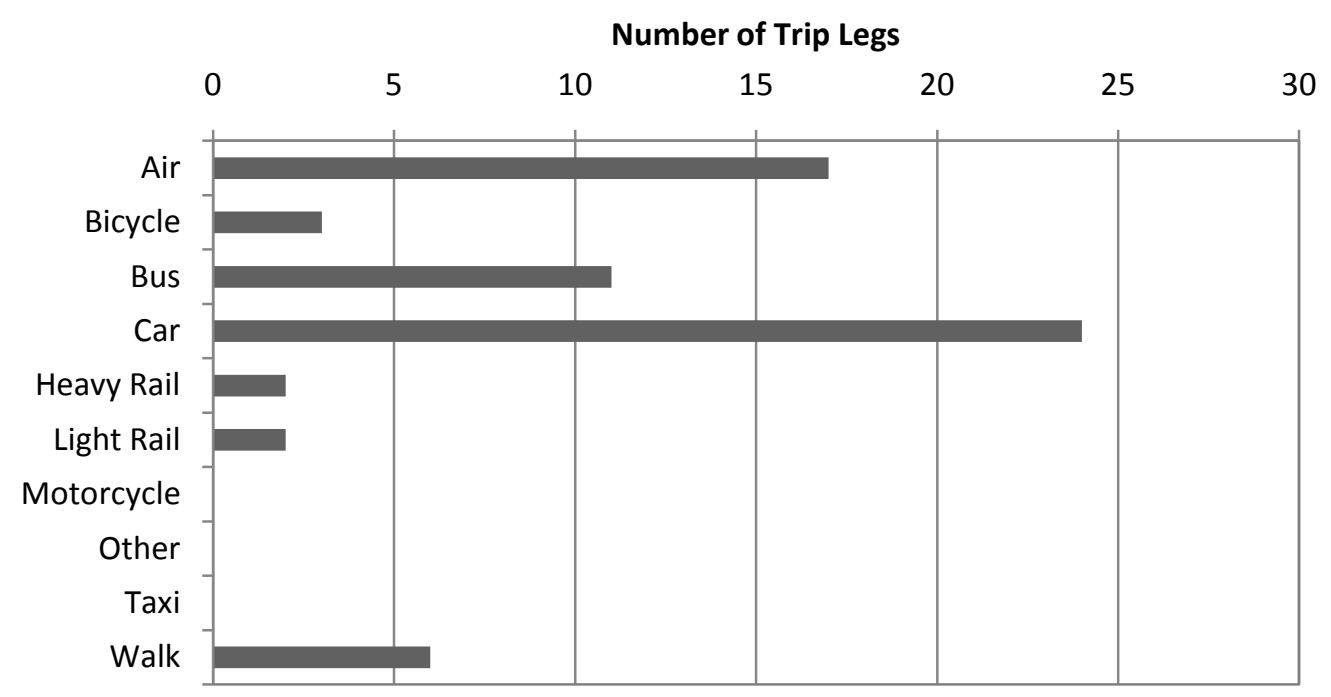

Figure 8: Number of trip legs for each mode

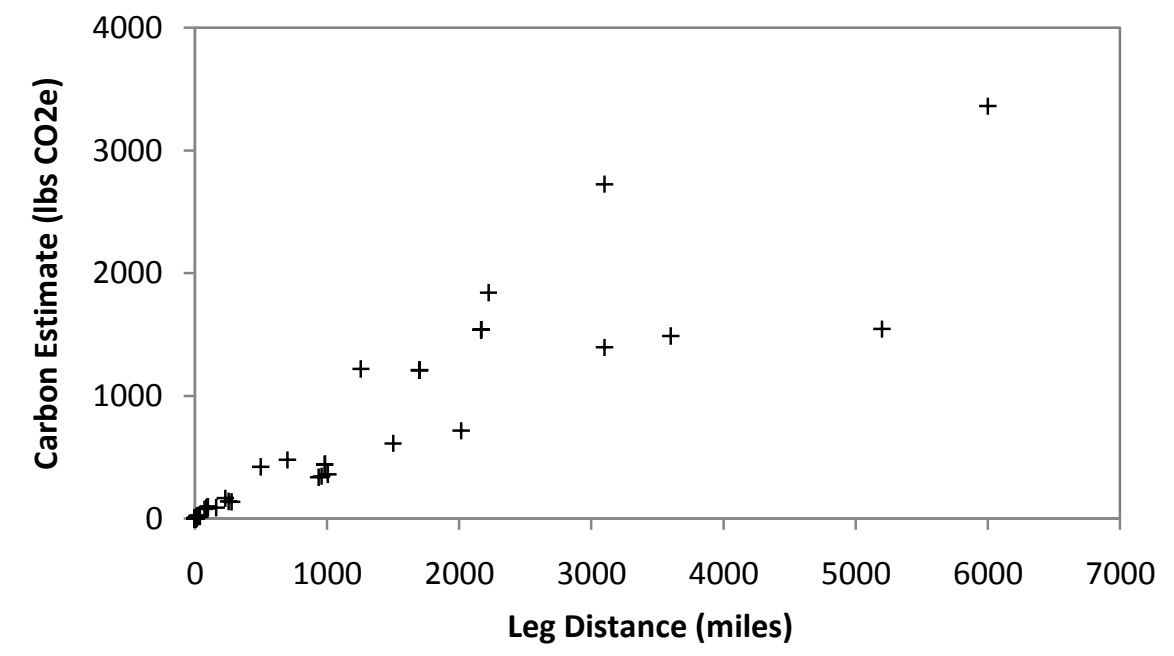

Figure 9: Carbon estimate vs. distance for each trip leg created

At the end of the study period, 29 pledges were active (0.51 per trip and 0.58 per user). Carbon savings per pledge were roughly evenly distributed from 0 to $50 \mathrm{lbs} \mathrm{CO}$ e. Figure 10 shows the pledges by pledge type, where laundry was the most popular category. About half each of the laundry pledges were for line drying and washing in cold 
water. Food pledges were popular as well, but the other categories were lightly used. Heat was not used at all because of the season.

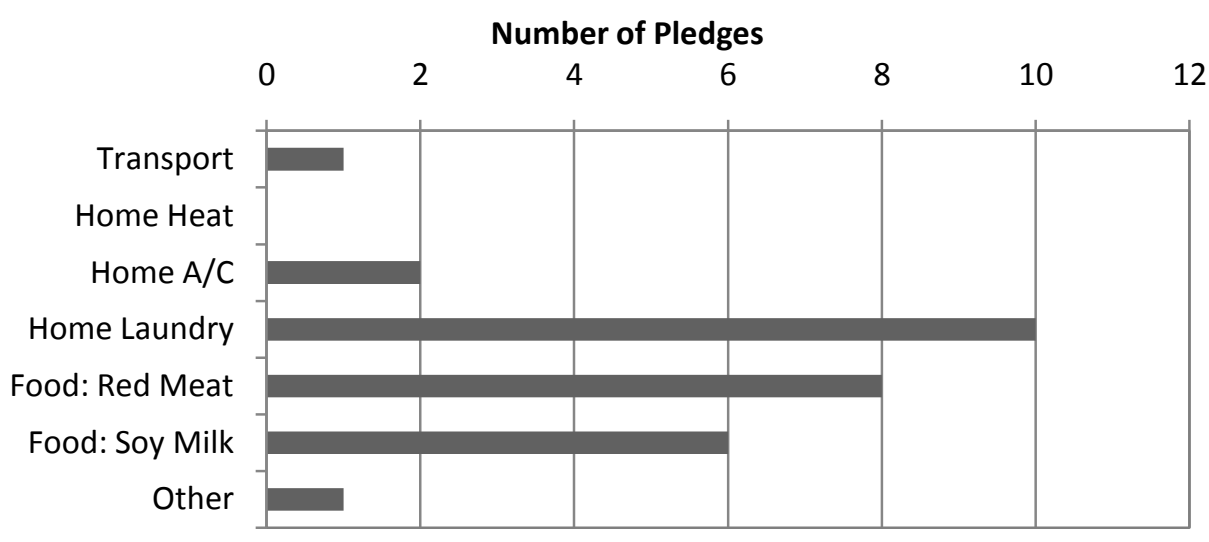

Figure 10: Pledges by pledge category

\subsection{Feedback Form}

Participants input feedback through a one page online form, reproduced in its entirety in the Appendix. A few other comments, suggestions, and questions also came directly to the researcher through verbal or email communications (the website provides an email address). As much as possible, design of the feedback form followed the principles of the tailored design method presented by Dillman (1999). This approach seeks accurate survey results by increasing trust and rewards for respondents while minimizing their costs. Dillman also suggests some details for internet surveys such as layout and question structures that improve response rate and quality.

While the feedback form was designed to perform well within the constraints of the demonstration project, large errors in sampling and coverage are built in to the study. A well-designed feedback from can still minimize measurement errors, and to a lesser extent decrease non-response rates. As with any sustainability-centered survey, there will 
also be additional biases because it is a socially and morally charged issue, leading to exaggeration of the likelihood of behavior change (Bonsall, 2009).

The first set of questions in the feedback form addresses the pledge activities presented on the website. For the three pledge categories of transport, home energy, and food, respondents are asked three questions per category, with an open field for comments in each category. The first question addresses the change in awareness about the carbon footprint of the activity. The second question addresses the likelihood of behavior change in that area. The third question asks about the validity of behavior change in that area to address climate change. For the transport category, these three questions are phrased:

1. Which best describes your awareness of the climate footprint of personal travel?

2. Which best describes the likelihood you will take steps to reduce the footprint of your travel?

3. Which best describes the validity of changing your travel behaviors to reduce your footprint?

The next two questions ask about the respondent's likelihood to use the tool again and recommend it to a friend. Then come three questions about awareness of carbon trading and willingness/preference to pay for carbon offsets. The final two questions ask respondents to rate carbon sponsoring and the website. The form finishes with two open comment fields for the website and 'other.' Other than the comment fields, these are all closed-response questions. This second set of questions is phrased:

1. How likely or unlikely are you to use CarbonSponsor.org in the future?

2. How likely or unlikely are you to recommend CarbonSponsor.org to a friend? 
3. After visiting CarbonSponsor.org, which best describes your awareness of carbon trading?

4. Given the choice, would you prefer to offset the climate footprint of your travel through: [Carbon sponsoring; Purchasing carbon offsets; Neither]

5. When purchasing carbon offsets, about how much would you be willing to pay per pound of $\mathrm{CO} 2$ ?

6. How would you rate the idea of carbon sponsoring?

7. How would you rate this tool in particular (CarbonSponsor.org)?

\subsection{Survey Results}

In total users submitted 29 feedback forms. This represents $58 \%$ of registered users, though individuals did not have to be registered users to leave feedback.

\subsubsection{Pledge activities}

Figure 11 shows responses for the questions about awareness of carbon impacts. Most users reported an introduction or increase in awareness. Figure 12 shows feedback on willingness to change, with at least $77 \%$ in all categories stating willingness for behavior change. Figure 13 shows responses for the validity of the action in mitigating climate change. Users perceived the validity as high in all three categories, though the least for food actions. 
Which best describes your awareness of the climate footprint of this activity?

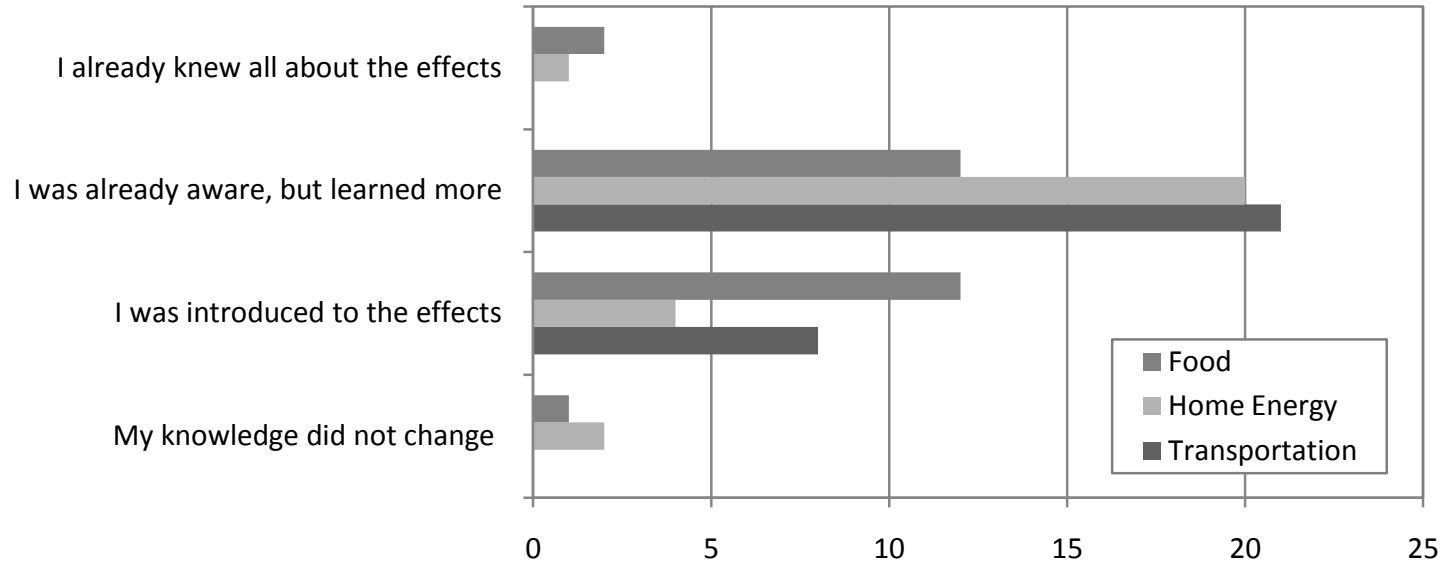

Figure 11: Awareness of carbon footprint feedback

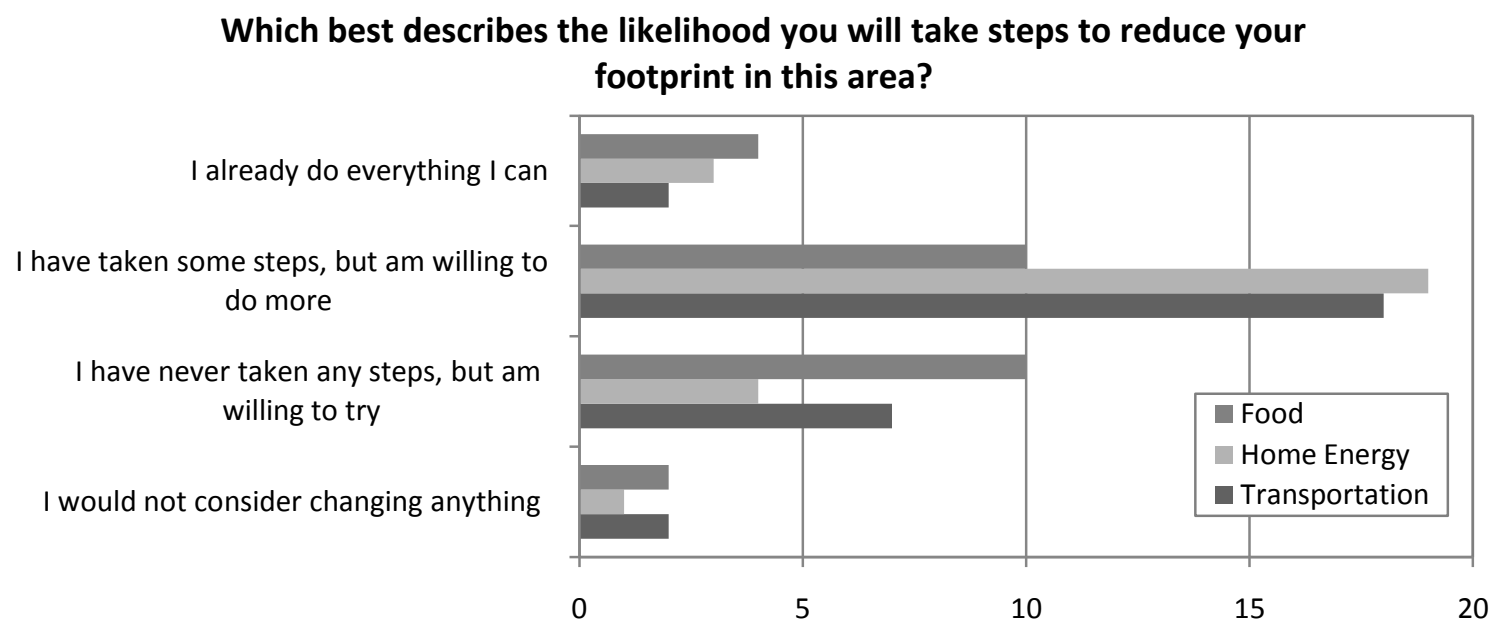

Figure 12: Likelihood of behavior change feedback

In the comments section, all three categories received at least one request for more data or a statement that the user was unconvinced of the impacts. Respondents also stated that they were already maximally engaged in the carbon-reducing activity. One respondent included estimates for carbon savings by switching to a certain brand of "ecofriendly" beer, claiming that New Belgium's Fat Tire has emissions of $3.2 \mathrm{kgCO} 2 \mathrm{e}$ versus an industry average of $7.2 \mathrm{kgCO} 2 \mathrm{e}$ for a 6-pack of bottled beer. A final comment of 
import in this section was an expression of confusion as to the differences between the "Trip" and "Pledge" sections of the website - a clear lack of understanding of carbon sponsoring and the demonstration tool.

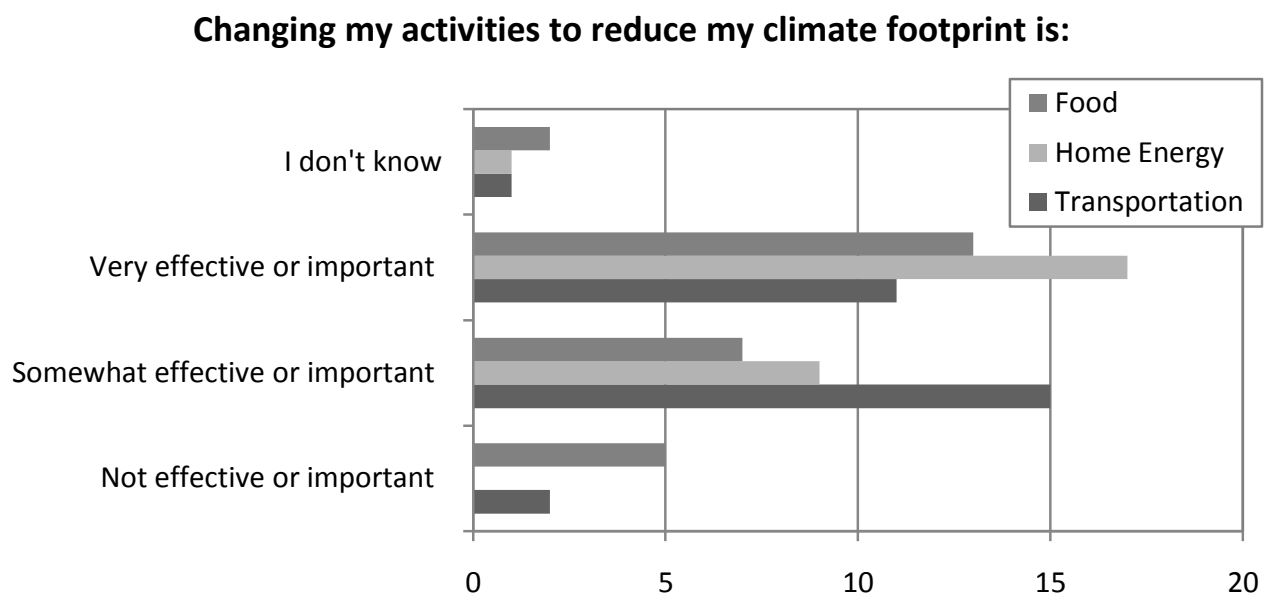

Figure 13: Feedback on validity of action for climate change

\subsubsection{Website}

Figure 14 shows responses about the likelihood of using the tool again or recommending it to others. A total of $65.5 \%$ would use the site again and $83 \%$ would recommend it to others (likely or definitely). Comments about the website were a mix of compliments, criticisms, and suggestions. Most suggestions related to website design. Several users suggested links or embedding of online mapping programs to get distances for trip calculations. Users also suggested better graphical navigation on the site for where visitors are and where they are going next. A related suggestion recommended graphical explanation of the carbon sponsoring process, which could coincide with site navigation images. Other suggestions were more links to related websites (offsets, climate change, etc.) and a discussion forum to share carbon-savings ideas. The three main criticisms of the site were that it was confusing to use (the most common with five 
respondents mentioning in some way), navigation was challenging, and visitors did not want to have to register to participate.

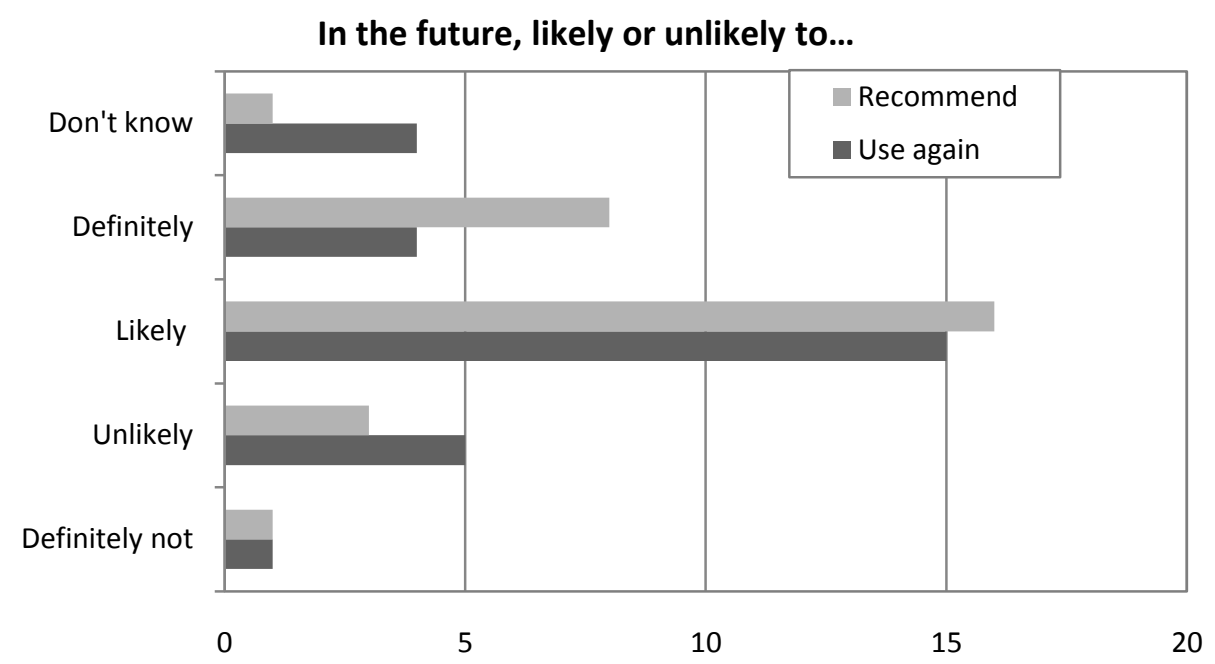

Figure 14: Feedback on the likelihood to use again or recommend

\subsubsection{Carbon sponsoring}

As shown in Figure 15, 86.2\% of respondents reported being introduced or learning more about carbon trading, an important metric for the objectives of the project.

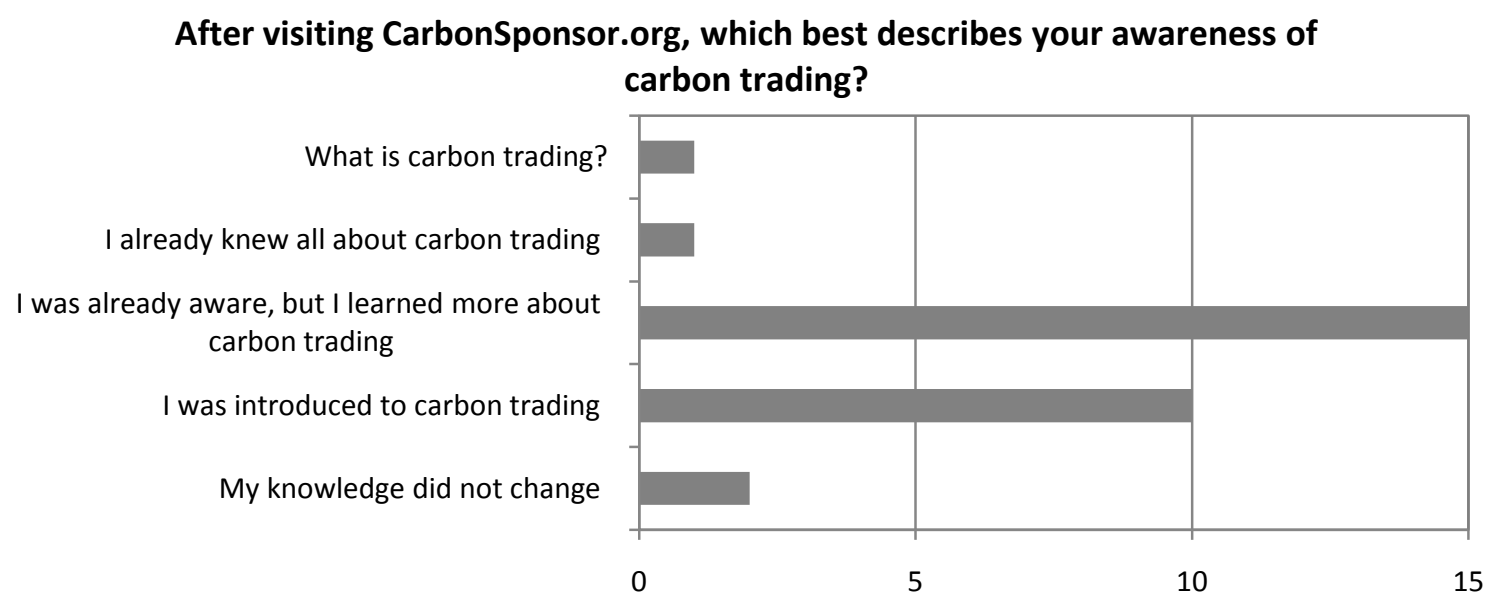

Figure 15: Feedback on users' awareness of carbon trading

Figure 16 shows a strong preference for carbon sponsoring over carbon offsetting after using the site. Given the option, $75 \%$ would sponsor, $18 \%$ would do neither, and $7 \%$ 
would choose to purchase offsets. Only nine respondents offered any kind of price estimate for a value of carbon, with an average of $\$ 0.70$ and a range of $\$ 0.001-\$ 2.00$ per lb CO2e (compared to a typical price on the carbon markets of about $\$ 0.01$ ). Figure 17 shows a positive opinion of the website and the trading tool with $93 \%$ of respondents rating each one favorably.

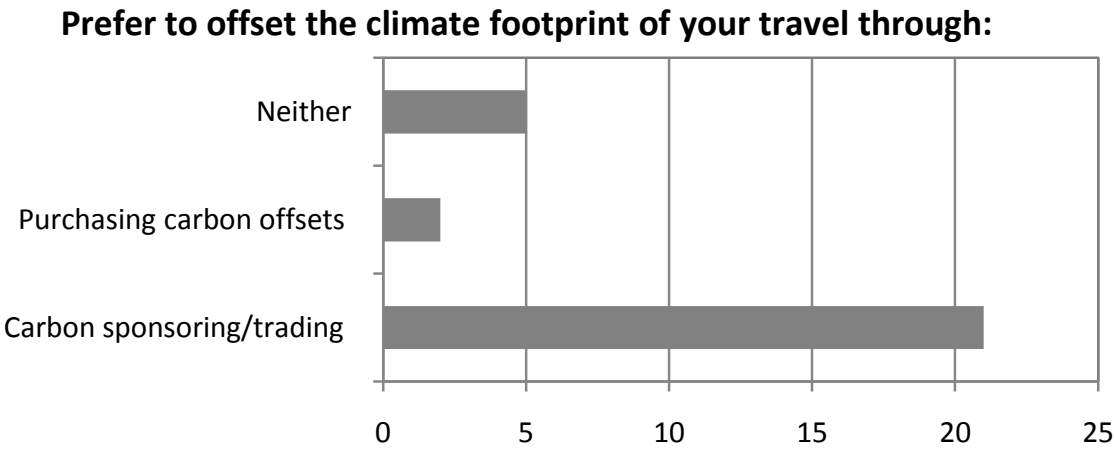

Figure 16: Feedback on preference to sponsor or offset carbon footprint

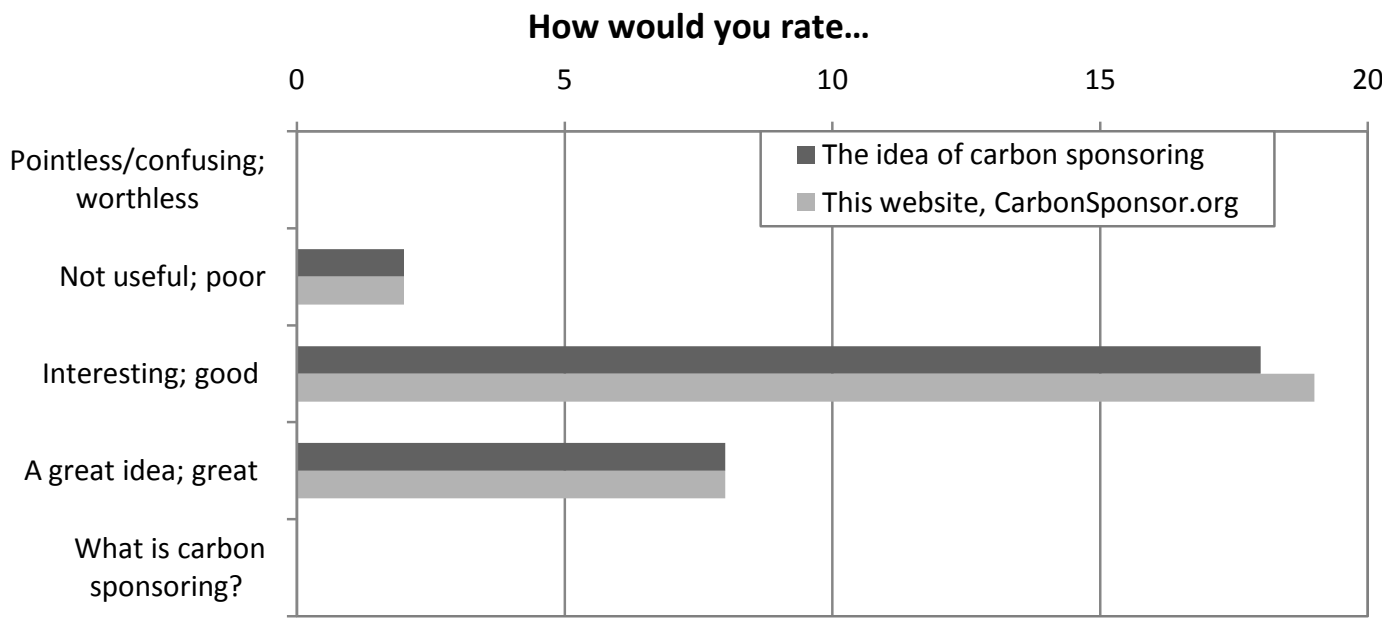

Figure 17: Feedback on rating of carbon sponsoring and the website

Only a few general comments related to the idea of carbon sponsoring, as most concentrated on the design of the website. One respondent found the concept still "somewhat confusing" after using the site. Some other comments expressed futility of 
efforts at climate change mitigation, personal unwillingness to change for climate reasons, and frustration with those unwilling to change for climate reasons. An oftenexpressed positive comment was the website "got me thinking," which coincides with the core drive of the tool.

\subsubsection{Feedback summary}

The study period only acquired feedback from a small sample of users (29). Despite the small number of respondents, the nature of the feedback produces a general picture of participants' reactions. Expressed interest in carbon sponsoring and likelihood of use were high, though some participants did not well understand the tool. Feedback results suggest the tool successfully meets the project objectives to:

1. Increase awareness of personal carbon footprint

2. Increase awareness of personal carbon reduction strategies

3. Facilitate personal carbon reductions

4. Familiarize public with carbon trading

Evaluation of feedback, however, should include consideration that the demonstration participants were skewed toward young Portlanders, studying engineering or transportation, and acquainted with the researcher. Feedback from a cross-section of Americans would likely show less interest in climate change and mitigation efforts, less interest in behavior change, and lower overall rating of the trading scheme and the online tool. Most Americans, though, would have less prior awareness of carbon trading and personal activity footprints, meaning more potential for education. 


\section{NEXT STEPS}

Feedback suggests the website needs improvement to communicate better the process of carbon sponsoring. The online tool must serve to both explain carbon sponsoring and facilitate sponsorship. Specific areas for improvement are to create graphical explanation and navigation tools, integrate mapping functionality, and clarify the trip versus pledge distinction. Web design skills can also improve the user experience by improving visual and functional layout of the website. To these ends, grant money could fund website upgrade by skilled practitioners. Another strategy is to solicit the participation of graphic design/computer science students interested in a project.

Carbon calculation can also be improved and expanded. Different estimation techniques can easily be incorporated as they are found. This will be more possible as research improves in the area of micro-footprints and marginal emissions estimates. The inventory of pledge options should also expand with user interest. Specific suggestions were received for beer, pork, computer monitor, appliance standby, and dishwasher pledges.

Another opportunity for improvement is through integration with other online tools. Social networking sites in particular could provide a channel for sponsorship connections. Automation with email platforms could also improve the pledge solicitation experience. An application for portable electronic devices could provide a visual measure of the level of sponsorship and a medium for solicitations.

Two popular aspects of the website were the ability to compute and compare carbon estimates in different areas and to create total carbon estimates for individual trips. Another possible application is a carbon calculator outside of the sponsorship 
program that provides for easy comparison of carbon footprints from different types of trips and different types of activities. Another large future step is a new tool that facilitates carbon sponsoring for activities other than trips, such as the purchase of large consumer goods or an event.

Along with improvements to the website, promotion of carbon sponsoring can increase participation and expand the data set. A major potential promotional tool is through online travel websites, some of which currently provide links to retail carbon offset sites. The data collected through the online tool can be a rich source of information on voluntary mitigation efforts. As participation increases, these data can be used to study personal behavior changes and willingness to act. 


\section{CONCLUSIONS}

This thesis presents the idea of carbon sponsoring, a new tool for personal carbon trading. Unlike carbon offsets, the main current option for individuals wishing to mitigate their carbon footprint, carbon sponsoring is a purely social instrument involving carbonreducing pledges. Carbon sponsoring is intended for individuals who seek immediate, direct carbon offsets for their personal emissions. It is not meant to be a broad tool correcting the various deficiencies of the carbon trading markets, but a specialized mechanism with a small role in the struggle against climate change.

As a demonstration project, this paper describes an online implementation for carbon sponsoring of personal travel, crafted with the following objectives:

1. Increase awareness of size of carbon footprint from personal travel and other activities

2. Increase awareness of personal carbon reduction strategies

3. Facilitate personal carbon reductions unavailable to carbon offset programs

4. Familiarize users with carbon trading concepts

A three-week initial study period showed good results, with participants reporting increased awareness of person carbon footprints, carbon reduction strategies, and carbon trading. While the overall results are positive, the website created for this study has some deficiencies related to the visual design and ease of navigation. These shortcomings, however, are not central to the idea of carbon sponsoring, and skilled web designers can easily rectify them as a next step. The most relevant criticism of the demonstration project is that the website does not sufficiently explain the concept and process of carbon 
sponsoring for some participants. Another next step is promotion of the online tool and carbon sponsoring as an option for individuals seeking personal action on climate change. Carbon sponsoring sustains some of the problems of carbon offsetting, including insufficient quality control and lack of third-party verification of carbon reductions. However, carbon sponsoring also offers new benefits and improvements, such as in the areas of equity, user costs and co-benefits, and carbon time accounting. Carbon sponsoring also accesses personal emissions reductions in a way that indirect, upstream methods cannot. This benefit, especially, secures carbon sponsoring a convincing role in mitigation efforts to address climate change. Carbon sponsoring might only lead to a small volume of carbon reductions with respect to the entirety of anthropogenic emissions, but it can provide important assistance in efforts to promote public awareness of carbon footprints, carbon reduction strategies, carbon budgeting, and carbon trading. 


\section{REFERENCES}

Bomberg, M., Kockelman, K., \& Thompson, M. (2009). Greenhouse Gas Emission Control Options: Assessing Transportation and Electricity Generation Technologies and Policies to Stabilize Climate Change. Presented at the $88^{\text {th }}$ Annual Meeting of the Transportation Research Board. Washington, DC.

Bonsall, P. (2009).Particular Problems to be Overcome when Seeking Data on Sustainable Travel Behaviour. Presented at the $88^{\text {th }}$ Annual Meeting of the Transportation Research Board. Washington, DC.

Bristow, A. \& Zanni, M. (2009). Designing and Implementing a Test of Behavioural Response to Personal Carbon Trading and Carbon Taxes. Presented at the $88^{\text {th }}$ Annual Meeting of the Transportation Research Board. Washington, DC.

British Standards Insitution (2008). Specification for the Assessment of the Life Cycle Greenhouse Gas Emissions of Goods and Services (PAS 2050:2008).

Brouwer, R., Brander, L., \& Van Beukering, P. (2008). "A convenient truth": Air travel passengers' willingness to pay to offset their $\mathrm{CO} 2$ emissions. Climatic Change, 90(3), 299-313.

City of Portland, Multnomah County (2009). Draft Climate Action Plan 2009.

Clean Air-Cool Planet (2006). A Consumers' Guide to Retail Carbon Offset Providers.

Climate Trust (n. d.). Apply for Offset Funding: Project Requirements. Retrieved June 3, 2009, from http://www.climatetrust.org/solicitations_open.php

Dalgaard R., Schmidt J., Halberg N., Christensen P., Thrane M., \& Pengue W. (2008). LCA of Soybean Meal. International Journal of Life Cycle Assessment 13 (3) 240-254.

Department for Environment, Food and Rural Affairs (2008a). 2008 Guidelines to Defra's GHG Conversion Factors: Methodology Paper for Transport Emission Factors.

Department for Environment, Food and Rural Affairs (2008b). Act on CO2 Calculator: Data, Methodology and Assumptions Paper(V1.2).

Dillman, D. (1999). Mail and Internet Surveys: The Tailored Design Method. John Wiley \& Sons, Inc. 
Druckman, A., \& Jackson, T. (2008). Household energy consumption in the UK: A highly geographically and socio-economically disaggregated model. Energy Policy, 36(8), 3177-3192.

Energy Information Administration (2000). Winter Energy Savings from Lower Thermostat Settings. Retrieved from http://www.eia.doe.gov/emeu/consumptionbriefs/recs/thermostat_settings/ thermostat.html

Energy Information Administration (2001). Residential Energy Consumption Survey. Retrieved from http://www.eia.doe.gov/emeu/recs/

Energy Information Administration (2008). Emissions of Greenhouse Gases in the United States 2007 (Publication No. DOE-EIA-0573(2007)).

Environmental Protection Agency, (2005). Municipal Solid Waste in the United States: 2003 Facts and Figures (Publication No. EPA-530-F-05-003).

Environmental Protection Agency, (2006). Solid Waste Management and Greenhouse Gases: A Life-Cycle Assessment of Emissions and Sinks (Publication No. EPA-530-R-06004).

Environmental Protection Agency, (2008a). Climate Leaders Greenhouse Gas Inventory Protocol Core Module Guidance: Direct Emissions from Mobile Combustion Sources (Publication No. EPA-430-K-08-004).

Environmental Protection Agency, (2008b). Light-Duty Automotive Technology and Fuel Economy Trends: 1975 Through 2008 (Publication No. EPA-420-S-08-003).

Environmental Protection Agency, (2009a). The Emissions \& Generation Resource Integrated Database for 2007 (eGRID2007).

Environmental Protection Agency, (2009b). Inventory of U.S. Greenhouse Gas Emissions and Sinks: 1990-2007 (Publication No. EPA-430-R-09-004).

Environmental Protection Agency, (2009c). Mandatory reporting of greenhouse gases; proposed rule (Publication No. EPA-HQ-OAR-2008-0508).

Environmental Protection Agency, (2009d). Proposed Endangerment and Cause or Contribute Findings for Greenhouse Gases Under Section 202(a) of the Clean Air Act (Publication No. EPA-HQ-OAR-2009-0171). 
Environmental Protection Agency, (n.d.). Personal Greenhouse Gas Emissions

Calculator. Retrieved April, 2009 from

http://www.epa.gov/climatechange/emissions/ind_calculator.html

Eshel, G., and Martin, P. (2006). Diet, Energy, and Global Warming. Earth Interactions, 10.

Filippone, A. (2008). Analysis of carbon-dioxide emissions from transport aircraft. Journal of Aircraft, 45(1), 185-197.

Garnett, T. (2009). Livestock-Related Greenhouse Gas Emissions: Impacts and Options for Policy Makers, Environmental Science \& Policy.

Government Accountability Office (2008). Carbon Offsets: The U.S. Voluntary Market Is Growing, but Quality Assurance Poses Challenges for Market Participants (Publication No. GAO-08-1048).

Hakansson, S., Gavrilita, P., Bengoa, X. (2005). Comparative Life Cycle Assessment of Pork vs. Tofu. Life Cycle Assessment 1N1800, Stockholm.

Hamilton, K., Sjardin, M., Marcello, T. \& Xu, G. (2008). Forging a Frontier: State of the Voluntary Carbon Markets 2008. Ecosystem Market place \& New Carbon Finance.

Hepburn, C. (2007). Carbon trading: A review of the kyoto mechanisms. Annual Review of Environment and Resources, 32, 375-393.

Intergovernmental Panel on Climate Change, (2007a). Climate Change 2007: Impacts, Adaptation and Vulnerability. Contribution of Working Group II to the Fourth Assessment Report of the Intergovernmental Panel on Climate Change, M.L. Parry, O.F. Canziani, J.P. Palutikof, P.J. van der Linden and C.E. Hanson, Eds., Cambridge University Press, Cambridge, UK.

Intergovernmental Panel on Climate Change, (2007b). Climate Change 2007: Mitigation. Contribution of Working Group III to the Fourth Assessment Report of the Intergovernmental Panel on Climate Change, B. Metz, O.R. Davidson, P.R. Bosch, R. Dave, L.A. Meyer, Eds., Cambridge University Press, Cambridge, UK and New York, NY, USA.

Intergovernmental Panel on Climate Change (2007c). Climate Change 2007: The Physical Science Basis. Contribution of Working Group I to the Fourth Assessment 
Report of the Intergovernmental Panel on Climate Change, Solomon, S., D. Qin, M. Manning, Z. Chen, M. Marquis, K.B. Averyt, M.Tignor and H.L. Miller, Eds., Cambridge University Press, Cambridge, UK and New York, NY, USA.

Johnson, E. (2009). Goodbye to carbon neutral: Getting biomass footprints right. Environmental Impact Assessment Review, 29(3), 165-168.

Jones, E., \& Niemeier, D. (2009). The Quality of Online Carbon Calculators: So you want to calculate your footprint? Presented at the $88^{\text {th }}$ Annual Meeting of the Transportation Research Board. Washington, DC.

Kenny, T., \& Gray, N. F. (2009). Comparative performance of six carbon footprint models for use in ireland. Environmental Impact Assessment Review, 29(1), 1-6.

Krambeck, H. (2009). The Role of Surface Transport in US Compliance \& Voluntary Greenhouse Gas Emissions Trading Schemes. Presented at the $88^{\text {th }}$ Annual Meeting of the Transportation Research Board. Washington, DC.

Lusas, E., Erickson, D., \& Nip, W. (1989). Food Uses of Whole Oil and Protein Seeds. The American Oil Chemists Society.

McCarl, B. A., \& Sands, R. D. (2007). Competitiveness of terrestrial greenhouse gas offsets: Are they a bridge to the future? Climatic Change, 80(1-2), 109-126.

Millard-Ball, A. (2008). Municipal mobility manager: New transportation funding stream from carbon trading? Transportation Research Record, (2079), 53-61.

National Oceanic and Atmospheric Administration (2009). Historical Climatology Series.

Niemeier, D., Gould, G., Karner, A., Hixson, M., Bachmann, B., Okma, C., et al. (2008). Rethinking downstream regulation: California's opportunity to engage households in reducing greenhouse gases. Energy Policy, 36(9), 3436-3447.

Padgett, J. P., Steinemann, A. C., Clarke, J. H., \& Vandenbergh, M. P. (2008). A comparison of carbon calculators. Environmental Impact Assessment Review, 28(2-3), 106-115.

Passey, R., MacGill, I., \& Outhred, H. (2008). The governance challenge for implementing effective market-based climate policies: A case study of the new south wales greenhouse gas reduction scheme. Energy Policy, 36(8), 3009-3018. 
Phetteplace, H., Johnson, D., \& Seidl, A. (2001). Greenhouse Gas Emissions from Simulated Beef and Dairy Livestock Systems in the United States. Nutrient Cycling in Agroecosystems, 60.

Pimentel, D., \& Pimentel, M. (1996). Food, Energy, and Society (Rev. ed.). Colorado: University Press of Colorado.

Rose, A., Bulte, E., \& Folmer, H. (1999). Long-run implications for developing countries of joint implementation of greenhouse gas mitigation. Environmental and Resource Economics, 14(1), 19-31.

Rousse, O. (2008). Environmental and economic benefits resulting from citizens' participation in $\mathrm{CO} 2$ emissions trading: An efficient alternative solution to the voluntary compensation of CO2 emissions. Energy Policy, 36(1), 388-397.

Semenza, J. C., Hall, D. E., Wilson, D. J., Bontempo, B. D., Sailor, D. J., \& George, L. A. (2008). Public perception of climate change: Voluntary mitigation and barriers to behavior change. American Journal of Preventive Medicine, 35(5), 479-487.

Sivaraman, D., Pacca, S., Mueller, K., \& Lin, J. (2007). Comparative energy, environmental, and economic analysis of traditional and E-commerce DVD rental networks. Journal of Industrial Ecology, 11(3), 77-91.

Smith, K. (2007). The Carbon Neutral Myth: Offset Indulgences for your Climate Sins. Carbon Trade Watch, Transnational Institute.

Sperling, D., \& Gordon, D. (2009). Two Billion Cars: Driving toward Sustainability. Oxford University Press.

Stern N. (2006). Stern Review: The Economics of Climate Change. London: HM Treasury.

TRX Travel Analytics (2008). CO2 Emissions Model for Air Travel Public

Documentation (v1.4). Retrieved from

http://carbon.trx.com/TRX_CO2_Emissions_Documentation_v1.4.pdf

Tukker, A., \& Jansen, B. (2006). Environmental impacts of products: A detailed review of studies. Journal of Industrial Ecology, 10(3), 159-182. 
United Nations Framework Convention on Climate Change (2009, June 1). Kyoto Protocol; Status of Ratification. Retrieved from http://unfccc.int/kyoto_protocol/status_of_ratification/items/2613.php

Venner, M., Rue, H. \& Chavez, M. (2009). Using Visualization Tools to Build Consensus for Sustainability and Greenhouse Gas C02 Emission Reduction. Presented at the $88^{\text {th }}$ Annual Meeting of the Transportation Research Board. Washington, DC.

Weber, C. L., \& Matthews, H. S. (2008). Food-miles and the relative climate impacts of food choices in the united states. Environmental Science and Technology, 42(10), 35083513.

Wise, R., \& Cacho, O. (2005). Tree-crop interactions and their environmental and economic implications in the presence of carbon-sequestration payments. Environmental Modelling \& Software, 20(9), 1139-1148.

World Resources Institute (n.d.). CO2 emissions from transport or mobile sources. Retrieved April, 2009 from http://www.ghgprotocol.org/calculation-tools/all-tools. 


\section{APPENDIX}

A.1: Estimated portion of annual electricity used for heating and cooling

\begin{tabular}{lll}
\hline State & PAEH & PAEC \\
\hline AL & 0.066 & 0.216 \\
AZ & 0.051 & 0.297 \\
AR & 0.080 & 0.206 \\
CA & 0.062 & 0.118 \\
CO & 0.156 & 0.039 \\
CT & 0.131 & 0.077 \\
DE & 0.106 & 0.135 \\
FL & 0.017 & 0.336 \\
GA & 0.067 & 0.201 \\
ID & 0.147 & 0.063 \\
IL & 0.137 & 0.115 \\
IN & 0.128 & 0.117 \\
IA & 0.150 & 0.110 \\
KS & 0.113 & 0.175 \\
KY & 0.103 & 0.148 \\
LA & 0.043 & 0.276 \\
ME & 0.166 & 0.032 \\
MD & 0.108 & 0.132 \\
MA & 0.138 & 0.063 \\
MI & 0.148 & 0.077 \\
MN & 0.179 & 0.067 \\
MS & 0.060 & 0.235 \\
MO & 0.115 & 0.156 \\
MT & 0.172 & 0.035 \\
NE & 0.133 & 0.106 \\
NV & 0.087 & 0.221 \\
\hline & & \\
\hline
\end{tabular}

\begin{tabular}{lll}
\hline State & PAEH & PAEC \\
\hline NH & 0.159 & 0.043 \\
NJ & 0.119 & 0.102 \\
NM & 0.108 & 0.117 \\
NY & 0.132 & 0.084 \\
NC & 0.081 & 0.170 \\
ND & 0.191 & 0.063 \\
OH & 0.130 & 0.098 \\
OK & 0.086 & 0.217 \\
OR & 0.114 & 0.034 \\
PA & 0.128 & 0.089 \\
RI & 0.128 & 0.066 \\
SC & 0.065 & 0.210 \\
SD & 0.164 & 0.097 \\
TN & 0.091 & 0.166 \\
TX & 0.047 & 0.281 \\
UT & 0.142 & 0.090 \\
VT & 0.168 & 0.039 \\
VA & 0.100 & 0.134 \\
WA & 0.121 & 0.028 \\
WV & 0.117 & 0.102 \\
WI & 0.163 & 0.069 \\
WY & 0.171 & 0.042 \\
AK & 0.223 & 0.001 \\
HI & 0.001 & 0.307 \\
PR & 0.000 & 0.401 \\
AK & 0.223 & 0.001 \\
\hline & & \\
\hline
\end{tabular}




\section{A.2: Estimated portion of monthly electricity use for heating (PMEH)}

\begin{tabular}{|c|c|c|c|c|c|c|c|c|c|c|c|c|}
\hline State & Jan & Feb & Mar & Apr & May & Jun & Jul & Aug & Sep & Oct & Nov & Dec \\
\hline $\mathbf{A L}$ & 0.169 & 0.131 & 0.094 & 0.043 & 0.012 & 0.001 & 0.000 & 0.000 & 0.004 & 0.044 & 0.097 & 0.150 \\
\hline $\mathbf{A Z}$ & 0.128 & 0.095 & 0.076 & 0.039 & 0.012 & 0.001 & 0.000 & 0.000 & 0.002 & 0.022 & 0.080 & 0.128 \\
\hline AR & 0.200 & 0.154 & 0.114 & 0.052 & 0.015 & 0.001 & 0.000 & 0.001 & 0.008 & 0.049 & 0.120 & 0.181 \\
\hline CA & 0.126 & 0.100 & 0.097 & 0.069 & 0.042 & 0.015 & 0.003 & 0.003 & 0.009 & 0.034 & 0.088 & 0.126 \\
\hline CO & 0.270 & 0.231 & 0.214 & 0.166 & 0.107 & 0.042 & 0.010 & 0.017 & 0.068 & 0.146 & 0.219 & 0.264 \\
\hline CT & 0.260 & 0.230 & 0.202 & 0.135 & 0.065 & 0.012 & 0.001 & 0.004 & 0.033 & 0.112 & 0.169 & 0.233 \\
\hline DE & 0.230 & 0.200 & 0.167 & 0.100 & 0.037 & 0.003 & 0.000 & 0.000 & 0.012 & 0.078 & 0.142 & 0.203 \\
\hline FL & 0.060 & 0.044 & 0.023 & 0.005 & 0.000 & 0.000 & 0.000 & 0.000 & 0.000 & 0.003 & 0.018 & 0.046 \\
\hline GA & 0.169 & 0.133 & 0.097 & 0.045 & 0.014 & 0.001 & 0.000 & 0.000 & 0.004 & 0.044 & 0.097 & 0.152 \\
\hline ID & 0.266 & 0.220 & 0.193 & 0.142 & 0.091 & 0.041 & 0.012 & 0.015 & 0.063 & 0.137 & 0.211 & 0.262 \\
\hline IL & 0.284 & 0.238 & 0.199 & 0.124 & 0.060 & 0.011 & 0.001 & 0.006 & 0.029 & 0.106 & 0.184 & 0.257 \\
\hline IN & 0.268 & 0.227 & 0.187 & 0.115 & 0.055 & 0.009 & 0.002 & 0.005 & 0.028 & 0.101 & 0.172 & 0.242 \\
\hline IA & 0.304 & 0.255 & 0.212 & 0.130 & 0.061 & 0.012 & 0.003 & 0.009 & 0.038 & 0.117 & 0.208 & 0.281 \\
\hline KS & 0.252 & 0.203 & 0.161 & 0.090 & 0.036 & 0.005 & 0.001 & 0.002 & 0.019 & 0.076 & 0.166 & 0.233 \\
\hline KY & 0.231 & 0.190 & 0.151 & 0.085 & 0.037 & 0.004 & 0.000 & 0.001 & 0.017 & 0.079 & 0.144 & 0.206 \\
\hline LA & 0.128 & 0.092 & 0.057 & 0.018 & 0.001 & 0.000 & 0.000 & 0.000 & 0.000 & 0.018 & 0.061 & 0.109 \\
\hline ME & 0.303 & 0.270 & 0.243 & 0.174 & 0.103 & 0.036 & 0.010 & 0.017 & 0.067 & 0.148 & 0.205 & 0.274 \\
\hline MD & 0.234 & 0.201 & 0.167 & 0.098 & 0.038 & 0.004 & 0.000 & 0.001 & 0.015 & 0.083 & 0.148 & 0.208 \\
\hline MA & 0.266 & 0.236 & 0.211 & 0.146 & 0.076 & 0.018 & 0.002 & 0.006 & 0.041 & 0.119 & 0.174 & 0.238 \\
\hline MI & 0.284 & 0.252 & 0.222 & 0.148 & 0.077 & 0.020 & 0.004 & 0.011 & 0.042 & 0.123 & 0.192 & 0.257 \\
\hline MN & 0.340 & 0.288 & 0.251 & 0.163 & 0.083 & 0.027 & 0.010 & 0.017 & 0.066 & 0.149 & 0.241 & 0.316 \\
\hline MS & 0.161 & 0.121 & 0.084 & 0.034 & 0.007 & 0.000 & 0.000 & 0.000 & 0.003 & 0.036 & 0.088 & 0.142 \\
\hline MO & 0.256 & 0.208 & 0.165 & 0.091 & 0.039 & 0.005 & 0.001 & 0.003 & 0.021 & 0.083 & 0.162 & 0.233 \\
\hline MT & 0.292 & 0.247 & 0.225 & 0.170 & 0.114 & 0.058 & 0.026 & 0.029 & 0.091 & 0.163 & 0.237 & 0.284 \\
\hline NE & 0.265 & 0.220 & 0.189 & 0.120 & 0.060 & 0.015 & 0.004 & 0.006 & 0.038 & 0.109 & 0.196 & 0.252 \\
\hline NV & 0.186 & 0.142 & 0.121 & 0.079 & 0.038 & 0.011 & 0.002 & 0.003 & 0.016 & 0.062 & 0.134 & 0.185 \\
\hline NH & 0.296 & 0.262 & 0.233 & 0.163 & 0.088 & 0.025 & 0.005 & 0.014 & 0.062 & 0.144 & 0.201 & 0.268 \\
\hline NJ & 0.246 & 0.216 & 0.186 & 0.119 & 0.052 & 0.007 & 0.000 & 0.002 & 0.022 & 0.099 & 0.157 & 0.220 \\
\hline NM & 0.219 & 0.176 & 0.152 & 0.102 & 0.047 & 0.010 & 0.001 & 0.003 & 0.022 & 0.088 & 0.166 & 0.217 \\
\hline NY & 0.262 & 0.233 & 0.206 & 0.136 & 0.065 & 0.013 & 0.002 & 0.005 & 0.033 & 0.108 & 0.169 & 0.233 \\
\hline $\mathrm{NC}$ & 0.190 & 0.156 & 0.121 & 0.060 & 0.021 & 0.002 & 0.000 & 0.000 & 0.008 & 0.060 & 0.115 & 0.172 \\
\hline ND & 0.349 & 0.297 & 0.264 & 0.174 & 0.092 & 0.036 & 0.015 & 0.021 & 0.079 & 0.165 & 0.260 & 0.328 \\
\hline OH & 0.264 & 0.228 & 0.193 & 0.123 & 0.061 & 0.012 & 0.002 & 0.005 & 0.031 & 0.106 & 0.172 & 0.237 \\
\hline OK & 0.211 & 0.163 & 0.122 & 0.056 & 0.015 & 0.001 & 0.000 & 0.000 & 0.009 & 0.047 & 0.128 & 0.193 \\
\hline OR & 0.196 & 0.162 & 0.153 & 0.124 & 0.087 & 0.046 & 0.018 & 0.018 & 0.044 & 0.106 & 0.160 & 0.197 \\
\hline PA & 0.258 & 0.226 & 0.195 & 0.125 & 0.060 & 0.012 & 0.002 & 0.005 & 0.032 & 0.110 & 0.169 & 0.231 \\
\hline RI & 0.250 & 0.223 & 0.201 & 0.141 & 0.075 & 0.017 & 0.001 & 0.004 & 0.030 & 0.104 & 0.160 & 0.222 \\
\hline SC & 0.166 & 0.131 & 0.096 & 0.040 & 0.010 & 0.001 & 0.000 & 0.000 & 0.003 & 0.042 & 0.094 & 0.150 \\
\hline SD & 0.310 & 0.261 & 0.229 & 0.151 & 0.080 & 0.027 & 0.011 & 0.012 & 0.056 & 0.138 & 0.230 & 0.293 \\
\hline TN & 0.210 & 0.170 & 0.131 & 0.069 & 0.027 & 0.002 & 0.000 & 0.000 & 0.012 & 0.070 & 0.131 & 0.190 \\
\hline TX & 0.138 & 0.099 & 0.062 & 0.021 & 0.003 & 0.000 & 0.000 & 0.000 & 0.001 & 0.018 & 0.071 & 0.123 \\
\hline UT & 0.265 & 0.221 & 0.192 & 0.141 & 0.085 & 0.031 & 0.004 & 0.007 & 0.047 & 0.125 & 0.203 & 0.258 \\
\hline VT & 0.308 & 0.276 & 0.247 & 0.172 & 0.092 & 0.028 & 0.009 & 0.020 & 0.070 & 0.151 & 0.209 & 0.279 \\
\hline VA & 0.220 & 0.186 & 0.154 & 0.087 & 0.036 & 0.004 & 0.000 & 0.001 & 0.015 & 0.080 & 0.138 & 0.198 \\
\hline WA & 0.208 & 0.172 & 0.161 & 0.125 & 0.085 & 0.047 & 0.022 & 0.021 & 0.053 & 0.119 & 0.170 & 0.207 \\
\hline WV & 0.241 & 0.206 & 0.173 & 0.107 & 0.053 & 0.011 & 0.002 & 0.003 & 0.026 & 0.100 & 0.160 & 0.218 \\
\hline WI & 0.312 & 0.267 & 0.234 & 0.158 & 0.085 & 0.026 & 0.007 & 0.014 & 0.052 & 0.135 & 0.213 & 0.285 \\
\hline WY & 0.292 & 0.251 & 0.229 & 0.177 & 0.118 & 0.054 & 0.017 & 0.023 & 0.083 & 0.162 & 0.238 & 0.285 \\
\hline AK & 0.331 & 0.296 & 0.285 & 0.223 & 0.161 & 0.100 & 0.073 & 0.092 & 0.146 & 0.234 & 0.292 & 0.322 \\
\hline HI & 0.002 & 0.002 & 0.001 & 0.000 & 0.000 & 0.000 & 0.000 & 0.000 & 0.000 & 0.000 & 0.000 & 0.001 \\
\hline PR & 0.000 & 0.000 & 0.000 & 0.000 & 0.000 & 0.000 & 0.000 & 0.000 & 0.000 & 0.000 & 0.000 & 0.000 \\
\hline
\end{tabular}




\section{A.3: Estimated portion of monthly electricity use for cooling (PMEC)}

\begin{tabular}{|c|c|c|c|c|c|c|c|c|c|c|c|c|}
\hline State & Jan & Feb & Mar & Apr & May & Jun & Jul & Aug & Sep & Oct & Nov & Dec \\
\hline $\mathbf{A L}$ & 0.021 & 0.011 & 0.046 & 0.075 & 0.240 & 0.379 & 0.446 & 0.432 & 0.322 & 0.124 & 0.023 & 0.011 \\
\hline $\mathbf{A Z}$ & 0.005 & 0.020 & 0.061 & 0.164 & 0.326 & 0.476 & 0.539 & 0.521 & 0.435 & 0.241 & 0.042 & 0.001 \\
\hline AR & 0.001 & 0.004 & 0.029 & 0.057 & 0.213 & 0.375 & 0.459 & 0.438 & 0.297 & 0.092 & 0.006 & 0.001 \\
\hline CA & 0.004 & 0.004 & 0.013 & 0.038 & 0.093 & 0.189 & 0.288 & 0.292 & 0.219 & 0.086 & 0.012 & 0.002 \\
\hline $\mathrm{CO}$ & 0.000 & 0.000 & 0.000 & 0.000 & 0.008 & 0.090 & 0.167 & 0.125 & 0.032 & 0.000 & 0.000 & 0.000 \\
\hline CT & 0.000 & 0.000 & 0.000 & 0.000 & 0.031 & 0.143 & 0.286 & 0.247 & 0.069 & 0.004 & 0.000 & 0.000 \\
\hline DE & 0.000 & 0.000 & 0.000 & 0.004 & 0.091 & 0.266 & 0.384 & 0.346 & 0.180 & 0.032 & 0.000 & 0.000 \\
\hline FL & 0.147 & 0.137 & 0.200 & 0.259 & 0.384 & 0.450 & 0.481 & 0.480 & 0.448 & 0.354 & 0.232 & 0.153 \\
\hline GA & 0.017 & 0.009 & 0.038 & 0.061 & 0.220 & 0.362 & 0.433 & 0.412 & 0.296 & 0.103 & 0.023 & 0.008 \\
\hline ID & 0.000 & 0.000 & 0.000 & 0.002 & 0.024 & 0.108 & 0.237 & 0.216 & 0.067 & 0.002 & 0.000 & 0.000 \\
\hline IL & 0.000 & 0.000 & 0.002 & 0.006 & 0.110 & 0.245 & 0.337 & 0.296 & 0.126 & 0.023 & 0.000 & 0.000 \\
\hline IN & 0.000 & 0.000 & 0.004 & 0.007 & 0.117 & 0.251 & 0.336 & 0.292 & 0.140 & 0.024 & 0.000 & 0.000 \\
\hline IA & 0.000 & 0.000 & 0.002 & 0.007 & 0.107 & 0.244 & 0.332 & 0.284 & 0.109 & 0.016 & 0.000 & 0.000 \\
\hline KS & 0.000 & 0.002 & 0.012 & 0.024 & 0.149 & 0.334 & 0.439 & 0.410 & 0.236 & 0.049 & 0.001 & 0.000 \\
\hline KY & 0.002 & 0.000 & 0.014 & 0.018 & 0.142 & 0.289 & 0.382 & 0.351 & 0.206 & 0.044 & 0.001 & 0.001 \\
\hline LA & 0.045 & 0.034 & 0.091 & 0.161 & 0.336 & 0.441 & 0.484 & 0.478 & 0.399 & 0.212 & 0.074 & 0.028 \\
\hline ME & 0.000 & 0.000 & 0.000 & 0.000 & 0.003 & 0.045 & 0.160 & 0.129 & 0.013 & 0.000 & 0.000 & 0.000 \\
\hline MD & 0.000 & 0.000 & 0.001 & 0.007 & 0.097 & 0.261 & 0.376 & 0.338 & 0.173 & 0.028 & 0.000 & 0.000 \\
\hline MA & 0.000 & 0.000 & 0.000 & 0.000 & 0.016 & 0.113 & 0.252 & 0.212 & 0.049 & 0.002 & 0.000 & 0.000 \\
\hline MI & 0.000 & 0.000 & 0.000 & 0.001 & 0.069 & 0.169 & 0.264 & 0.223 & 0.068 & 0.009 & 0.000 & 0.000 \\
\hline MN & 0.000 & 0.000 & 0.000 & 0.003 & 0.063 & 0.155 & 0.244 & 0.190 & 0.042 & 0.003 & 0.000 & 0.000 \\
\hline MS & 0.022 & 0.016 & 0.058 & 0.100 & 0.270 & 0.405 & 0.463 & 0.450 & 0.346 & 0.143 & 0.028 & 0.013 \\
\hline MO & 0.000 & 0.000 & 0.011 & 0.021 & 0.144 & 0.304 & 0.407 & 0.373 & 0.201 & 0.042 & 0.001 & 0.000 \\
\hline MT & 0.000 & 0.000 & 0.000 & 0.000 & 0.008 & 0.063 & 0.149 & 0.134 & 0.032 & 0.000 & 0.000 & 0.000 \\
\hline NE & 0.000 & 0.000 & 0.000 & 0.005 & 0.078 & 0.230 & 0.331 & 0.287 & 0.116 & 0.009 & 0.000 & 0.000 \\
\hline NV & 0.001 & 0.007 & 0.025 & 0.089 & 0.225 & 0.380 & 0.478 & 0.454 & 0.318 & 0.127 & 0.010 & 0.000 \\
\hline NH & 0.000 & 0.000 & 0.000 & 0.000 & 0.015 & 0.079 & 0.194 & 0.152 & 0.019 & 0.000 & 0.000 & 0.000 \\
\hline NJ & 0.000 & 0.000 & 0.000 & 0.001 & 0.056 & 0.200 & 0.334 & 0.288 & 0.114 & 0.014 & 0.000 & 0.000 \\
\hline NM & 0.000 & 0.000 & 0.001 & 0.013 & 0.090 & 0.262 & 0.340 & 0.295 & 0.143 & 0.015 & 0.000 & 0.000 \\
\hline NY & 0.000 & 0.000 & 0.000 & 0.000 & 0.041 & 0.159 & 0.292 & 0.257 & 0.091 & 0.011 & 0.000 & 0.000 \\
\hline $\mathrm{NC}$ & 0.005 & 0.002 & 0.017 & 0.027 & 0.165 & 0.324 & 0.412 & 0.381 & 0.247 & 0.067 & 0.007 & 0.003 \\
\hline ND & 0.000 & 0.000 & 0.000 & 0.004 & 0.049 & 0.141 & 0.226 & 0.198 & 0.042 & 0.000 & 0.000 & 0.000 \\
\hline OH & 0.000 & 0.000 & 0.001 & 0.004 & 0.092 & 0.209 & 0.303 & 0.261 & 0.116 & 0.018 & 0.000 & 0.000 \\
\hline OK & 0.000 & 0.005 & 0.024 & 0.058 & 0.208 & 0.383 & 0.479 & 0.463 & 0.312 & 0.097 & 0.006 & 0.000 \\
\hline OR & 0.000 & 0.000 & 0.000 & 0.000 & 0.009 & 0.040 & 0.134 & 0.134 & 0.056 & 0.002 & 0.000 & 0.000 \\
\hline PA & 0.000 & 0.000 & 0.000 & 0.002 & 0.062 & 0.182 & 0.295 & 0.256 & 0.097 & 0.012 & 0.000 & 0.000 \\
\hline RI & 0.000 & 0.000 & 0.000 & 0.000 & 0.012 & 0.105 & 0.256 & 0.230 & 0.065 & 0.004 & 0.000 & 0.000 \\
\hline SC & 0.015 & 0.007 & 0.037 & 0.061 & 0.232 & 0.377 & 0.451 & 0.425 & 0.307 & 0.109 & 0.021 & 0.008 \\
\hline SD & 0.000 & 0.000 & 0.000 & 0.004 & 0.073 & 0.206 & 0.319 & 0.271 & 0.097 & 0.005 & 0.000 & 0.000 \\
\hline TN & 0.003 & 0.002 & 0.020 & 0.030 & 0.165 & 0.319 & 0.405 & 0.377 & 0.238 & 0.064 & 0.003 & 0.001 \\
\hline TX & 0.026 & 0.031 & 0.098 & 0.171 & 0.334 & 0.446 & 0.500 & 0.493 & 0.397 & 0.221 & 0.071 & 0.020 \\
\hline UT & 0.000 & 0.000 & 0.000 & 0.007 & 0.042 & 0.169 & 0.307 & 0.271 & 0.097 & 0.009 & 0.000 & 0.000 \\
\hline VT & 0.000 & 0.000 & 0.000 & 0.000 & 0.021 & 0.069 & 0.177 & 0.135 & 0.020 & 0.000 & 0.000 & 0.000 \\
\hline VA & 0.001 & 0.000 & 0.003 & 0.009 & 0.106 & 0.266 & 0.372 & 0.335 & 0.187 & 0.035 & 0.001 & 0.001 \\
\hline WA & 0.000 & 0.000 & 0.000 & 0.000 & 0.009 & 0.038 & 0.114 & 0.119 & 0.036 & 0.000 & 0.000 & 0.000 \\
\hline WV & 0.001 & 0.000 & 0.004 & 0.006 & 0.088 & 0.209 & 0.308 & 0.275 & 0.131 & 0.023 & 0.000 & 0.000 \\
\hline WI & 0.000 & 0.000 & 0.000 & 0.001 & 0.052 & 0.151 & 0.247 & 0.208 & 0.051 & 0.007 & 0.000 & 0.000 \\
\hline WY & 0.000 & 0.000 & 0.000 & 0.000 & 0.010 & 0.088 & 0.179 & 0.143 & 0.033 & 0.000 & 0.000 & 0.000 \\
\hline AK & 0.000 & 0.000 & 0.000 & 0.000 & 0.000 & 0.002 & 0.003 & 0.002 & 0.000 & 0.000 & 0.000 & 0.000 \\
\hline HI & 0.211 & 0.193 & 0.238 & 0.259 & 0.303 & 0.341 & 0.371 & 0.388 & 0.379 & 0.366 & 0.309 & 0.253 \\
\hline PR & 0.336 & 0.313 & 0.353 & 0.377 & 0.419 & 0.438 & 0.450 & 0.452 & 0.440 & 0.435 & 0.399 & 0.362 \\
\hline
\end{tabular}




\section{A.4: Estimated portion of heating energy saved per degree-day thermostat lowered}

\begin{tabular}{|c|c|c|c|c|c|c|c|c|c|c|c|c|}
\hline State & Jan & Feb & Mar & Apr & May & Jun & Jul & Aug & Sep & Oct & Nov & Dec \\
\hline $\mathbf{A L}$ & 0.037 & 0.043 & 0.061 & 0.092 & 0.100 & 0.100 & 0.100 & 0.100 & 0.100 & 0.091 & 0.058 & 0.041 \\
\hline $\mathbf{A Z}$ & 0.048 & 0.057 & 0.069 & 0.092 & 0.100 & 0.100 & 0.100 & 0.100 & 0.100 & 0.100 & 0.066 & 0.048 \\
\hline $\mathbf{A R}$ & 0.031 & 0.037 & 0.052 & 0.085 & 0.100 & 0.100 & 0.100 & 0.100 & 0.100 & 0.087 & 0.049 & 0.035 \\
\hline CA & 0.048 & 0.054 & 0.060 & 0.072 & 0.094 & 0.100 & 0.100 & 0.100 & 0.100 & 0.100 & 0.062 & 0.048 \\
\hline CO & 0.023 & 0.025 & 0.031 & 0.045 & 0.077 & 0.100 & 0.100 & 0.100 & 0.100 & 0.053 & 0.036 & 0.026 \\
\hline CT & 0.022 & 0.024 & 0.029 & 0.037 & 0.055 & 0.093 & 0.100 & 0.100 & 0.073 & 0.043 & 0.028 & 0.023 \\
\hline DE & 0.077 & 0.085 & 0.100 & 0.100 & 0.100 & 0.100 & 0.100 & 0.100 & 0.100 & 0.100 & 0.100 & 0.088 \\
\hline FL & 0.027 & 0.029 & 0.038 & 0.057 & 0.100 & 0.100 & 0.100 & 0.100 & 0.100 & 0.068 & 0.043 & 0.031 \\
\hline GA & 0.037 & 0.043 & 0.059 & 0.090 & 0.100 & 0.100 & 0.100 & 0.100 & 0.100 & 0.092 & 0.058 & 0.041 \\
\hline ID & 0.023 & 0.026 & 0.032 & 0.043 & 0.062 & 0.092 & 0.100 & 0.100 & 0.076 & 0.045 & 0.029 & 0.023 \\
\hline IL & 0.021 & 0.024 & 0.031 & 0.048 & 0.078 & 0.100 & 0.100 & 0.100 & 0.100 & 0.056 & 0.033 & 0.024 \\
\hline IN & 0.022 & 0.025 & 0.033 & 0.051 & 0.082 & 0.100 & 0.100 & 0.100 & 0.100 & 0.058 & 0.036 & 0.025 \\
\hline IA & 0.019 & 0.022 & 0.029 & 0.046 & 0.078 & 0.100 & 0.100 & 0.100 & 0.096 & 0.051 & 0.029 & 0.021 \\
\hline KS & 0.027 & 0.030 & 0.041 & 0.064 & 0.097 & 0.100 & 0.100 & 0.100 & 0.100 & 0.068 & 0.042 & 0.030 \\
\hline KY & 0.024 & 0.028 & 0.039 & 0.061 & 0.098 & 0.100 & 0.100 & 0.100 & 0.100 & 0.070 & 0.037 & 0.027 \\
\hline LA & 0.048 & 0.058 & 0.081 & 0.100 & 0.100 & 0.100 & 0.100 & 0.100 & 0.100 & 0.100 & 0.077 & 0.054 \\
\hline ME & 0.019 & 0.020 & 0.025 & 0.035 & 0.057 & 0.100 & 0.100 & 0.100 & 0.074 & 0.042 & 0.030 & 0.022 \\
\hline MD & 0.026 & 0.029 & 0.038 & 0.058 & 0.098 & 0.100 & 0.100 & 0.100 & 0.100 & 0.066 & 0.041 & 0.030 \\
\hline MA & 0.023 & 0.024 & 0.030 & 0.041 & 0.070 & 0.100 & 0.100 & 0.100 & 0.096 & 0.051 & 0.035 & 0.026 \\
\hline MI & 0.021 & 0.022 & 0.028 & 0.041 & 0.069 & 0.100 & 0.100 & 0.100 & 0.093 & 0.049 & 0.032 & 0.024 \\
\hline MN & 0.017 & 0.019 & 0.024 & 0.038 & 0.066 & 0.100 & 0.100 & 0.100 & 0.075 & 0.042 & 0.025 & 0.018 \\
\hline MS & 0.039 & 0.046 & 0.065 & 0.100 & 0.100 & 0.100 & 0.100 & 0.100 & 0.100 & 0.098 & 0.062 & 0.044 \\
\hline MO & 0.024 & 0.028 & 0.038 & 0.061 & 0.095 & 0.100 & 0.100 & 0.100 & 0.100 & 0.066 & 0.038 & 0.027 \\
\hline MT & 0.020 & 0.023 & 0.027 & 0.036 & 0.053 & 0.079 & 0.100 & 0.100 & 0.061 & 0.038 & 0.025 & 0.021 \\
\hline NE & 0.023 & 0.026 & 0.033 & 0.049 & 0.083 & 0.100 & 0.100 & 0.100 & 0.100 & 0.055 & 0.031 & 0.024 \\
\hline NV & 0.034 & 0.040 & 0.050 & 0.066 & 0.089 & 0.100 & 0.100 & 0.100 & 0.100 & 0.077 & 0.045 & 0.034 \\
\hline NH & 0.020 & 0.021 & 0.026 & 0.037 & 0.064 & 0.100 & 0.100 & 0.100 & 0.078 & 0.043 & 0.030 & 0.022 \\
\hline NJ & 0.025 & 0.026 & 0.034 & 0.050 & 0.086 & 0.100 & 0.100 & 0.100 & 0.100 & 0.059 & 0.039 & 0.028 \\
\hline NM & 0.028 & 0.033 & 0.041 & 0.056 & 0.089 & 0.100 & 0.100 & 0.100 & 0.100 & 0.064 & 0.037 & 0.029 \\
\hline NY & 0.023 & 0.024 & 0.030 & 0.044 & 0.076 & 0.100 & 0.100 & 0.100 & 0.100 & 0.055 & 0.036 & 0.026 \\
\hline $\mathrm{NC}$ & 0.033 & 0.037 & 0.050 & 0.079 & 0.100 & 0.100 & 0.100 & 0.100 & 0.100 & 0.079 & 0.051 & 0.037 \\
\hline ND & 0.016 & 0.018 & 0.023 & 0.035 & 0.061 & 0.096 & 0.100 & 0.100 & 0.066 & 0.038 & 0.023 & 0.017 \\
\hline OH & 0.023 & 0.025 & 0.032 & 0.048 & 0.078 & 0.100 & 0.100 & 0.100 & 0.100 & 0.056 & 0.036 & 0.026 \\
\hline OK & 0.029 & 0.035 & 0.050 & 0.081 & 0.100 & 0.100 & 0.100 & 0.100 & 0.100 & 0.089 & 0.047 & 0.032 \\
\hline OR & 0.032 & 0.036 & 0.041 & 0.048 & 0.064 & 0.090 & 0.100 & 0.100 & 0.091 & 0.056 & 0.038 & 0.032 \\
\hline PA & 0.024 & 0.025 & 0.032 & 0.048 & 0.079 & 0.100 & 0.100 & 0.100 & 0.100 & 0.054 & 0.036 & 0.027 \\
\hline RI & 0.024 & 0.026 & 0.031 & 0.043 & 0.071 & 0.100 & 0.100 & 0.100 & 0.100 & 0.056 & 0.038 & 0.028 \\
\hline SC & 0.038 & 0.043 & 0.060 & 0.096 & 0.100 & 0.100 & 0.100 & 0.100 & 0.100 & 0.093 & 0.060 & 0.042 \\
\hline SD & 0.019 & 0.021 & 0.027 & 0.040 & 0.067 & 0.100 & 0.100 & 0.100 & 0.080 & 0.045 & 0.026 & 0.020 \\
\hline $\mathbf{T N}$ & 0.030 & 0.034 & 0.047 & 0.073 & 0.100 & 0.100 & 0.100 & 0.100 & 0.100 & 0.073 & 0.046 & 0.033 \\
\hline TX & 0.045 & 0.055 & 0.077 & 0.100 & 0.100 & 0.100 & 0.100 & 0.100 & 0.100 & 0.100 & 0.071 & 0.049 \\
\hline UT & 0.023 & 0.026 & 0.033 & 0.043 & 0.065 & 0.100 & 0.100 & 0.100 & 0.088 & 0.049 & 0.030 & 0.024 \\
\hline VT & 0.019 & 0.020 & 0.025 & 0.036 & 0.062 & 0.100 & 0.100 & 0.100 & 0.073 & 0.041 & 0.029 & 0.021 \\
\hline VA & 0.028 & 0.031 & 0.041 & 0.063 & 0.100 & 0.100 & 0.100 & 0.100 & 0.100 & 0.067 & 0.044 & 0.032 \\
\hline WA & 0.030 & 0.033 & 0.039 & 0.048 & 0.065 & 0.089 & 0.100 & 0.100 & 0.084 & 0.051 & 0.036 & 0.030 \\
\hline WV & 0.026 & 0.028 & 0.036 & 0.054 & 0.084 & 0.100 & 0.100 & 0.100 & 0.100 & 0.058 & 0.038 & 0.029 \\
\hline WI & 0.019 & 0.021 & 0.026 & 0.039 & 0.065 & 0.100 & 0.100 & 0.100 & 0.084 & 0.046 & 0.028 & 0.021 \\
\hline WY & 0.020 & 0.022 & 0.027 & 0.035 & 0.051 & 0.082 & 0.100 & 0.100 & 0.064 & 0.039 & 0.025 & 0.021 \\
\hline AK & 0.017 & 0.018 & 0.021 & 0.027 & 0.039 & 0.057 & 0.072 & 0.062 & 0.041 & 0.026 & 0.020 & 0.018 \\
\hline HI & 0.100 & 0.100 & 0.100 & 0.100 & 0.100 & 0.100 & 0.100 & 0.100 & 0.100 & 0.100 & 0.100 & 0.100 \\
\hline PR & 0.100 & 0.100 & 0.100 & 0.100 & 0.100 & 0.100 & 0.100 & 0.100 & 0.100 & 0.100 & 0.100 & 0.100 \\
\hline
\end{tabular}




\section{A.5: Estimated portion of cooling energy saved per degree-day thermostat raised}

\begin{tabular}{|c|c|c|c|c|c|c|c|c|c|c|c|c|}
\hline State & Jan & Feb & Mar & Apr & May & Jun & Jul & Aug & Sep & Oct & Nov & Dec \\
\hline $\mathbf{A L}$ & 0.005 & 0.005 & 0.006 & 0.030 & 0.042 & 0.050 & 0.049 & 0.049 & 0.047 & 0.024 & 0.008 & 0.005 \\
\hline $\mathbf{A Z}$ & 0.007 & 0.007 & 0.011 & 0.023 & 0.043 & 0.047 & 0.043 & 0.045 & 0.048 & 0.035 & 0.011 & 0.026 \\
\hline $\mathbf{A R}$ & 0.005 & 0.005 & 0.005 & 0.027 & 0.041 & 0.049 & 0.049 & 0.049 & 0.045 & 0.023 & 0.007 & 0.005 \\
\hline CA & 0.010 & 0.020 & 0.016 & 0.019 & 0.029 & 0.041 & 0.048 & 0.048 & 0.045 & 0.038 & 0.022 & 0.021 \\
\hline CO & 0.005 & 0.005 & 0.005 & 0.100 & 0.015 & 0.028 & 0.049 & 0.047 & 0.024 & 0.027 & 0.005 & 0.005 \\
\hline CT & 0.005 & 0.005 & 0.005 & 0.005 & 0.030 & 0.048 & 0.050 & 0.048 & 0.043 & 0.025 & 0.005 & 0.005 \\
\hline DE & 0.005 & 0.005 & 0.005 & 0.040 & 0.034 & 0.049 & 0.050 & 0.050 & 0.044 & 0.017 & 0.005 & 0.005 \\
\hline FL & 0.014 & 0.019 & 0.035 & 0.047 & 0.050 & 0.049 & 0.048 & 0.048 & 0.049 & 0.048 & 0.038 & 0.021 \\
\hline GA & 0.005 & 0.005 & 0.006 & 0.032 & 0.042 & 0.049 & 0.049 & 0.050 & 0.047 & 0.025 & 0.008 & 0.005 \\
\hline ID & 0.005 & 0.005 & 0.005 & 0.006 & 0.012 & 0.026 & 0.043 & 0.041 & 0.016 & 0.009 & 0.005 & 0.005 \\
\hline IL & 0.005 & 0.005 & 0.005 & 0.006 & 0.015 & 0.042 & 0.049 & 0.046 & 0.034 & 0.006 & 0.005 & 0.005 \\
\hline IN & 0.005 & 0.005 & 0.005 & 0.009 & 0.017 & 0.044 & 0.049 & 0.047 & 0.034 & 0.007 & 0.006 & 0.005 \\
\hline IA & 0.005 & 0.005 & 0.005 & 0.005 & 0.015 & 0.042 & 0.048 & 0.044 & 0.028 & 0.005 & 0.005 & 0.005 \\
\hline KS & 0.005 & 0.005 & 0.005 & 0.011 & 0.028 & 0.047 & 0.049 & 0.049 & 0.037 & 0.013 & 0.005 & 0.005 \\
\hline KY & 0.005 & 0.005 & 0.005 & 0.018 & 0.027 & 0.047 & 0.050 & 0.049 & 0.039 & 0.013 & 0.008 & 0.005 \\
\hline LA & 0.005 & 0.005 & 0.018 & 0.041 & 0.049 & 0.049 & 0.048 & 0.048 & 0.050 & 0.038 & 0.016 & 0.005 \\
\hline ME & 0.005 & 0.005 & 0.005 & 0.005 & 0.043 & 0.055 & 0.048 & 0.047 & 0.051 & 0.005 & 0.005 & 0.005 \\
\hline MD & 0.005 & 0.005 & 0.005 & 0.024 & 0.032 & 0.048 & 0.050 & 0.050 & 0.042 & 0.015 & 0.100 & 0.005 \\
\hline MA & 0.005 & 0.005 & 0.005 & 0.005 & 0.033 & 0.047 & 0.050 & 0.049 & 0.045 & 0.035 & 0.005 & 0.005 \\
\hline MI & 0.005 & 0.005 & 0.005 & 0.005 & 0.010 & 0.038 & 0.048 & 0.044 & 0.033 & 0.005 & 0.005 & 0.005 \\
\hline MN & 0.005 & 0.005 & 0.005 & 0.005 & 0.008 & 0.033 & 0.044 & 0.040 & 0.020 & 0.005 & 0.005 & 0.005 \\
\hline MS & 0.005 & 0.005 & 0.009 & 0.033 & 0.046 & 0.050 & 0.048 & 0.049 & 0.048 & 0.028 & 0.011 & 0.005 \\
\hline MO & 0.005 & 0.005 & 0.005 & 0.012 & 0.026 & 0.047 & 0.050 & 0.049 & 0.035 & 0.011 & 0.005 & 0.005 \\
\hline MT & 0.005 & 0.005 & 0.005 & 0.005 & 0.010 & 0.020 & 0.036 & 0.034 & 0.008 & 0.050 & 0.005 & 0.005 \\
\hline NE & 0.005 & 0.005 & 0.005 & 0.005 & 0.005 & 0.013 & 0.021 & 0.018 & 0.006 & 0.005 & 0.005 & 0.005 \\
\hline NV & 0.005 & 0.005 & 0.005 & 0.007 & 0.024 & 0.045 & 0.047 & 0.048 & 0.040 & 0.013 & 0.005 & 0.005 \\
\hline NH & 0.005 & 0.005 & 0.005 & 0.005 & 0.021 & 0.051 & 0.050 & 0.045 & 0.048 & 0.005 & 0.005 & 0.005 \\
\hline NJ & 0.005 & 0.005 & 0.005 & 0.067 & 0.030 & 0.047 & 0.050 & 0.049 & 0.042 & 0.013 & 0.005 & 0.005 \\
\hline NM & 0.005 & 0.005 & 0.012 & 0.010 & 0.025 & 0.044 & 0.049 & 0.048 & 0.038 & 0.021 & 0.009 & 0.005 \\
\hline NY & 0.005 & 0.005 & 0.005 & 0.005 & 0.024 & 0.045 & 0.049 & 0.047 & 0.036 & 0.011 & 0.005 & 0.005 \\
\hline $\mathrm{NC}$ & 0.005 & 0.005 & 0.005 & 0.037 & 0.039 & 0.049 & 0.050 & 0.050 & 0.045 & 0.019 & 0.009 & 0.005 \\
\hline ND & 0.005 & 0.005 & 0.005 & 0.005 & 0.007 & 0.027 & 0.041 & 0.037 & 0.011 & 0.005 & 0.005 & 0.005 \\
\hline $\mathbf{O H}$ & 0.005 & 0.005 & 0.005 & 0.008 & 0.016 & 0.043 & 0.049 & 0.047 & 0.034 & 0.008 & 0.005 & 0.005 \\
\hline OK & 0.005 & 0.005 & 0.005 & 0.023 & 0.041 & 0.049 & 0.048 & 0.048 & 0.045 & 0.024 & 0.005 & 0.005 \\
\hline OR & 0.005 & 0.005 & 0.005 & 0.100 & 0.036 & 0.043 & 0.044 & 0.045 & 0.035 & 0.073 & 0.005 & 0.005 \\
\hline PA & 0.005 & 0.005 & 0.005 & 0.020 & 0.020 & 0.044 & 0.049 & 0.047 & 0.036 & 0.009 & 0.005 & 0.005 \\
\hline RI & 0.005 & 0.005 & 0.005 & 0.005 & 0.046 & 0.051 & 0.050 & 0.049 & 0.049 & 0.040 & 0.005 & 0.005 \\
\hline SC & 0.005 & 0.005 & 0.007 & 0.038 & 0.044 & 0.050 & 0.049 & 0.050 & 0.048 & 0.026 & 0.010 & 0.005 \\
\hline SD & 0.005 & 0.005 & 0.005 & 0.005 & 0.009 & 0.031 & 0.044 & 0.042 & 0.017 & 0.005 & 0.005 & 0.005 \\
\hline $\mathbf{T N}$ & 0.005 & 0.005 & 0.005 & 0.023 & 0.033 & 0.049 & 0.050 & 0.050 & 0.042 & 0.014 & 0.007 & 0.005 \\
\hline $\mathbf{T X}$ & 0.005 & 0.005 & 0.015 & 0.037 & 0.048 & 0.049 & 0.047 & 0.047 & 0.049 & 0.038 & 0.011 & 0.005 \\
\hline UT & 0.005 & 0.005 & 0.005 & 0.005 & 0.010 & 0.030 & 0.047 & 0.046 & 0.023 & 0.005 & 0.005 & 0.005 \\
\hline VT & 0.005 & 0.005 & 0.005 & 0.005 & 0.014 & 0.049 & 0.048 & 0.042 & 0.033 & 0.005 & 0.005 & 0.005 \\
\hline VA & 0.005 & 0.005 & 0.005 & 0.030 & 0.032 & 0.048 & 0.050 & 0.050 & 0.041 & 0.014 & 0.016 & 0.005 \\
\hline WA & 0.005 & 0.005 & 0.005 & 0.084 & 0.039 & 0.043 & 0.044 & 0.044 & 0.037 & 0.100 & 0.005 & 0.005 \\
\hline WV & 0.005 & 0.005 & 0.005 & 0.016 & 0.021 & 0.044 & 0.049 & 0.048 & 0.036 & 0.009 & 0.005 & 0.005 \\
\hline WI & 0.005 & 0.005 & 0.005 & 0.005 & 0.009 & 0.034 & 0.046 & 0.041 & 0.029 & 0.005 & 0.005 & 0.005 \\
\hline WY & 0.005 & 0.005 & 0.005 & 0.005 & 0.007 & 0.019 & 0.040 & 0.039 & 0.012 & 0.012 & 0.005 & 0.005 \\
\hline AK & 0.005 & 0.005 & 0.005 & 0.005 & 0.005 & 0.100 & 0.100 & 0.100 & 0.005 & 0.005 & 0.005 & 0.005 \\
\hline HI & 0.050 & 0.050 & 0.049 & 0.049 & 0.049 & 0.049 & 0.049 & 0.049 & 0.049 & 0.049 & 0.049 & 0.049 \\
\hline PR & 0.049 & 0.049 & 0.049 & 0.049 & 0.049 & 0.049 & 0.048 & 0.048 & 0.049 & 0.049 & 0.049 & 0.049 \\
\hline
\end{tabular}


A.6: Data from transportation mode table used in calculations

\begin{tabular}{lllll}
\hline modeid & mode_desc & mpg & lbs CO2e/gallon & lbs CO2e/pax-mi \\
\hline 1 & Air & NA & NA & 0.45 \\
2 & Heavy rail (Amtrak) & NA & NA & 0.409 \\
3 & Light rail (subway, tram) & NA & NA & 0.361 \\
4 & Bus & NA & NA & 0.236 \\
5 & Taxi & 20 & 19.4 & 0.97 \\
6 & Car (also pickup, van, or SUV) & 20 & 19.4 & 0.97 \\
7 & Motorcycle & 62 & 19.4 & 0.313 \\
8 & Bicycle & NA & NA & 0 \\
9 & Walk & NA & NA & 0 \\
10 & Other & 20 & 20 & 1 \\
\hline
\end{tabular}




\section{A.7: Details of database table structures (5 dynamic, 6 static)}

\begin{tabular}{|lll|}
\hline users & & \\
\hline Field & Format & Info \\
\hline userid & int(6) & primary key; auto-index \\
\hline username & varchar(20) & required, unique \\
\hline password & varchar(20) & required \\
\hline admin & $\operatorname{varchar}(6)$ & Y/N \\
\hline email & $\operatorname{varchar}(40)$ & optional \\
\hline zip & int(10) & optional; not used \\
\hline reg_date & timestamp & automatic; date of registration \\
\hline comment & text & not currently used \\
\hline
\end{tabular}

\section{trips}

\section{Field}

\section{Format}

\section{Info}

tripid

$\operatorname{int}(6)$

primary key; auto-index

username

$\operatorname{varchar}(20)$

automatic; associated user

title varchar(40)

user entry; default to "no title"

create_date

timestamp

automatic; date of creation

c_total

double

lbs $\mathrm{CO} 2 \mathrm{e}$

c_pledged

double

lbs $\mathrm{CO} 2 \mathrm{e}$

comment text

deleted

bit(1)

user entered

mark if deleted by user

\begin{tabular}{|lll|}
\hline legs & & \\
\hline Field & Format & Info \\
\hline legid & $\operatorname{int}(8)$ & primary key; auto-index \\
\hline tripid & $\operatorname{int}(8)$ & automatic; associated tripid \\
\hline mode_code & $\operatorname{int}(3)$ & modeid from mode table \\
\hline mode & $\operatorname{varchar}(40)$ & description of mode \\
\hline intensity & $\operatorname{double}$ & lbs CO2e/pax-mile \\
\hline pax & $\operatorname{int}(2)$ & number of passengers \\
\hline eff_or & bit(1) & mark if efficiency (mpg) directly entered by user \\
\hline distance & double & miles \\
\hline carbon & double & carbon estimate, lbs CO2e \\
\hline
\end{tabular}




\begin{tabular}{|lll|}
\hline carb_or & bit(1) & mark if total carbon directly entered by user \\
\hline origin & varchar(20) & optional \\
\hline destination & varchar(20) & optional \\
\hline
\end{tabular}

\begin{tabular}{|lll|}
\hline pledges & Format & Info \\
\hline Field & $\operatorname{int}(8)$ & primary key; auto-index \\
\hline pledgeid & $\operatorname{int}(8)$ & automatic; associated tripid \\
\hline tripid & $\operatorname{varchar}(20)$ & automatic; associated username \\
\hline username & varchar(20) & user entered \\
\hline sponsorname & $\operatorname{timestamp}$ & automatic; date of creation \\
\hline create_date & varchar(140) & user entered \\
\hline description & varchar(20) & automatic; pledge category description \\
\hline category & decimal( $(8,1)$ & total carbon pledged, lbs CO2e \\
\hline carbon & $\operatorname{tinyint}(4)$ & mark if deleted by user \\
\hline deleted & $\operatorname{tinyint}(4)$ & marked completed by user \\
\hline completed & text & user comments when marking completed \\
\hline completetedcomment & text & automatic field coded for later data analysis \\
\hline details &
\end{tabular}

\begin{tabular}{|lll|}
\hline feedback & & \\
\hline Field & Format & Info \\
\hline feedbackID & $\operatorname{int}(8)$ & primary key; auto-index \\
\hline username & varchar(20) & automatic if logged in \\
\hline date_added & timestamp & automatic; date of submittal \\
\hline tran_know & $\operatorname{int}(2)$ & $\mathrm{Q} 1 \mathrm{a}-$ awareness of transportation emissions \\
\hline tran_act & $\operatorname{int}(2)$ & $\mathrm{Q} 1 \mathrm{a}-$ likelihood of transportation actions \\
\hline tran_valid & $\operatorname{int}(2)$ & $\mathrm{Q} 1 \mathrm{a}-$ validity of transportation actions \\
\hline tran_comment & $\operatorname{text}$ & $\mathrm{Q} 1 \mathrm{a}-$ comments on transportation actions \\
\hline home_know & $\operatorname{int}(2)$ & $\mathrm{Q} 1 \mathrm{~b}-$ awareness of home energy emissions \\
\hline home_act & $\operatorname{int}(2)$ & $\mathrm{Q} 1 \mathrm{~b}-$ likelihood of home energy actions \\
\hline home_valid & $\operatorname{int}(2)$ & $\mathrm{Q} 1 \mathrm{~b}-$ validity of home energy actions \\
\hline home_comment & $\operatorname{text}$ & $\mathrm{Q} 1 \mathrm{~b}-$ comments on home energy actions \\
\hline food_know & $\operatorname{int}(2)$ & $\mathrm{Q} 1 \mathrm{c}-$ awareness of food emissions \\
\hline food_act & $\operatorname{int}(2)$ & $\mathrm{Q} 1 \mathrm{c}-$ likelihood of food actions \\
\hline
\end{tabular}




\begin{tabular}{|lll|}
\hline food_valid & $\operatorname{int}(2)$ & $\mathrm{Q} 1 \mathrm{c}-$ validity of food actions \\
\hline food_comment & $\operatorname{text}$ & $\mathrm{Q} 1 \mathrm{c}-$ comments on food actions \\
\hline use_again & $\operatorname{int}(2)$ & $\mathrm{Q} 2 \mathrm{a}-$ likelihood to use CS.org in the future \\
\hline recommend & $\operatorname{int}(2)$ & $\mathrm{Q} 2 \mathrm{~b}-$ likelihood to recommend CS.org \\
\hline trade_know & $\operatorname{int}(2)$ & $\mathrm{Q} 2 \mathrm{c}-$ awareness of carbon trading \\
\hline purchase & $\operatorname{int}(2)$ & $\mathrm{Q} 2 \mathrm{~d}-$ preference to purchase, sponsor, or neither \\
\hline purchase_price & $\operatorname{double}$ & $\mathrm{Q} 2 \mathrm{e}-$ price willing to pay for offsets $(\$ / \mathrm{lb} \mathrm{CO} \mathrm{e})$ \\
\hline rate_cs & $\operatorname{int}(2)$ & $\mathrm{Q} 2 \mathrm{f}-$ rate the idea of carbon sponsoring \\
\hline rate_site & $\operatorname{int}(2)$ & $\mathrm{Q} 2 \mathrm{~g}-$ rate this website \\
\hline site_comment & $\operatorname{text}$ & $\mathrm{Q} 2 \mathrm{~h}-$ open comments on site \\
\hline other_comment & $\operatorname{text}$ & $\mathrm{Q} 2 \mathrm{i}-$ open comments \\
\hline
\end{tabular}

\begin{tabular}{|lll|}
\hline modes (static) & & \\
\hline Field & Format & Info \\
\hline modeid & $\operatorname{int}(8)$ & primary key \\
\hline mode_desc & $\operatorname{varchar}(40)$ & description of mode \\
\hline mpg & double & miles per gallon of fuel, if applicable \\
\hline lbsCO2_gall & double & typical lbs CO2 per gallon of fuel \\
\hline pax_veh & double & typical passengers per vehicle \\
\hline lbsCO2_pax_mi & double & typical lbs CO2e per passenger-mile \\
\hline
\end{tabular}

state_elec_c (static)

\section{Field Format Info}

\begin{tabular}{|c|c|c|}
\hline state & $\operatorname{varchar}(2)$ & \\
\hline intensity & $\operatorname{decimal}(8,7)$ & lbs CO2e per kWh \\
\hline
\end{tabular}

\begin{tabular}{|lll|}
\hline pct_mon_elec_heat (static) & \\
\hline Field & Format & Info \\
\hline State & $\operatorname{varchar}(2)$ & \\
\hline Jan & $\operatorname{decimal}(4,3)$ & fraction of January electricity use for electric heat \\
\hline Feb & $\operatorname{decimal}(4,3)$ & fraction of February electricity use for electric heat \\
\hline Mar & $\operatorname{decimal}(4,3)$ & fraction of March electricity use for electric heat \\
\hline etc $\ldots$ & & \\
\hline
\end{tabular}




\begin{tabular}{|lll|}
\hline pct_mon_elec_ac (static) & \\
\hline Field & Format & Info \\
\hline State & varchar(2) & \\
\hline Jan & decimal $(4,3)$ & fraction of January electricity use for A/C \\
\hline Feb & decimal $(4,3)$ & fraction of February electricity use for A/C \\
\hline Mar & decimal $(4,3)$ & fraction of March electricity use for A/C \\
\hline etc $\ldots$ & & \\
\hline
\end{tabular}

\begin{tabular}{|lll|}
\hline hdd (static) & & \\
\hline Field & Format & Info \\
\hline State & varchar(2) & \\
\hline Jan & decimal $(4,3)$ & fraction heat saved per degree F thermostat lowered \\
\hline Feb & decimal $(4,3)$ & fraction heat saved per degree F thermostat lowered \\
\hline Mar & decimal $(4,3)$ & fraction heat saved per degree F thermostat lowered \\
\hline etc $\ldots$ & & \\
\hline
\end{tabular}

\begin{tabular}{|lll|}
\hline cdd (static) & & \\
\hline Field & Format & Info \\
\hline State & varchar $(2)$ & \\
\hline Jan & decimal $(4,3)$ & fraction cooling saved per degree $\mathrm{F}$ thermostat raised \\
\hline Feb & decimal $(4,3)$ & fraction cooling saved per degree $\mathrm{F}$ thermostat raised \\
\hline Mar & decimal $(4,3)$ & fraction cooling saved per degree $\mathrm{F}$ thermostat raised \\
\hline etc $\ldots$ & & \\
\hline
\end{tabular}




\section{A.8: Online feedback form, reproduced exactly}

\section{Thank you for visiting CarbonSponsor.org! \\ Please fill out the feedback form to help up improve this tool. (16 questions) \\ 1. Activity questions: Transport, Home Energy, and Food \\ 1a. Transportation}

After visiting CarbonSponsor.org...

Which best describes your awareness of the climate footprint of personal travel?

r.

My knowledge did not change

(1)

I was introduced to the effects of travel

(1)

I was already aware, but learned more about the effects of trave

C

I already knew all about the effects of travel

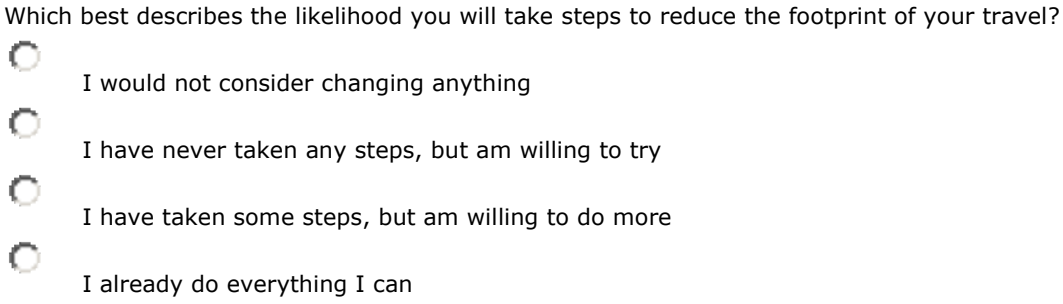

\begin{tabular}{|l|l|l|l|}
\hline 1 & \\
\hline 1 & &
\end{tabular}




\section{1b. Home Energy: Heating/Cooling and Laundry}
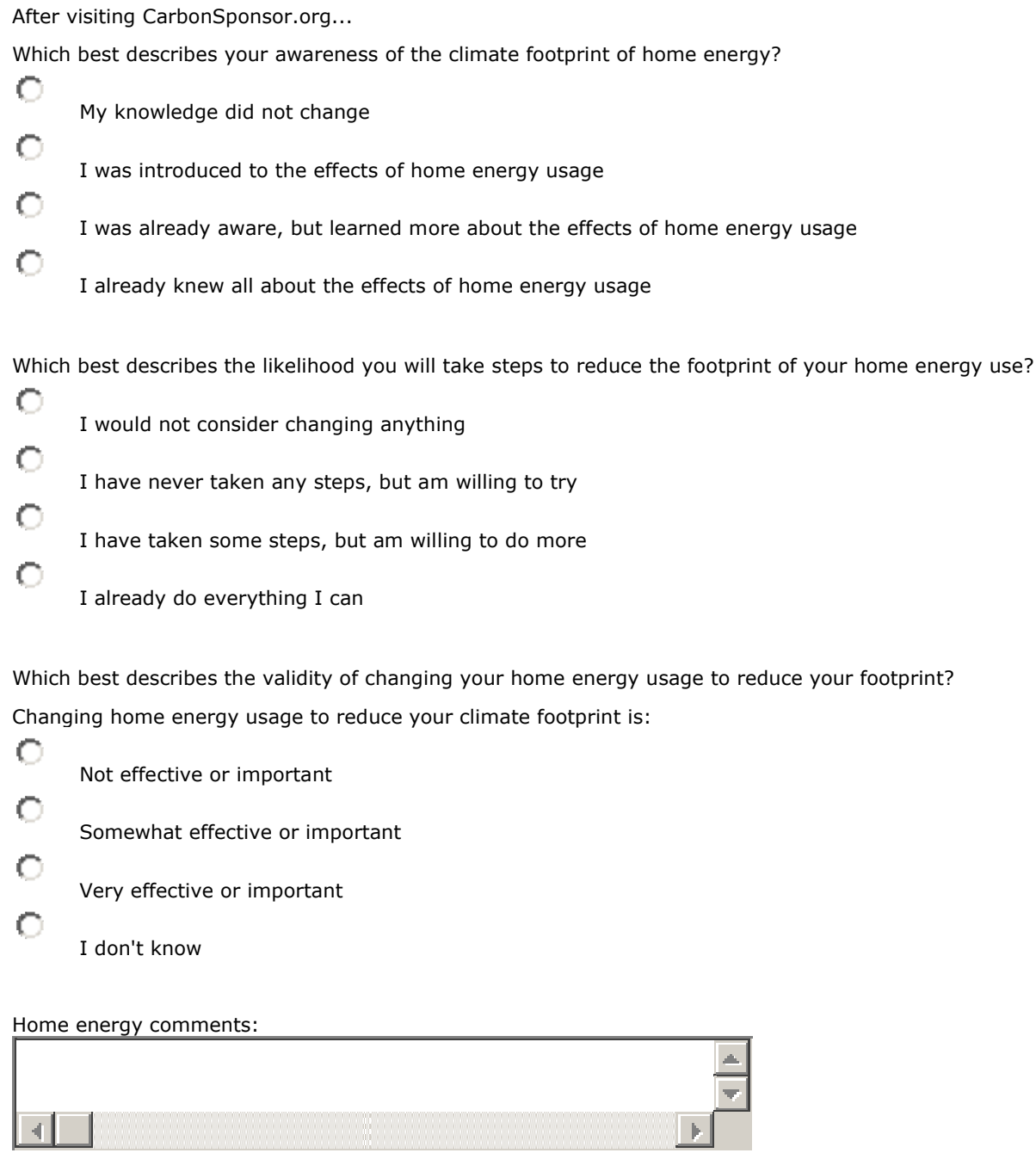

\section{1c. Food: Red Meat and Milk}

After visiting CarbonSponsor.org...

Which best describes your awareness of the climate footprint of certain foods?

C

C

My knowledge did not change

$C$

I was introduced to the effects of red meat and dairy

$C$

I was already aware, but learned more about the effects of red meat and dairy

I already knew all about the effects of red meat and dairy 
Which best describes the likelihood you will take steps to reduce the footprint of your foods?

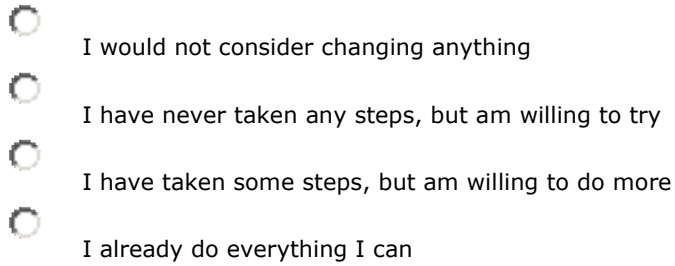

\section{Other questions}

2.a) How likely or unlikely are you to use CarbonSponsor.org in the future?

( Definitely will not use again

(1)

r.

Unlikely to use again

Likely to use again

Definitely will use again

C.

I don't know

2.b) How likely or unlikely are you to recommend CarbonSponsor.org to a friend?

(1) Definitely will not recommend

(1) Unlikely to recommend

(1) Likely to recommend

(1)

1 Definitely will recommend

I don't know 
2.c) After visiting CarbonSponsor.org, which best describes your awareness of carbon trading?

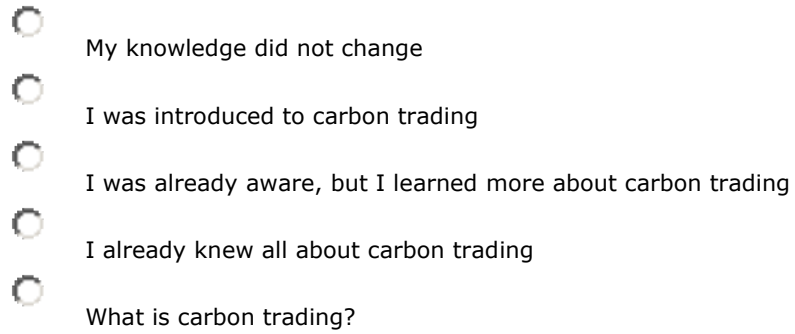

2.d) Given the choice, would you prefer to offset the climate footprint of your travel through:
(1) Carbon sponsoring/trading
(1) Purchasing carbon offsets
(3) Neither

2.e) When purchasing carbon offsets, about how much would you be willing to pay per pound of $\mathrm{CO}_{2}$ ? (a typical car emits $\sim 1 \mathrm{lb}$ CO2 per mile)

$\$$ per lb $\mathrm{CO} 2$

2.f) How would you rate the idea of carbon sponsoring?
(3)
1- Totally pointless or confusing
(3)
2- Not useful
C. 3- Interesting
C. 4- A great idea
(1) What is carbon sponsoring?

2.g) How would you rate this tool in particular (CarbonSponsor.org)?
(1- Worthless
2-Poor
(C) -Good
4- Great

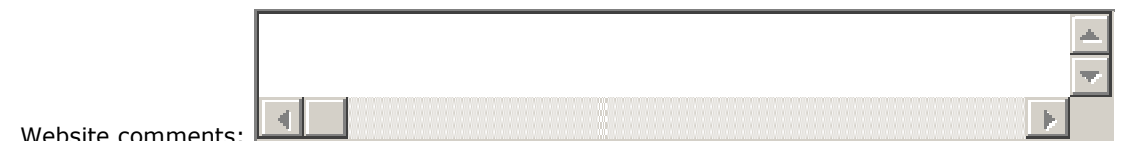

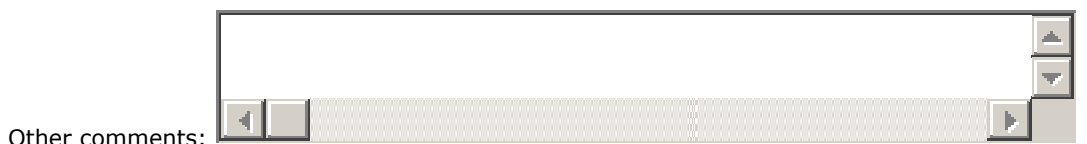

Submit feedback form: $\underline{\text { Submit }}$

Thank you for participating! 